\title{
Board out of Your Mind: Mapping Players' Mental Models of Game Systems and Potentials for Systems-Thinking Instruction
}

Joe A. Wasserman

Follow this and additional works at: https://researchrepository.wvu.edu/etd

\section{Recommended Citation}

Wasserman, Joe A., "Board out of Your Mind: Mapping Players' Mental Models of Game Systems and Potentials for Systems-Thinking Instruction" (2016). Graduate Theses, Dissertations, and Problem Reports. 6919.

https://researchrepository.wvu.edu/etd/6919

This Thesis is protected by copyright and/or related rights. It has been brought to you by the The Research Repository @WVU with permission from the rights-holder(s). You are free to use this Thesis in any way that is permitted by the copyright and related rights legislation that applies to your use. For other uses you must obtain permission from the rights-holder(s) directly, unless additional rights are indicated by a Creative Commons license in the record and/ or on the work itself. This Thesis has been accepted for inclusion in WVU Graduate Theses, Dissertations, and Problem Reports collection by an authorized administrator of The Research Repository @ WVU. For more information, please contact researchrepository@mail.wvu.edu. 
Board out of Your Mind: Mapping Players' Mental Models of Game Systems and Potentials for Systems-Thinking Instruction

Joe A. Wasserman

Thesis submitted to the Eberly College of Arts and Sciences at West Virginia University

in partial fulfillment of the requirements for the degree of

\author{
Master of Arts \\ in \\ Communication Studies
}

Approved by

Jaime Banks, Ph.D., Chair

Elizabeth L. Cohen, Ph.D.

Matthew M. Martin, Ph.D.

Department of Communication Studies

Morgantown, West Virginia

2016

Keywords: game-based instruction, analog games, systems thinking, mental models Copyright 2016 Joe A. Wasserman 


\begin{abstract}
Board out of Your Mind: Mapping Players' Mental Models of Game Systems and Potentials for Systems-Thinking Instruction
\end{abstract}

Joe A. Wasserman

Despite evidence that game-based instruction is effective, and suggestive evidence that they are specifically effective for teaching systems thinking - the ability to think about complex systems - the mechanisms behind this learning are not well understood. One promising perspective on game-based learning is rooted in the development of mental models of game systems. Mental models are cognitive representations of the perceived entities and relationships between entities in a system. This study explores the entities and entity relationships in novice players' mental models of an analog game. Grounded, interpretive analysis of mental models externalized through cognitive mapping identified five categories of entities: formal game entities, player actions, sociality, learning processes, and subjective experience. Content analysis of the relationships among these entities revealed that complex relationships were rarely identified, as players primarily described simple relationships. The implications of these findings for a) understandings of the nature of games and gameplay and b) effective game-based instruction are discussed. 


\section{Acknowledgements}

I would like, first, to thank my advisor, Dr. Jaime Banks, for her constant mentorship, guidance, and excitement throughout the writing of this thesis. I would also like to thank the members of my committee, Drs. Elizabeth L. Cohen and Matthew M. Martin, for their insightful comments, questions, and critiques. Finally, I would like to thank my family and friends, who have supported and encouraged me over the years - even when I decided to move across the country to study board games. 
Table of Contents

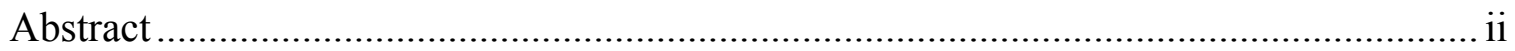

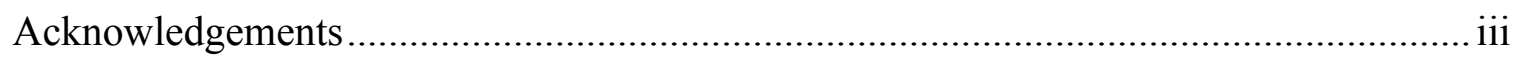

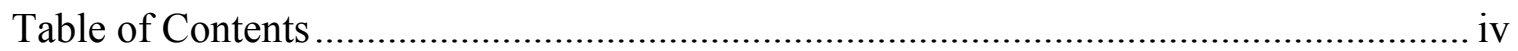

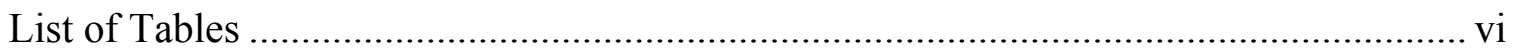

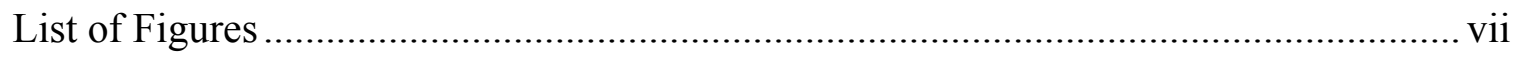

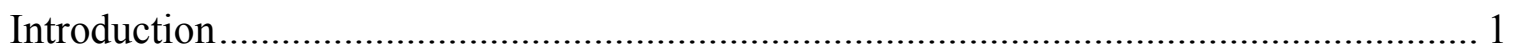

Systems Thinking as a Contemporary Skill ......................................................... 2

Challenges to Systems Thinking: System Complexity ............................................ 3

Learning about Complex Systems as Mental Model Development............................ 9

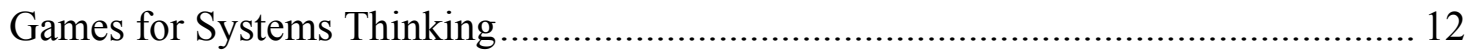

Potential of Analog Games for Systems-Thinking Instruction ................................ 17

The Complexity of Game-Derived Mental Models .............................................. 23

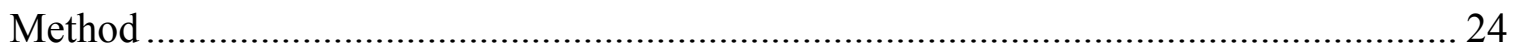

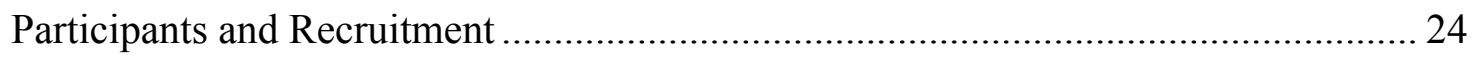

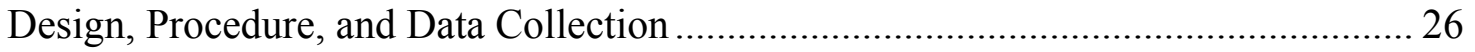

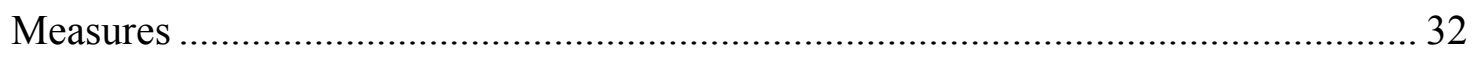

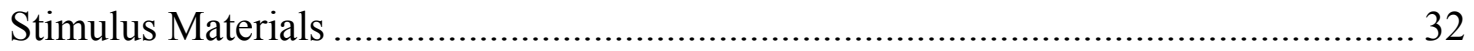

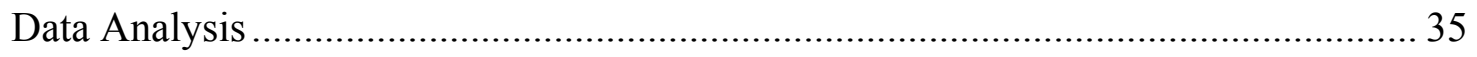

RQ1 Analysis: Mental Model Entities .......................................................... 35

RQ2 Analysis: Mental Model Entity Relationships............................................. 37

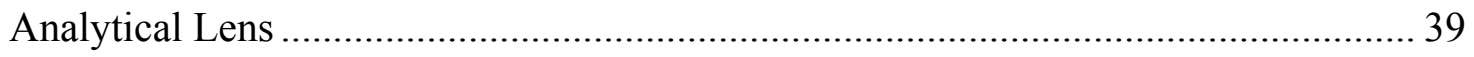

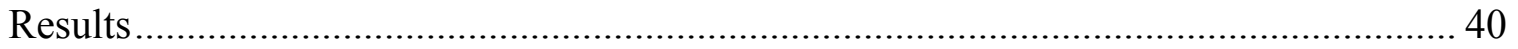




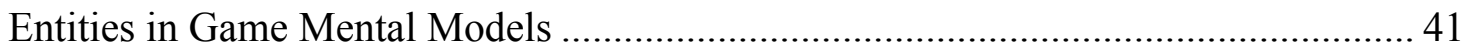

Entity Relationships in Game Mental Models ....................................................... 55

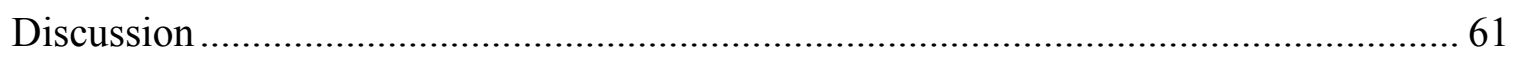

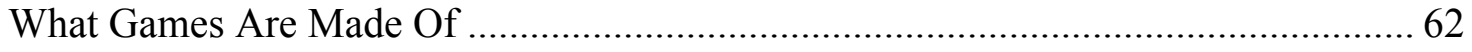

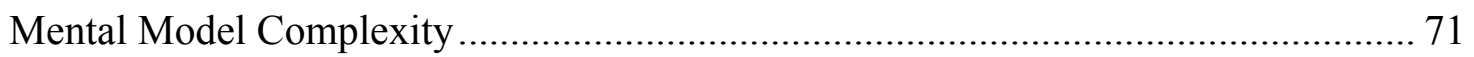

Practical Implications for Game-based Instruction................................................. 75

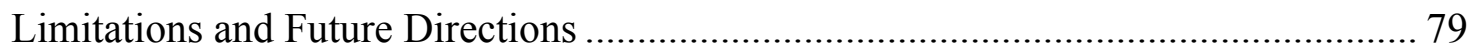

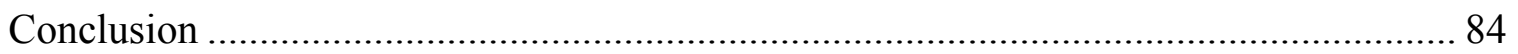

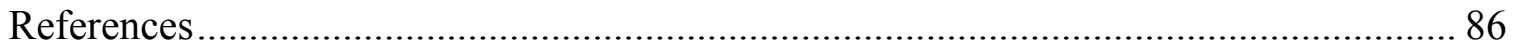

Appendix A: Recruitment Announcement/Text ........................................................... 103

Appendix B: Online Cover Letter and Initial Survey ……............................................. 105

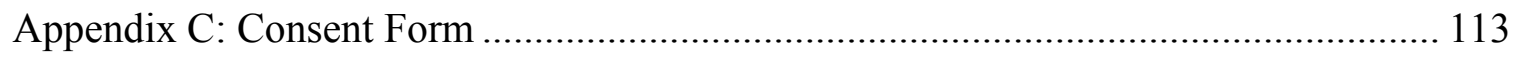

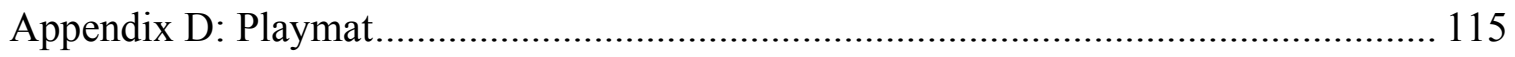

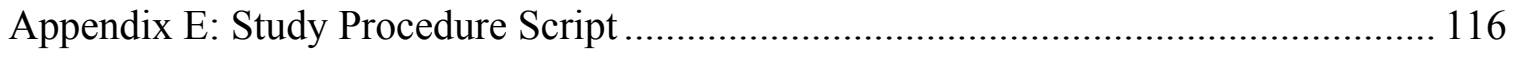

Appendix F: Anonymized Cognitive Maps ................................................................ 123

Appendix G: Codebook: Complex Relationship Variables ............................................. 141 


\section{List of Tables}

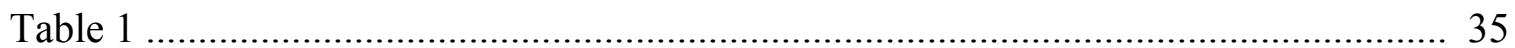

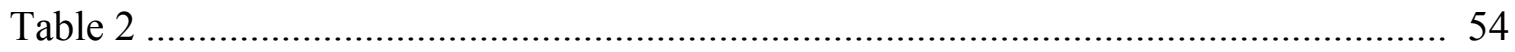

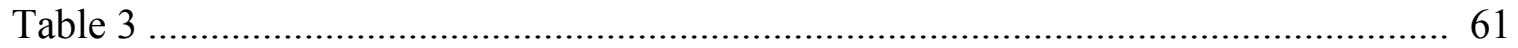

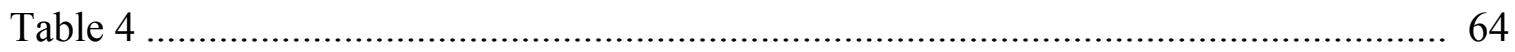




\section{List of Figures}

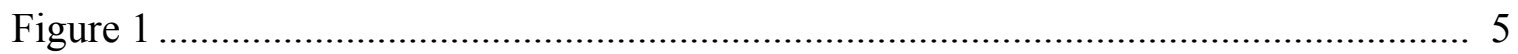

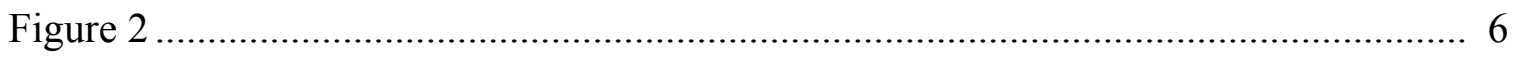

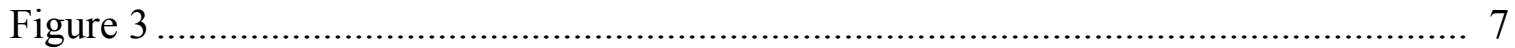

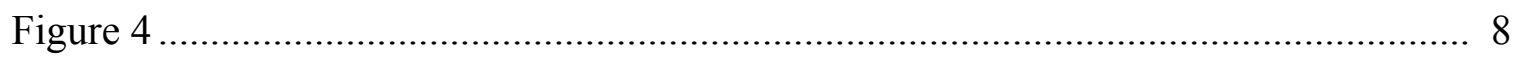

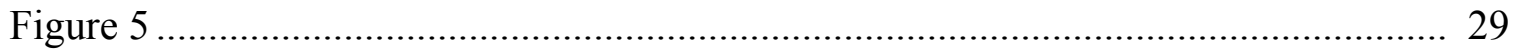

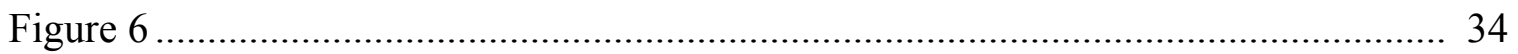

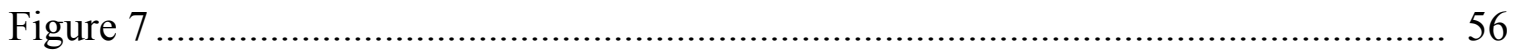

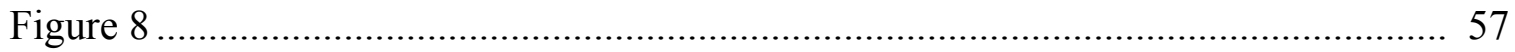

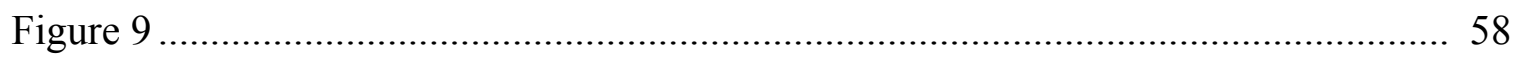

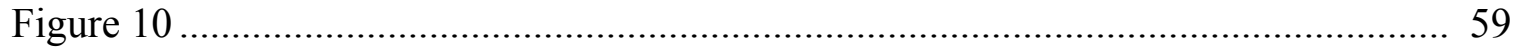

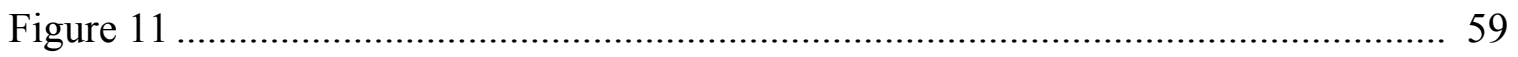

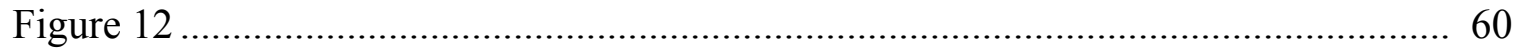




\section{Introduction}

Games have a strong potential for use as instructional tools (Gee, 2003; National Research Council, 2011) across disciplines as diverse as the humanities (Shapiro, 2013); nursing (Nehring \& Lashley, 2009); science, technology, engineering, and math (STEM); health; business; and economics (Boyle et al., 2016; Clark, Tanner-Smith, \& Killingsworth, 2016). Although most discussion of game-based instruction has focused on digital games, research on analog games - which involve face-to-face manipulation of material components and a communicative orientation (W. J. White, 2012)—suggests that analog games are also effective instructional tools (e.g., Berland, 2011; Jiménez, Acholonu, \& Arena, 2014; Laski \& Siegler, 2014). Despite evidence of the learning benefits of playing games, the mechanisms by which this learning occurs — and the characteristics of games that support this learning — have not yet been well-established empirically. In other words, it is not yet known how game dynamics are internalized or how the things that people learn from playing a game are transferred to other contexts, such as other academic learning activities or applied contexts.

In order to understand how learning from a game can be transferred to other non-game contexts, it is first necessary to understand what individuals learn from playing games themselves. This study seeks to advance understandings of how games may function in a particular type of learning — the development of the ability to think about complex systems-by framing game-based learning as a process of developing mental models of game systems. As such, the present study investigates the building blocks of these mental models: what game elements individuals attend to and find subjectively salient during gameplay. The salience of game elements to phenomenological experiences of gameplay is crucial, because it is imperative for using games as instructional tools that learners attend to the parts of the game in which 
instructional objectives are embedded. Furthermore, in order to understand the complexity of individuals' mental models of an analog game system, the present study identifies the kinds of relationships individuals perceived among its constitutive elements. This exploratory study takes a grounded, interpretive approach to examining the elements learners find salient in a commercial, off-the-shelf analog game that encompasses key features of complex systems. Findings suggest that players identify a range of material and immaterial objects, processes, and assessments; however, the finer complexities of the game system may be difficult for some players to identify.

\section{Systems Thinking as a Contemporary Skill}

Systems thinking, or the ability to think about and understand systems (Lane, 1995), is a necessary $21^{\text {st }}$ Century skill (National Research Council, 2012) in order to understand and interact with the systems that pervade everyday life. These systems are ubiquitous and cross domains. They include biological systems like the transport of ions in a cell or an ecosystem's predator-prey dynamics; technological systems like a hospital's electronic health record's interconnected and mutually dependent servers, workstations, software, databases, and users; organizational systems like the flow of products and documentation through formal hierarchies and informal channels; and economic systems of producers and consumers. These examples are far from exhaustive. All of these systems involve a number of things—-whether organelles, computers, or people - that influence, affect, or interact with each other. Because the kinds of things within systems vary so dramatically (material and immaterial, human and nonhuman, static and processual), they are referred to here by the generic term "entity."

Systems thinking has received considerable attention in business management and organizational studies (Checkland, 1999). In the social sciences, systems thinking is relevant to 
modeling social (Garson, 2009) and social psychological processes (Levine \& Doyle, 2002).

Education researchers and policymakers have identified systems thinking as a core competency for STEM education (Jacobson \& Wilensky, 2006; National Research Council, 2012). Systems saturate everyday life as well: legal and government systems, economic systems, social systems, mechanical and electrical systems. Because systems are ubiquitous, the ability to accurately understand and productively think about them is important for not only STEM and business, but for engagement with these systems in everyday life.

The ability to accurately identify the entities within a system is a crucial systems thinking competency, but one that operates at the lowest-level cognitive processes within the well-known revision to Bloom's learning typology (Anderson \& Krathwohl, 2001). Indeed, systems thinking can operate at every level of the revised taxonomy of educational objectives (see Hopper \& Stave, 2008) that includes, from lowest to highest, remembering, understanding, applying, analyzing, evaluating, and creating (Anderson \& Krathwohl, 2001). At the lowest levels of this taxonomy, systems thinking involves identifying a system's components. At higher levels, systems thinking involves identifying how a system's entities relate to each other. At yet higher levels, it involves using those understandings to make predictions about the system or to guide interactions with the system. At the highest level, systems thinking involves designing and creating novel systems. Progressing up this taxonomy, these systems thinking competencies build on each other. This study focuses on the foundational systems thinking competencies of identifying the entities within a system and how they influence each other.

\section{Challenges to Systems Thinking: System Complexity}

Systems thinking and teaching systems thinking competencies are both challenging, particularly when the systems involved are complex (Sterman, 1994). System complexity has 
two dimensions: the number of parts within the system and the kinds of relationships it contains. System complexity due to the number of parts within a system is referred to as "detail complexity," while system complexity due to the kinds of relationships in a system is referred to as "dynamic complexity" (Senge, 2006). At its simplest, a system might involve one entity influencing one other entity. Take for example a car's accelerator pedal and the whole car: when the accelerator pedal is pressed, the car accelerates forward. In reality, few systems are this simple. They involve numerous interrelated entities. Continuing the example of driving a car, consider the role of the mechanical and electronic systems underlying the operation of the car, the physiological characteristics of its human operator, the condition of the road, the laws governing driving, and the economic systems that enabled the car's production and maintenance. Depending on the aspect of driving a car at issue, any or all of these may be relevant aspects of the system. A system with more entities and more interrelationships between those entities has more detail complexity (Senge, 2006). In other words, detail complexity is the number of entities and interrelationships in a system. Increased detail complexity makes understanding a system difficult, because it strains cognitive working memory capacity by requiring individuals to attend to more bits of information simultaneously (Lang, 2000).

At another level, systems can increase in complexity not because of their size, but because of the nature of the relationships among entities in the system. When thinking about systems, individuals often apply heuristics to understand the interrelationships among entities, so as to preserve cognitive resources (Tversky \& Kahneman, 1974). The heuristics individuals apply to these relationships frequently misidentify their nature (Sterman, 1994). Typically, these heuristics treat the relationships in systems as direct, linear, deterministic, and immediate (Gleick, 1988; Jacobson \& Wilensky, 2006; Sterman, 1994; Sweeney \& Sterman, 2007). In 
contrast, the relationships among entities in a system are often indirect, nonlinear, stochastic, and delayed. Additionally, combinations of relationships can form feedback loops. These five kinds of relationships are defined and described below. Collectively, these kinds of relationships that contribute to a system's complexity are referred to here as "complex relationships." To illustrate the nature of these relationships in an analog game context, examples are drawn from the analog game Dominion (Vaccarino, 2008), which exemplifies these kinds of relationships. Notably, the game as a whole is not of interest in this section, merely the relationships among the game's components.

Indirect relationships. An indirect relationship is one in which an entity influences another entity via at least one other. For example, when turning on a gas stove, turning the knob activates a spark, which ignites gas into flames. Here, the relationship between the knob and gas is indirect, since it goes through the spark. An example of an indirect relationship in Dominion is that between treasure cards and victory cards. Although the goal of the game is to acquire victory point cards, it is not possible to acquire the most valuable victory point cards without first acquiring more valuable treasure cards and action cards. As such, action cards and other treasure cards are intermediaries in the relationship between treasure cards and victory point cards. In other words, treasure cards indirectly influence victory point cards through action cards and other treasure cards. More generically, an indirect relationship is one in which some entity, A, influences another entity, D, through at least one other entity, B and C. See Figure 1 for an illustration of a generic indirect relationship.

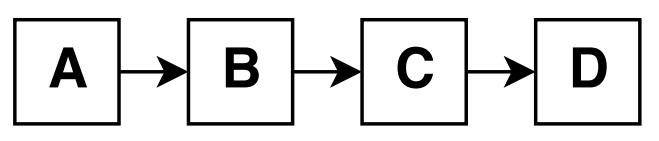

Figure 1. Illustration of an indirect relationship between entity A and entity D, in which entity A influences entity D through entities B and C. 
Nonlinear relationships. Whereas a linear relationship involves a constant proportion of input to output, nonlinear relationships change depending on the input (Groesser \& Schaffernicht, 2012; Hmelo-Silver \& Pfeffer, 2004). In other words, the size of the influence of one entity on another entity depends on the quantity or strength of the influencing entity. Generically, these relationships are curvilinear, and include exponential and logarithmic relationships. The relationships between the length of a square's sides and its surface area are nonlinear. A square with a 1 inch side has a surface area of $1 \mathrm{in}^{2}$, while a 2 in square has a surface area of $4 \mathrm{in}^{2}$, and a 3 in square has a surface area of $9 \mathrm{in}^{2}$. As can be seen, the greater the increase in the length of a square's side, the more it increases the surface are of the square. Because this increase increases, the relationship is nonlinear. In Dominion, the relationship between treasure cards and victory cards is nonlinear: more valuable cards cost more treasure, but yield an increasingly greater proportion of points to treasure. Specifically, 1-point victory cards cost 2 treasure (1:2), 3-point victory cards cost 5 treasure (3:5), and 6-point victory cards cost 8 treasure (3:4). The proportion of points to treasure increases from .5 to .6 to .75 . See Figure 2 for an example of a generic nonlinear relationship.

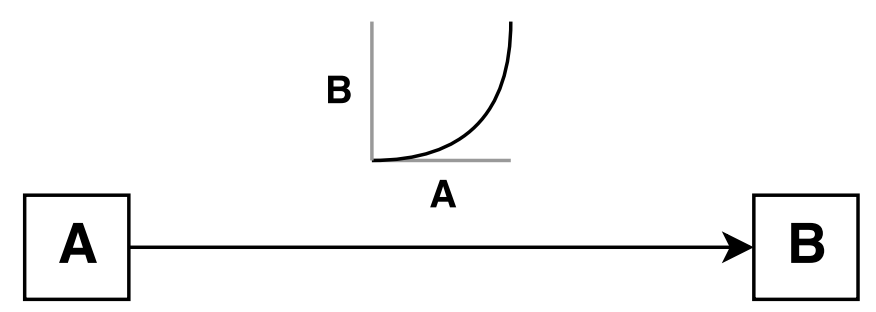

Figure 2. Illustration of a nonlinear relationship between entity A and entity B, such that the influence of A on B increases for higher levels of A.

Stochastic relationships. Stochastic relationships are non-deterministic (Resnick \& Wilensky, 1998), because they involve randomness. In other words, the influence of entity A on entity $\mathrm{B}$ is probabilistic. One example of a stochastic relationship is that between air and a dust 
particle. Because air molecules move about in random directions (Kramers, 1940), when they come into contact with a dust particle, they move that dust particles about in random directions as well. In a game context, many of the relationships in Dominion are stochastic, since each player's deck of cards is randomized by shuffling. How cards can be used to interact with each other, therefore, involves randomness, as the cards drawn from players' decks are randomized.

Delayed relationships. Delayed relationships involve a lapse of time in between an event or an input and its consequences (Groesser \& Schaffernicht, 2012; Landriscina, 2013; Sweeney \& Sterman, 2007). In other words, the influence of entity A on entity B does not occur immediately, but only after some temporal delay. See Figure 3 for an example of a generic delayed relationship. One example of a delayed relationship is ordering food at a restaurant. Once a patron orders food, say a hamburger, that hamburger is not available immediately. Because the hamburger needs to be cooked, there is a time lag between placing an order for food and receiving that food. In Dominion, the effect of each newly acquired card is delayed, since it does not come into play until it is shuffled into a deck and then drawn into a player's hand on a future turn.

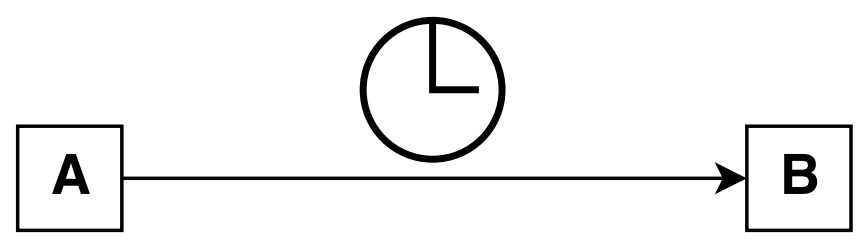

Figure 3. Illustration of a delayed relationship between entity A and entity B, in which there is a temporal delay in the influence of A on B.

Feedback loops. In combination, the relationships between entities in a system can form structures called feedback loops (Eden, Ackermann, \& Cropper, 1992; Groesser \& Schaffernicht, 2012; Jacobson \& Wilensky, 2006; Landriscina, 2013). In a feedback loop, an entity influences itself, often through indirect relationships described above. Under ideal conditions, stock market 
investments are a feedback loop. Money invested in stocks leads to more money, which when reinvested in the stock market, leads to more money. In this way, money comes to act on itself through stock market investments: money leads to more money. In Dominion, for example, action cards form a feedback loop, in which playing them allows players to not only draw more cards, but also play more cards. In this way, action cards influence themselves. This example is a positive feedback loop, also referred to as a "virtuous" or "vicious" cycle (Eden et al., 1992), because it is self-reinforcing. In other words, an event or change in one entity (e.g., playing an action) leads to more of the same (e.g., playing more action cards). Negative, or balancing, feedback loops involve an event or change in an entity that suppresses more of the same. For example, in natural populations of predators and prey, when predator populations increase, they consume more prey, thus decreasing prey populations. Because of the reduced availability of prey, predator populations decrease, leading to less consumption of prey, and therefore increasing prey populations. In this way, predator populations and prey populations are involved in a negative feedback loop with each other. Dominion also contains negative feedback loops. Victory cards in players' decks, for example, are part of a negative feedback loop. Because victory cards added to players' decks do not allow players to do anything besides score points at the end of the game, whenever these point cards are drawn, they make it more difficult to play other cards (e.g., action and treasure cards) and to buy more victory cards. Generically, feedback loops involve an entity that influences itself, possibly through indirect relationships with other entities. See Figure 4 for an illustration of a generic feedback loop. 


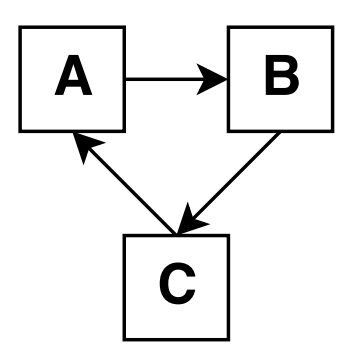

Figure 4. Illustration of a feedback loop in which entity A influences itself through entities B and C.

These complex relationships_-indirect relationships, nonlinear relationships, stochastic relationships, delayed relationships, and feedback loops - all contribute to a system's dynamic complexity (Senge, 2006). Following, the definition of systems thinking can be made more specific, referring to the ability to think about and understand not just simple systems, but relatively complex systems in particular. Whereas detail complexity is strictly the amount of things - entities and relationships — in a system, dynamic complexity has to do with the kinds of relationships between entities. The more feedback loops and the more indirect, nonlinear, stochastic, or delayed relationships, the greater a system's dynamic complexity. The more entities and relationships between entities, the more detail complexity. The processes involved in learning about complex systems are discussed below.

\section{Learning about Complex Systems as Mental Model Development}

It has been suggested that learning about a complex system, both through playing games and more generally, is a process that involves understanding and forming a cognitive representation of it (Landriscina, 2013; Sterman, 1994). Based on the perception of, interaction with, and communication about a system — as well as pre-existing stocks of knowledge and experience - individuals develop mental models specific to that system (Doyle \& Ford, 1998, 1999; Landriscina, 2013; Roskos-Ewoldsen, Roskos-Ewoldsen, \& Dillman Carpentier, 2002). 
The view of mental models of complex systems proposed here is that they are cognitive representations of systems that include both a) the entities an individual perceives to be part of that system and b) how those entities related to each other (Doyle \& Ford, 1998, 1999; Groesser \& Schaffernicht, 2012; Landriscina, 2013; Roskos-Ewoldsen et al., 2002). Drawing from the above discussion of complex relationships, an individual's mental model of Dominion might include a number of entities: perhaps several different kinds of cards (e.g., action, treasure, and victory cards), the people playing the game, and their goal while playing the game (e.g., to get the most points, to try a new strategy, to have fun). This mental model would also include the relationships among these entities: perhaps the influence of a specific goal and the behavior of other players on the types of cards acquired, as well as the interaction of those acquired cards that facilitate the acquisition of victory cards. In sum, a mental model consists of these entities and interrelationships.

Like systems themselves, mental models have varying degrees of complexity, which can again be categorized into two types: detail complexity and dynamic complexity (Senge, 2006). A mental model's detail complexity is its number of entities and relationships between entities. A mental model's dynamic complexity is the degree to which it contains complex relationshipsthe kinds of relationships and structures that are typical of complex systems-described above: indirect relationships, nonlinear relationships, stochastic relationships, delayed relationships, and feedback loops. Taken together, these relationships form the total structure of a mental model.

These mental models, once developed, are activated when further engaging with the complex system (Jones, Ross, Lynam, Perez, \& Leitch, 2011; Landriscina, 2013). In practice, individuals use their mental models to make predictions or explanations about the system, as well as to inform decision-making. This process can be thought of almost as a cognitive 
simulation of a system, in which individuals predict behaviors and outcomes by running scenarios through their mental models. While playing Dominion, for example, an individual might activate a mental model of the game to anticipate the effects of acquiring a certain card. This process can result in modifications to an individual's mental model of the system (Landriscina, 2013). An unexpected outcome, for instance, may prompt a revision to better take into account the observed behavior of the system. Acquiring a victory card, for example, may make it more difficult than anticipated to acquire further victory cards, thus prompting an alteration to an individual's mental model in terms of the relationship between victory cards in an individual's deck and the ability to acquire more of the same.

Once these mental models are developed, they can be transferred and applied to other contexts. Learning transfer can be broken down into two types: direct application and preparation for future learning (Bransford \& Schwartz, 1999). Traditional understandings of learning transfer, which view transfer as the application of mental models directly to other contexts or problems, fall under the "Direct Application" theory of transfer (Bransford \& Schwartz, 1999). Direct application transfer involves the application of mental models to problem-solving in other contexts. For example, individuals might develop a mental model of an analog game about climate policy (e.g., Castronova \& Knowles, 2015). Direct application transfer of this mental model of the climate policy game to a different context might involve drawing on that mental model when problem-solving policy issues in another area. Alternatively, the "preparation for future learning" (PFL) paradigm of learning transfer suggests that pre-existing mental models support the future development of mental models (Bransford \& Schwartz, 1999). In PFL, mental models are not directly applied to new contexts or problems, but are used as resources in subsequent learning experiences and to understand new knowledge. For example, PFL transfer 
might involve drawing on a mental model of a climate policy game when reading a text on global ecological politics. This process might involve relating the interests and proposals of various governments and interest groups in the text to the relationships between different entities an individual perceived while playing the climate policy game.

Given that learning about complex systems involves developing mental models that represent them, it is important to first understand the detail and dynamic complexities - the entities and relationships - of those mental models. Understanding this mental model content will provide insight into the potential effectiveness of various instructional tools - including games-for teaching systems thinking. Understanding mental model content empirically will improve understandings of mental models, as well as their role in the learning process.

\section{Games for Systems Thinking}

It has been suggested that games have a strong potential for learning in general (Gee, 2003) and for training systems thinking competencies specifically (National Research Council, 2011). As described above, the mechanism for learning about complex systems that is proposed in this study is a process of developing mental models of those complex systems. Despite some suggestive but indirect empirical evidence, reviewed below, that supports these claims, the mechanisms by which this learning occurs - and the characteristics of games that support this learning-have not yet been well-established empirically.

Games as exemplary complex systems. One of the reasons games are thought to be particularly effective for learning about complex systems is that some games are exemplary complex systems. Dominion, which has been used above to explain various characteristics of complex systems, is a prime example. As described above, Dominion's game system contains indirect relationships, nonlinear relationships, stochastic relationships, delayed relationships, and 
feedback loops. Because it contains all five of these complex relationships, Dominion's game system as a whole is ideal for investigating dynamic complexity. Theoretical and critical-cultural work on games, including both digital games and analog games, have further explored the notion of games as systems (Giddings, 2009; Juul, 2011; Ralph \& Monu, 2015; Steinkuehler, 2006; Taylor, 2009). In particular, this work has suggested that game systems contain various kinds of entities. Echoing one of the central insights of Actor-Network Theory (Latour, 2008)—-that human and non-human actors allow and constrain each others' actions by virtue of their interrelationships - this scholarship has suggested that games involve the interaction of human entities like players (e.g., Evans, 2013; Giddings, 2007) and game designers (e.g., Steinkuehler, 2006), conceptual entities like rules (e.g., Evans, 2013; Giddings, 2009; Juul, 2011; Steinkuehler, 2006) and norms (e.g., Steinkuehler, 2006), and material entities like cards and pawns (e.g., Leino, 2012b). In theoretical definitions of games, rules describe the meaning of a game's material artifacts insofar as they relate to achieving a game's potential outcomes. They are also thought to delimit what are possible and not possible actions to take within each game. Game designers create rules and material game artifacts with players' actions and interactions in mind (Robin, Marc, \& Robert, 2004). This theoretical work suggests that during gameplay, players engage a game's rules and manipulate its material artifacts to achieve their goals (Juul, 2011). Despite these theoretical suggestions of the entities that comprise games and critical-cultural analyses of what entities are important during gameplay, attention has not been paid to the phenomenological experience of gameplay. That is, the entities of a game system that are subjectively salient to individuals during and after gameplay are unknown. In other words, it is uncertain both a) which of many potential kinds of entities individuals include in their mental models of game systems and b) how they conceptualize these entities. Understanding the content 
of mental models of game systems is crucial to understanding what and how games can be used in an instructional context.

Game-based systems-thinking instruction. Research on learning about systems from playing games is fairly limited, but existing scholarship does suggest that games can indeed be effective instructional tools (e.g., Corredor, Gaydos, \& Squire, 2013). Furthermore, games seem to be effective instructional systems thinking tools across ages, from elementary school students (e.g., Corredor et al., 2013) to undergraduates (e.g., Stave, Beck, \& Galvan, 2015). Nevertheless, most of the studies of game-based systems-thinking instruction provide little evidence for the learning mechanisms at work or the elements of games that contribute to systems thinking. For example, fifth grade students who played a digital game and read a text about genetic and cellular systems were able to identify not only more relationships between entities, but also more delayed relationships between entities, than students who examined a diagram and read a text about the same (Corredor et al., 2013). As discussed above, delayed relationships are central to understanding complex systems. As such, this finding in particular accords with the present study's conceptualization of mental models as cognitive representations of entities and their relationships. In a different context, high school students who played a digital game about Newtonian physics, which deals with the relationships between objects and forces, improved their performance on a test of physics understanding more than students who merely took the same Newtonian physics test twice (B. Y. White, 1984). In terms of a more complex system, primary school students who played a fish farm digital simulation game scored significantly higher on two measures of system understanding than students who did non-game hands on activities about fish farming: diagramming a fish farm system and a problem-solving quiz on issues that could arise in their fish tank (McVeigh, Black, \& Flimlin, 2008). Diagramming a fish 
farm system involved identifying the entities and relationships contained therein, while the problem-solving quiz involved applying understandings of the overall fish farm system behavior to novel situations. In two naturalistic studies in which middle-schoolers played the commercial off-the-shelf digital game RollerCoaster Tycoon 3 (Frontier Developments, 2004), students improved their scores on a test of economics system understanding (Foster, 2011) and on a more general systems thinking test (Shah \& Foster, 2014).

This learning seems to be effective in older students as well. Among undergraduate students, running a game-like computer simulations of two different environmental accumulation scenarios - a) seeds drifting between islands and ocean and b) the accumulation of atmospheric carbon-more times was associated with greater improvement in test scores on accumulations in closed systems, even when controlling for accumulation task pre-test scores, graphing familiarity, interest in the course, and previous science experience (Stave et al., 2015). Accumulation involves the flow of resources between entities in a system. Also among undergraduates, students who played a digital simulation game of the economic incentive structures associated with different governmental organizations better understood these incentive structures three weeks after learning about them than students who attended a lecture about the same topic (Nishikawa \& Jaeger, 2011). This finding suggests that, in this case, students' understanding of government and economic systems persisted more over time after playing a game on the topic than attending a lecture. These studies suggest that games have the potential for training systems thinking competencies - understanding the entities and relationships between entities in a system, as well as the behavior of that system as a whole. Like much research on games for learning, however, these studies have not identified specific mechanisms, mediators, or moderators of this learning process; instead, they atheoretically measured learning 
outcomes (see Bryant \& Fondren, 2009). Although the preceding studies suggest that learning systems thinking from playing games can happen, without investigating mechanisms or theories related to this learning, it is not possible to understand either how this learning happens or how it can be facilitated.

Some of the most systematic, but nevertheless indirect, evidence for the process and antecedents of developing mental models that are analogously related to a system comes from a program of research on a relatively simple system: the number line (e.g., Ramani \& Siegler, 2008). The number line is a linear, ordinal system of integers. This research program has experimentally investigated the antecedents of preschoolers' and kindergarteners' understanding of the number line from playing an analog game: the physical structure of the game and the actions learners performed during gameplay. Mental model development was inferred from students' improvement—or lack thereof—in terms of several basic numeracy skills related to linear, ordinal representations of integers. In particular, they measured magnitude comparison and number line estimation. Magnitude comparison is the ability to identify which of two integers is larger. Number line estimation is the spatial accuracy of placing an integer on a blank number line. In terms of the game's physical structure, only the linear version - as opposed to a circular version —of a numeric analog game led to preschoolers' improvements in the aforementioned numeracy skills (Siegler \& Ramani, 2009). These findings suggest that mental models based on a linear numeric game were structured in a linear fashion (Siegler \& Ramani, 2009). In other words, the structures of learners' mental models were analogous to the physical structure of the game. Similarly, the gameplay activity of counting each space on the game board led to kindergartners' improvements in the same numeracy skills by reinforcing the ordinal relationship between the numbers, whereas other kinds of counting did not (Laski \& Siegler, 
2014). These findings suggest that the specific actions performed during gameplay can influence mental model development. Although these findings relate to how a relatively simple analog game can be used to develop relatively simple mental models, they nonetheless reaffirm the theoretical suggestions elaborated above that both material objects and player actions during gameplay are key to the understanding of games and gameplay.

\section{Potential of Analog Games for Systems-Thinking Instruction}

Little research has addressed the potential for analog games as instructional tools. The experimental research on numeracy learning from numeric analog games reviewed above (e.g., Laski \& Siegler, 2014; Siegler \& Ramani, 2009) is one notable exception. Additionally, correlational surveys have found that playing analog games outside of school is positively associated with better magnitude comparison and number line estimation among preschoolers (Ramani \& Siegler, 2008). A small number of other studies have found positive results when using analog games as instructional tools. For example, a commercial off-the-shelf analog game, Pandemic (Leacock, 2007), has been found to improve computational thinking among undergraduate students (Berland \& Lee, 2011). Computational thinking is the ability to think about, understand, implement, and create a series of rules, which in the computational literature are known as algorithms (Berland, 2011). Because algorithms are series of rules that relate chains of entities to each other, computational thinking can be thought of as a kind of systems thinking. In Dominion, for example, one such algorithm might be: 1) Draw five cards from your deck. 2) If you are unable to draw five cards from your deck, draw as many as possible. 3) If you were not able to draw five cards, shuffle your discard pile to form a new deck. 4) If you were initially unable to draw five cards, draw cards from your new deck so that you have drawn a total of five. This series of four rules, or algorithm, describes the cleanup phase of Dominion, and is a 
simple example of the kind of algorithm with which computational literacy is concerned. In a very different context, an analog card game improved fourth graders' in-class and standardized test scores on fractions more than regular in-class math work (Jiménez et al., 2014; Jiménez, Arena, \& Acholonu, 2011). An analog game about the spread of polio increased children's and adults' interest in global public health (Okitika et al., 2015). Finally, even just using analog game components in a learning context improved students' enjoyment of the activity (Lieberoth, 2015). Taken together, these findings suggest that analog games can be effective instructional tools for teaching systems thinking.

Analog games have two characteristics that may make them particularly effective for training systems thinking. First, analog games centrally involve material objects. Second, analog games make players responsible for manually executing rules. Before addressing the role of materiality and player responsibility for rules, analog games and communication are elaborated upon.

Characterizing analog games. Analog games involve, at a minimum, both material and conceptual elements. Their material elements include boards, cards, pawns, tiles, tokens, dice, etc. Conceptual elements of analog games include the rules, which are descriptions - usually written - of the meaning of the material components insofar as they relate to achieving the game's various outcomes. Rules also delimit what are possible and not possible actions to take within each analog game. An extensive list of analog games can be found at BoardGameGeek ("BoardGameGeek," n.d.). An increasingly popular genre of analog game, Eurogames (Woods, 2012; see "Seven years of plenty," 2016), are played with material components that may or may not include a board, have relatively simple rules that in combination lead to many different circumstances throughout a game, tend to have low elements of luck and high amounts of 
decision-making, and are typified by mechanics for indirect conflict—like auctions, selecting limited actions, placing tiles, and competing over limited resources. The most well-known Eurogame is Catan (Teuber, 1995; see “The Settlers of Catan ${ }^{\circledR}$, , 2015), a game of building towns and roads on a fertile island. In Catan, players accumulate five different types of resources to build towns, cities, and roads. Although players compete over the limited spaces on the board, this competition is indirect. Furthermore, by combining simple rules for building, resource gathering, and trading, Catan allows for many possible circumstances to arise during gameplay. Although there is some luck involved, strategic decision-making has more influence over the outcome. Dominion, which has already been described above, is also a Eurogame. Its rules for playing and buying cards are very simple, but by combining different cards with different abilities, there are many possibilities for gameplay. Furthermore, although there are limited ways of directly harming other players' positions, the majority of conflict in Dominion is through the indirect competition for limited stockpiles of cards. Additionally, while there is luck involved in shuffling decks of cards, making strategic decisions to mitigate this randomness is central to successful gameplay. Other kinds of analog games are more likely to have more complicated rules, higher degrees of chance, and more direct conflict. Depending on the specific characteristics of a given game, mental models of the game system will vary. Mental models of games without any randomness, for example, will be unlikely to include stochastic relationships between perceived entities in the game system.

Analog games as communication. Communication is integral to the experience and process of playing analog games. Because they are played face-to-face (Nicholson \& Begy, 2014), analog games are a significant pretext for social interpersonal communication (Woods, 2012), relationship formation and maintenance, and small-group communication (Duncan \& 
Berland, 2012). Moreover, communication is central to the gameplay process itself. Not only are rules learned through collaborative communication (Duncan \& Berland, 2012), but they are negotiated, debated, and enforced via communication (Xu, Barba, Radu, Gandy, \& MacIntyre, 2011). Without temporarily halting gameplay to resolve rules disputes, the entire play situation would disintegrate (Juul, 2011). From yet another perspective, the material game artifact can be thought of as a communication channel (Shannon \& Weaver, 1949). In this view, a player's actions during gameplay encode meaning that the other players decode. For example, acquiring a certain type of card in Dominion may indicate a particular strategy to other players. Acquiring an attack card might suggest an aggressive strategy, and a player may decide to acquire a defense card in response. Unlike many other communication contexts, in the case of analog games, the sender may want to obscure the meaning behind their actions for strategic reasons, by introducing noise to inhibit other players from decoding that meaning. While acquiring an attack card, for example, a player may attempt to disguise their true intent-i.e., to attack the other players - by saying, "I'm only getting this card for its other ability, don't worry." In other words, players may be motivated to increase the uncertainty of their communication partners (cf. Afifi \& Weiner, 2004). While player motivations to increase uncertainty may seem to conflict with effective instruction, in which clarity is key for learning (Civikly, 1992), these circumstances may provide a unique situation for learners to practice and improve uncertainty reduction strategies (see Berger, 1997).

Materiality and action. Analog games' material components are prominent features of these games and their gameplay. Engaging with a game's material elements during gameplay may uniquely facilitate players' identification of entities and their relationships in the game system, thereby facilitating mental model development. These material objects could include 
cards, dice, tokens, or figurines. During gameplay, players manually manipulate these material objects as they perform actions. For example, players might draw and play cards for abilities, place and move figurines, roll dice to determine outcomes, and collect or spend tokens representing resources. In analog games, these material components represent entities within the game whose behavior and relationships are at least in part described by the game's rules. Thus, physically manipulating these material-conceptual objects during gameplay should reinforce the relationships between entities in the analog game system.

In tabletop miniature battle games, for example, handfuls of dice are used to resolve the outcomes of players' decisions. Carter, Harrop, and Gibbs (2014) identified three ways in which the dice in these games represented relationships between entities in the game system. Because one die was rolled per unit in an action, the number of dice was directly proportional to the potential consequences of each given action. In addition to the weight and feel of these dice in players' hands, the sound of physical dice colliding with each other and the table reinforced this analogous relationship. Furthermore, players tended to roll their dice between the groups of miniatures involved in the action, thus reinforcing the relationship between those two particular groups by representing it spatially. Horn et al. (2012) capitalized on the representational affordances of analog games' materiality by preceding a digital agent-based simulation with a similar analog game in which students manually controlled the individual agents. This analog game heightened students' ability to understand the relationships between agents and the processes underlying the dynamic behavior in the digital simulation. Furthermore, in a comparison of digital and analog versions of the same game, players preferred material to digital components for certain kinds of in-game actions (Ip \& Cooperstock, 2011). Specifically, whereas they preferred to use digital components for automated game set-up, they preferred to use 
material components for negotiation and trading (Ip \& Cooperstock, 2011). This finding suggests that something about material as opposed to digital objects facilitated negotiation and trading actions during gameplay. Finally, attaching conceptual meaning to an analog game's material objects by defining them through rules may facilitate players' attention to and recollection of those concepts. In an experiment in which adults were tasked with arranging either digital squares or material blocks that were associated with news story summaries, participants who arranged material blocks recalled significantly more of the news stories (Patten \& Ishii, 2000). In this experiment, conceptual information (news stories) was associated with either digital or physical objects. The finding that material objects improved recall of conceptual information suggests that material objects in analog games may facilitate developing a mental model of the game system by facilitating recall of conceptual information. Taken together, these studies suggest that manually manipulating material objects during gameplay may contribute to players' understandings of the relationships between entities in a system. Nevertheless, the role of materiality in the process of mental model development has yet to be specifically investigated.

Chores and responsibility. In addition to their materiality, analog games require players to manually enact all changes to a game. Without software to automatically resolve the results of player input, in analog games players need to manually roll dice, shuffle and draw cards, move pieces, and do all the other "chores" and "articulation work" that accompany the physical medium (Leino, 2012a; Mosca, 2011; Nicholson \& Begy, 2014; Rogerson, Gibbs, \& Smith, 2015; Xu et al., 2011). In Dominion, for example, when an individual plays a card that allows them to draw another card and buy another card, they must do two things. First, they must manually draw another card into their hand. Second, they must track the information that they will be able to buy another card when the time comes. This example points up three aspects of 
performing manual chores in analog games that is expected to facilitate the development of mental models of the game system. First, there are no hidden entities in the system of an analog game - whereas digital games may obscure and hide entities within software to which players do not have access. This accessibility of entities should facilitate their identification for inclusion in mental models. Second, every time an individual performs an action during gameplay, they actively perform the relationships between the entities involved in that action. Continuing the above example, playing a card that allows one to draw another one involves performing the relationships between playing that card and drawing a card, i.e., manually drawing another card. This performance should facilitate identification of relationships between entities for inclusion in mental models. Third, chores in analog games require players to cognitively attend to entities and relationships. In order to correctly play a game as described by its rules, players have to continually monitor the game to ensure that all rules have been appropriately applied at the appropriate time. This cognitive attention should further facilitate players' identification of both entities and relationships between entities for inclusion in mental models of the game system.

\section{The Complexity of Game-Derived Mental Models}

This study investigates the first steps of the mental model learning process developed above - the initial development of mental models of a complex system. Specifically, it investigates mental models of an analog game system. Given the scattered and scant state of research on learning systems thinking from playing games, this study explores the entities (detail complexity) and relationships (dynamic complexity) individuals include in externalizations of their mental models, guided by these research questions:

RQ1 What entities do individuals include in their mental models of analog game systems? 
RQ2 What are the interrelationships between the entities in individuals' mental models of analog game systems?

\section{Method}

To address these research questions regarding the complexity of individuals' mental models of analog game systems, data was collected in two stages from an online questionnaire and an in-person session aimed, respectively, at a) evaluating participant characteristics to construct study session groups and b) conducting gameplay sessions and documenting participants' game-derived mental models.

\section{Participants and Recruitment}

College students age 18 and over were recruited from a large, Eastern university in the United States, and local community members age 18 and over were recruited from the area surrounding this university. College students were an ideal population for this study because not only are they actively engaged in learning complex material that could be understood in terms of systems, but they are also preparing to enter the workforce - a complex system in and of itself. As such, they represented a target audience for game-based learning. Because different disciplines attract students with different thinking styles (Kolb, 2014) that may influence how they mentally model systems, college student participants were recruited from general education classes, which are taken by a wide variety of academic majors, through announcements both inclass and through online class portals (see Appendix A for this announcement). Local community member participants were recruited through local neighborhood social media groups. Participants were told that they would play a board game and that the study was about how they thought about board games. No incentive for participation was offered. 
Participants completed an initial online survey (see Appendix B for the complete survey) in which they indicated their availability for the in-person session in two-hour weekend time slots. During recruitment, sign-ups were checked multiple times daily and participants were scheduled manually in groups of three to four, at which point they were sent an email with logistical information and a reminder of the purpose of the study. Sessions of three to four participants were decided upon because three to four is in the center of the range of ideal sizes for collaborative small-group learning, which is thought to be between two and six individuals (A. L. Brown \& Campione, 1996; Heller \& Hollabaugh, 1992; Johnson, Johnson, Holubee, \& Roy, 1984). In larger groups, however, individuals' clarification questions are more likely to be ignored (Webb, 1989) and they are more likely to experience hostility than those in groups of two or four (Eastin, 2007). Participants who indicated that they had experience playing Dominion were grouped together whenever possible, although during study sessions all participants except one indicated that they had never before played or heard of the game. This prevented situations in which expert players could teach the novice players how to play, which may have influenced the mental models of the novice players. Whenever possible, groups were gender balanced with two men and two women to minimize differences in gender dynamics between groups. Three days before their scheduled session, participants were emailed to remind them of the study and the time they agreed to.

Sampling was performed until saturation (Bowen, 2008b), which is the point at which no new information is being captured during data collection, leading to diminishing returns for collecting novel data (Özesmi \& Özesmi, 2004). To identify the saturation point, entity description data was open coded as it was collected, constantly comparing the new to the old (Glaser, 1965). Because of the likelihood that participants would identify a small number of 
additional, idiosyncratic entities (Özesmi \& Özesmi, 2004), saturation was defined as the point at which no more than one new entity had been identified in the most recent three participants. Saturation was reached at $N=30$.

\section{Design, Procedure, and Data Collection}

Pre-session survey. Participants signed up via the online survey (see Appendix B for the complete survey) for an in-person study session at the lab, and were instructed to arrive on time to their scheduled start time. The stimulus game-Dominion, described in detail below-was fully set up and covered before participants arrived for each in-person study session.

Study introduction. Upon arriving at the lab, participants were thanked for their participation and consented individually (see the consent form in Appendix C) to minimize any group pressure to do so. They were reminded that the study involved playing a game and then doing a writing and drawing activity related to their thoughts about the game. After verbally reviewing the key points of informed consent and the nature of the study and asking if they have any questions, they were informed that they may leave without any penalty or effect. All participants signed the informed consent form after reviewing it.

After consent, participants were seated at a table with Dominion, with the game obscured by a sheet of posterboard. Dominion was not shown to participants until a) all participants had arrived or b) if participants were late, 10 minutes since the scheduled starting time had elapsed, to ensure that they did not begin to form pre-conceptions about the game before the study began. As participants were seated, they were not given instructions for how to interact with each other, such as making introductions or remaining silent before the study begins, so as to maintain as natural as possible a group dynamic between players. 
Gameplay session. Two to four participants participated in each session. Before participants arrived, Dominion had been setup to standardize the layout of gameplay materials and to minimize the duration of the study session. All materials remained covered until the session began. Players also received standardized playmats (see Appendix D) on which to place their game materials, again to standardize the play situation across sessions. These playmats were also intended to reduce the number of things participants need to track (i.e., what card types were called and where they should be placed) while learning the game, thereby reducing extraneous cognitive load (Sweller, van Merrienboer, \& Paas, 1998) associated with learning the mechanics of the game so that they could focus instead on learning the dynamics of the game system. Standardizing the layout of the materials also minimized variability in terms of how the physical layout of the game might have influenced participants' mental models of the game system. Additionally, each participant was presented with an identical simplified rulebook (removing extraneous content provided by the game's publishers, e.g., examples, derivative scenarios) while still conforming to the standard set of rules. This fidelity of session rules to published game rules had one exception: players were told that the winner was the player with the most points after 10 rounds instead of the usual ending and win conditions. This round limit standardized the amount of exposure that participants had to the game, thus contributing to the comparability of their mental models by limiting variation in the progression of games across sessions. Additionally, the round limit restricted the amount that players were able to learn by observing other players (Wegner, 1987), which was desirable because the other players in each group represented uncontrollable variation that may have influenced participants' individual mental models. 
When all participants had arrived, the game was uncovered and participants were asked to learn and play it from the short rulebook and the text on the cards (see Appendix E for the full study protocol and script). Not providing verbal instructions mitigated any potential for participants to rely on the researcher as an expert in the game. After playing the game for 10 rounds, participants were separated and given written instructions to follow for the cognitive mapping exercise described below. Once participants completed their cognitive maps, participants were dismissed. The in-person sessions lasted about 90 minutes each.

Cognitive mapping task. After playing for 10 rounds, participants individually followed written instructions for a cognitive mapping exercise designed to externalize their mental models of the game they had just played (adapted from Brandstädter, Harms, \& Großschedl, 2012). Because mental models are cognitive representations, they are not directly accessible, and some procedure for externalizing them was necessary (Gray, Zanre, \& Gray, 2014). All potential procedures to externalize mental models are necessarily incomplete and subject to potential demand effects (Doyle, Radzicki, \& Trees, 2008). Nevertheless, this cognitive mapping procedure was designed with three main considerations in mind. First, to capture the entities that participants found most subjectively salient, and not potential entities that the researcher suspected were important, prompts (see Appendix E) were created to be as non-leading as possible. Second, to reduce cognitive demand during recall (Grenier \& Dudzinska-Przesmitzki, 2015; Kearney \& Kaplan, 1997; Özesmi \& Özesmi, 2004), this procedure was divided into multiple, discrete steps. Third, following the conception of mental models developed in the preceding literature review as a cognitive representation of interrelated entities, this cognitive mapping procedure was designed to diagrammatically elicit the entities and their interrelationships that participants perceived in Dominion's game system. Following Gray et al. 
(2014), this process is called "cognitive mapping" to distinguish externalized representations of mental models from cognitive mental models proper. The products of cognitive mapping are called simply "cognitive maps." This procedure (see Appendix E for the full procedure), first asked participants to generate a list of things they thought were important to their play of the game before asking them to identify how they were related with arrows and descriptions of those relationships. See Figure 5 for an example cognitive map.

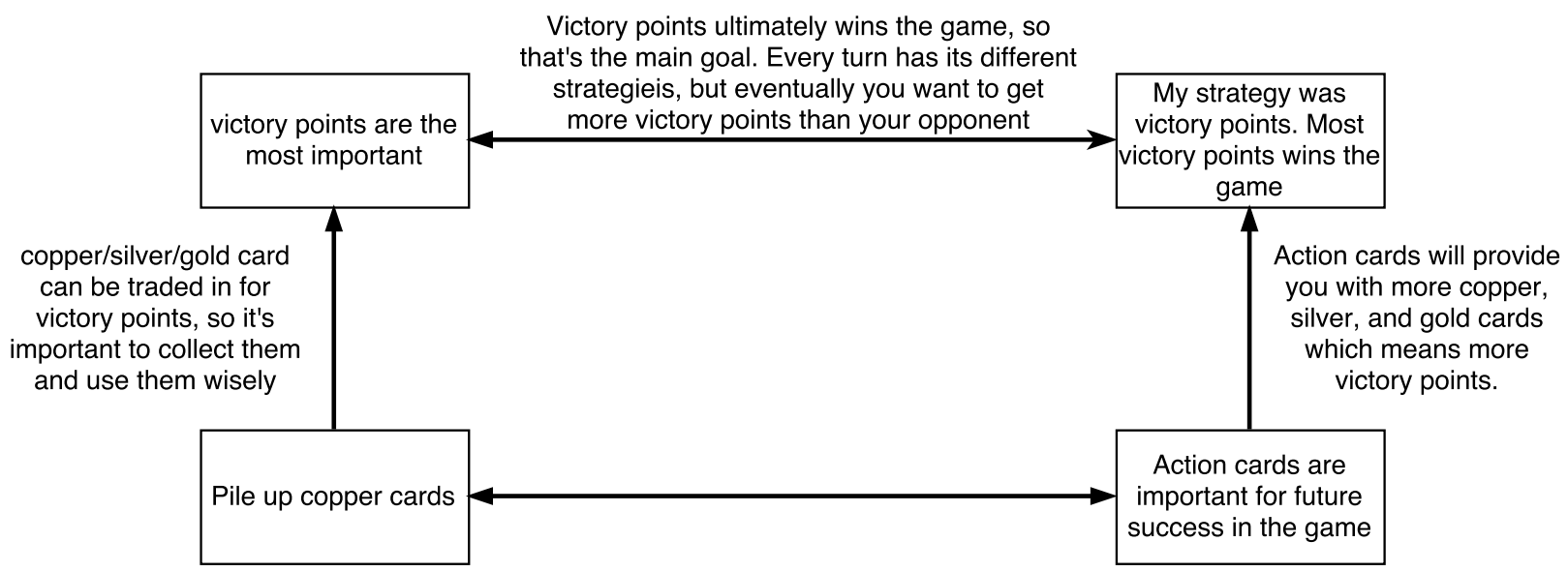

Figure 5. An example cognitive map transcribed by the researcher.

Immediately after the conclusion of the game, the researcher asked participants to move into different corners of the room that were arranged with tables and chairs. Separating participants from each other minimized their influence on each other's performance in the cognitive mapping task, and separation from the game materials ensured that mental models were elicited from memory (Doyle et al., 2008). They were given a medium-point marker, a stack of small sticky notes, and a written prompt that guided them through the first step of cognitive mapping, as described below. Prompts were provided in written format to allow participants to proceed through each task at their own pace. The second step in cognitive mapping involved arranging these sticky notes on a large piece of blank paper and drawing arrows between them, as well as labeling these arrows. So as not to restrict the number of entities 
in participants' cognitive maps, small sticky notes and large pieces of paper were used. To try to elicit discrete entity descriptions by preventing participants from writing too small on each sticky note, medium-point markers were used.

The first step in this cognitive mapping exercise asked participants to identify the elements of the game that they found salient and to write them on sticky notes, which would be used for subsequent steps in the process: "We are interested in how you think about the game you just played and what you think is important. When you think about the game you just played, what are the things that come to your mind? Reflect on this question for a moment, and then write each thing on a separate sticky note and set them aside. Write as many as you'd like. Just make sure to note the things that you thought were important while you were playing. Go at your own pace. It's okay to make any changes you want as you go along. Wave to the researcher when you feel satisfied with what you have written." As mentioned, this and all other prompts were designed to be as open-ended and non-leading as possible, so as not to influence the type of entities participants described.

Further steps in the procedure asked participants to arrange and diagram these sticky notes to identify relationships between them. After participants completed the first prompt, they were given the second prompt and a large blank piece of paper, and their pad of blank sticky notes was replaced with another pad of slightly differently-colored sticky notes to allow the researcher to identify any entity descriptions added during the second part of cognitive mapping. Their medium-point markers were also replaced by pencils and erasers to allow them to revise their arrows as they rearranged sticky notes on their large piece of paper. The second prompt was divided into several pages as a flipbook, because it involved several steps (see Appendix E). Participants were asked to arrange their sticky notes on the large, blank piece of paper before 
asking them to indicate relationships between them with arrows. They were then asked to describe each relationship, and finally asked to circle the most important part of their diagram. These prompts were designed to be as open-ended as possible, and participants were encouraged to revise as they saw fit.

Study session completion. After participants completed their cognitive maps, they were brought back to the gameplay table to inspect their decks at the end of the game so they could count their victory cards to see who won. As defined above, games include variable outcomes (Juul, 2011), so it was necessary to provide this closure for participants. Afterward, they were thanked for their participation, asked if they have any questions or concerns, and then dismissed.

Data preparation. After participants left the session, participants' cognitive maps were photographed to preserve them for analysis. See Appendix F for participants' anonymized cognitive maps. A notecard of the study session date and time and the participant's identification number was included in the photograph for record-keeping. Photographs of participants' cognitive maps were transcribed and converted to spreadsheet format for analysis. Both the content of individual sticky notes, as well as participants' descriptions of the arrows between sticky notes, were transcribed verbatim, including misspellings, capitalization, and punctuation. At the conclusion of data collection, participants' email addresses were expunged from all data systems, including Qualtrics and email clients, in order to preserve participant confidentiality. In total, 30 participants wrote a total of 227 sticky notes $(M=7.69, S D=3.16$, range $=3-19)$ and drew a total of 207 arrows $(M=6.90, S D=3.78$, range $=2-15)$ between them. After transcribing each day's cognitive maps, entity descriptions were compared for saturation. 


\section{Measures}

Because this study was primarily exploring the qualitative data collected via cognitive mapping, few measures were collected in the initial online questionnaire. Measures were collected to group participants for in-person study sessions. Gender was used to attempt to gender-balance every study session, while experience with the game used as stimulus material was collected to group experienced participants together.

Demographics. Five open-ended items prompted participants for brief responses about their demographic characteristics: age, gender, ethnicity, major, and year in college.

Analog gaming experience. Subjective expertness with various analog games was selfreported with 1010 -point semantic differential items $(0=$ Never played to $10=$ Expert $)$. The 10 most popular analog games, operationalized as the 10 games that have received the most ratings on BoardGameGeek ("BoardGameGeek," n.d.), were used. This list will include Dominion. For each game, they were prompted to indicate their level of experience. Only responses to the item for Dominion was used to identify novice and experienced Dominion players for study session grouping. The other games were included only to prevent participants from identifying the game of interest.

\section{Stimulus Materials}

Participants played the popular analog game Dominion (Vaccarino, 2008; see Figure 6) in which players compete to acquire the most victory points. This game, and its introductory set of cards specifically, was selected for this study because it contains the five kinds of complex relationships described in the preceding literature review: indirect relationships, nonlinear relationships, stochastic relationships, delayed relationships, and feedback loops. See Challenges to Systems Thinking: System Complexity, pp. 3-9, for a description of these relationships in 
Dominion. Furthermore, it was selected for its balance of a relatively simple rule set and relatively complex gameplay - a combination that would likely be appropriate in instructional settings. Furthermore, it won the prestigious Spiel des Jahres (Game of the Year) award in 2009 (“Spiel des Jahres: Dominion,” 2015), which specifically targets games that are thought to have broad appeal to a general audience beyond hardcore hobbyist analog gamers. Moreover, it is both highly rated and has received many ratings on BoardGameGeek ("BoardGameGeek," n.d.), suggesting that people with varied gaming preferences find it enjoyable. As such, Dominion should be an engaging game for a wider variety of participants and is a good exemplar of contemporary analog games. In Dominion, players play figuratively as feudal lords expanding their domains. It is a deckbuilding game, which is a kind of analog game in which players start with their own small deck of cards and add to it throughout the game, developing more effective combinations of cards in their personal decks. Each turn, players in order a) play at least one action card that provides a variety special ability, b) spend treasure cards to buy new cards, c) discard all their played and unplayed cards that turn, and then d) draw a new hand of five cards for the next turn. As needed, players shuffle their played and discarded cards to form a new deck from which to draw. 


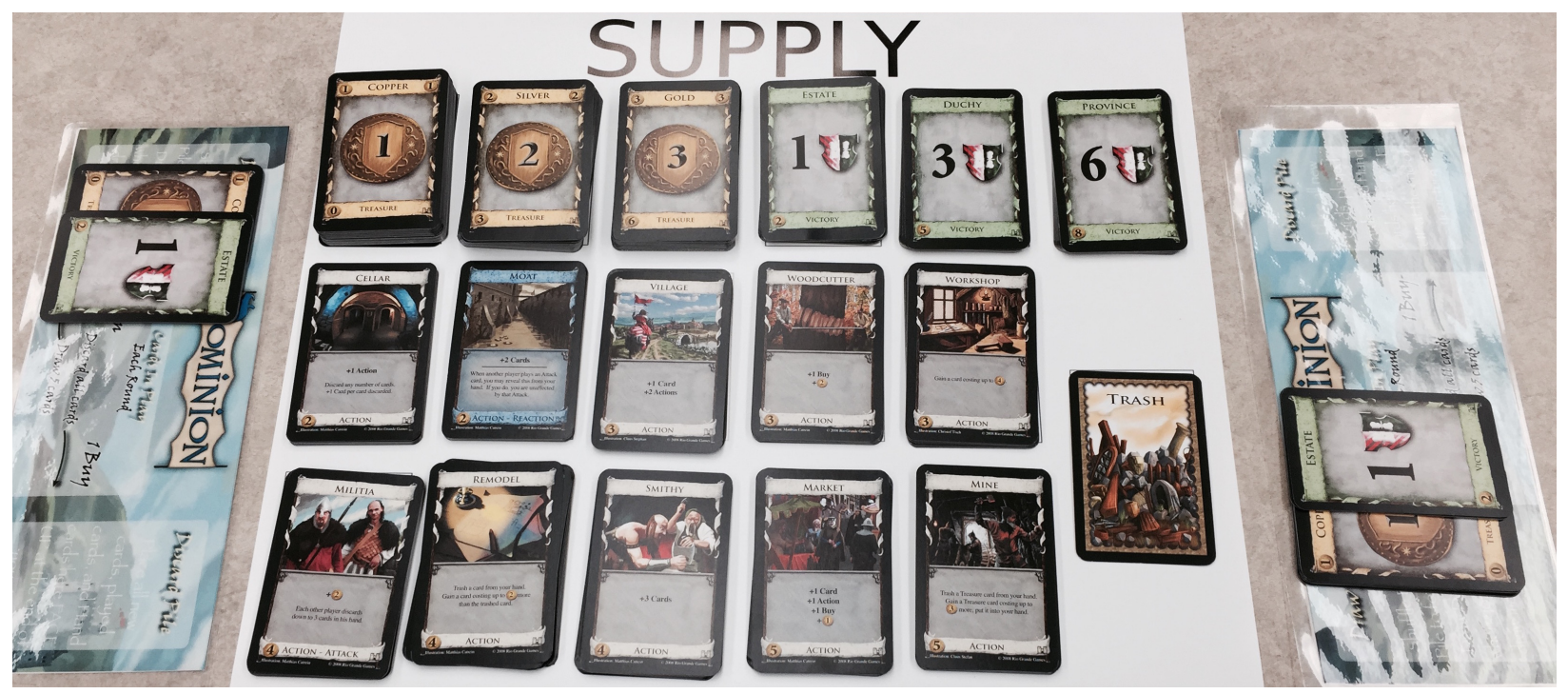

Figure 6. Layout of Dominion during study sessions.

Dominion had additional advantages for the stimulus in this study. Its popularity suggests that it has features that were likely to engage participants throughout the play session. It also has a relatively short playing time, between 30 and 90 minutes for a full game for new players, which allowed participants to experience more turns of the game, i.e., to have more experience with the system in a shorter amount of time. Part of Dominion's popularity is that it is relatively easy to learn. It was selected for its learnability, as it was important that participants were able to teach themselves how to play, since this learning process is the beginning of mentally modeling a game system. Moreover, Dominion's recommended number of players is between two and four, which as described above is, as detailed below, solidly within the ideal range of group sizes for collaborative learning, an activity that is central to playing a game unfamiliar to the individuals in a group. This range of group sizes was expected to not only facilitate participants' learning of the game, it also allowed data collection sessions to run if one or more of the scheduled participants failed to attend. 


\section{Data Analysis}

Once saturation was reached, more detailed analysis of participants' cognitive maps began, which is described in detail for each research question in the next section and summarized in Table 1. To answer RQ1 about the entities in participants' mental models of analog game systems, the categories of entities participants included in their cognitive maps were inductively discovered with grounded coding. To answer RQ2 about the relationships between entities in participants' mental models of analog game systems, the prevalence of different kinds of relationships between entities was content analyzed.

Table 1

Correspondence of research aims, data, analysis, and outcomes

\begin{tabular}{|c|c|c|c|}
\hline Research Questions & Data Collected & Analysis Approach & Analytical Outcome \\
\hline $\begin{array}{l}\text { RQ1 What entities do } \\
\text { individuals include in } \\
\text { their mental models } \\
\text { of analog game } \\
\text { systems? }\end{array}$ & $\begin{array}{l}\text { Descriptions of } \\
\text { entities written on } \\
\text { sticky notes, } \\
\text { converted to } \\
\text { spreadsheet format }\end{array}$ & $\begin{array}{l}\text { Grounded coding with } \\
\text { memos: discovering } \\
\text { categories of entities }\end{array}$ & $\begin{array}{l}\text { Catalog and } \\
\text { description of mental } \\
\text { model object } \\
\text { categories of objects in } \\
\text { models }\end{array}$ \\
\hline $\begin{array}{l}\text { RQ2 What are the } \\
\text { interrelationships } \\
\text { between the entities } \\
\text { in individuals' } \\
\text { mental models of } \\
\text { analog game } \\
\text { systems? }\end{array}$ & $\begin{array}{l}\text { Relationships } \\
\text { drawn between } \\
\text { entities as } \\
\text { directional arrows } \\
\text { plus qualitative } \\
\text { description written } \\
\text { on large piece of } \\
\text { paper, converted to } \\
\text { spreadsheet format }\end{array}$ & $\begin{array}{l}\text { Content analysis: coding } \\
\text { of relationships to } \\
\text { identify prevalence of } \\
\text { types of relationships }\end{array}$ & $\begin{array}{l}\text { Relative prevalence of } \\
\text { different types of } \\
\text { relationships in } \\
\text { participants' mental } \\
\text { models }\end{array}$ \\
\hline
\end{tabular}

\section{RQ1 Analysis: Mental Model Entities}

Categories of mental model entities were inductively discovered through grounded theory coding (Glaser \& Strauss, 1967), recognizing that the researcher was sensitized (Bowen, 2008a) to the concepts in the preceding literature review. By explicitly recognizing these sensitizing concepts, the researcher was able to bracket these ideas during inductive analysis (Ahern, 1999). 
Bracketing involved recognizing these sensitizing concepts to enable the researcher to inductively discover concepts and categories in the data that differed from those to which he had been sensitized. Because little was previously empirically known about the kinds of entities individuals include in their mental models of game systems, this inductive approach was appropriate for generating categories of discrete, identifiable, and small units of data; as such, it was appropriate for this unit of analysis - the brief descriptions written on small sticky notes in participants' cognitive maps.

Using grounded theory coding (Glaser \& Strauss, 1967), the data was iteratively open coded, which involved applying very specific, granular labels to units of data. The data extracts that were coded were as small as single words or phrases on the sticky notes that participants wrote and included in their cognitive maps. Because these descriptions were not as discrete as anticipated, non-exclusive coding, in which each unit can be assigned multiple codes, was used. In open coding, the researcher labeled entity descriptions and data extracts on a spreadsheet. This process involved constant comparison (Glaser, 1965), in which each coded unit was compared to previous units to determine whether they were the same type of thing or different. After open coding of all units, the codes themselves were compared to each other in reductive coding. This process identified points of comparison between codes and led to the identification of higherlevel categories or themes in the data. After the first round of reductive coding, each category was analyzed closely for internal consistency between entity descriptions and codes within the theme. Next, categories were compared to each other for external differentiation. These categories were then named and defined. Finally, all data extracts were reviewed once more to ensure that all applicable categories and codes had been applied to all data extracts. In the final 
round of coding, a conservative approach was taken to potentially ambiguous or vague entity descriptions, erring in favor of not coding unclear descriptions.

\section{RQ2 Analysis: Mental Model Entity Relationships}

Initially, RQ2 had been planned to be addressed with thematic analysis to identify themes in the kinds of relationships described by participants in their cognitive maps. The collected relationship description data, however, did not conform to expectations in two ways. First, as described further in the results, participants did not describe as many of the relationships in their cognitive maps as had been expected. Because the cognitive mapping prompts asked participants to describe each relationship, it was expected that nearly all relationships would be described. Instead, $28.5 \%(n=59)$ of entity relationships were unlabeled. Second, the entity descriptions that participants did write were not as detailed or as rich as had been anticipated. Because of the nuance the researcher perceived in the relationships between entity's in Dominion's game system, it was anticipated that participants' descriptions would also be detailed and nuanced. Both of these unexpected situations made the data unconducive to thematic analysis.

Given these deviations, it was decided to alter the analysis plan for RQ2 to interpretive content analysis to reflect the conceptualization of mental model complexity developed above. Specifically, entity descriptions in participants' cognitive maps were content analyzed for the five kinds of complex relationships described in the above literature review: stochastic relationships, delayed relationships, nonlinear relationships, indirect relationships, and feedback loops. In fact, this content analysis not only still answered RQ2 by identifying the prevalence of different types of entity relationships in participants' cognitive maps, it also more closely approached the aim of the study by directly addressing complex systems (in comparison to the original analysis plan). 
Content analysis rules were based on theoretical understandings of these complex relationships (see Appendix $\mathrm{G}$ for the full content analysis codebook). Content analysis began by identifying every relationship - -i.e., every arrow connecting two entities — and coding it for the type of relationship represented. In particular, relationships were coded for complex relationships that were defined as involving relationships between only two entities-i.e., delayed, nonlinear, and stochastic relationships. This coding was non-exclusive - that is, an identified relationship could be assigned multiple codes - since a given relationship may involve all (or none) of the kinds of complex relationships analyzed here. All codes were assigned by evaluating three cognitive map components: the arrow linking two entities, the description corresponding with that arrow, and (to support inferences made from these data) the linked entity descriptions. Subsequently, all relationships were coded for complex relationships that involved relationships among more than two entities-i.e., indirect relationships and feedback loops. Instead of analyzing discrete individual relationship descriptions, this required analyzing both text and the cognitive maps that more clearly suggested larger structures. The rules for coding indirect relationships and feedback loops specified that both a) series of relationship descriptions had to explicitly, semantically refer to linked entity descriptions, and b) those relationships had to be in the same direction. In other words, if A influenced B influenced C, both of those relationships were coded as part of an indirect relationship. If, on the other hand, A influenced B and $\mathrm{C}$ influenced $\mathrm{B}$, neither of those relationships were coded as indirect.

Finally, if a relationship had not been coded as any of the preceding, it was coded as simple. 


\section{Analytical Lens}

In the interpretive approaches employed in the present study, it is important to acknowledge the researcher's subjective lens employed as the analytical instrument. Following post-positivists, I believe ontologically in an actually existing universe independent from interpreting beings that cannot, however, be directly and fully understood empirically (Denzin \& Lincoln, 2011). I depart from post-positivists epistemologically, however, and see knowledge of this universe as mediated by semiotic processes of interpretation. As interpreting beings, our understandings of the world are always influenced by sensory and cognitive organs, culturally specific categories (Dall \& Boas, 1887) and habitual modes of thought (Whorf, 1944), and our interactional experiences of the world (Biesta, 2010). Each of these influences deserves more words than are possible here. At a physiological level, our sensory organs can perceive and distinguish only certain types, ranges, and gradations of physical phenomena. Our cognitions are limited by our cognitive capacities and structures. Even interoception of internal physiological and affective states are necessarily limited and shaped by nervous and cognitive systems (Craig, 2003). At another level, perception and cognition are culturally relative. The questions that we ask about the world, and how we ask them, are tethered to deeply taken-for-granted, culturally bound categories that vary across sociocultures and times. This cultural relativism makes a "value-free" social science impossible (Weber, 2011), and is aligned with perspectives that see knowledge as culturally and contextually situated (Haraway, 1988). Furthermore, our linguistic and non-linguistic cognitive processes and representations structure what and how we perceive and conceive of the world (Keller, 2015). Additionally, echoing the insights of pragmatists (Biesta, 2010), I see knowledge as a consequence of interacting with the world that mutually alters both myself and the world and kicks off a process of unlimited semiosis (Mladenov, 2001), 
in which interpretations of signs stimulate subsequent processes of interpretation (Bergman \& Paavola, n.d.).

As a consequence, the knowledge I produce as a researcher is a product of my active engagement with my research object. It is therefore necessarily limited by and situated in my history, capacities, and perspectives. This perspective makes interpretive qualitative research relatively unproblematic. All research is an inherently interpretive practice that provisionally fixes this semiotic chain for future re-interpretation. Different methods produce different knowledges (Biesta, 2010). I arrive, therefore, at a flexible methodological position like that of the bricoleur (Denzin \& Lincoln, 2011). Because all knowing is provisional and interpretive, I am open to using the methodology that seems to best allow me to construct the kind of knowledge I am seeking. Additionally, the interpretations I represent in my research are shaped by my cultural and personal history and are an outcome of my interaction with my object of study. In the present study, results and interpretations thereof should be considered with these ontological and epistemological grounds in mind.

\section{Results}

Of the 30 individuals who participated, 27 were currently enrolled in college, 17 identified as female and 13 as male, 27 identified as white, and the average age was $27(S D=$ 12.5 , range $=18-69)$. Of those currently enrolled in college, a plurality $(n=11)$ were Communication Studies majors. Two participants indicated that they had some experience with Dominion. Not included in these numbers or the results below were four participants who were scheduled but did not show up to their study session. 


\section{Entities in Game Mental Models}

RQ1 focused on discovering what entities individuals include in their mental models of analog game systems, toward better understanding how mental model development processes may facilitate analog game-based learning processes. This research question was addressed with a grounded thematic analysis of the descriptions of game entities that participants wrote in their cognitive maps. Participants wrote a total of 227 entity descriptions $(M=7.69, S D=3.16$, range $=3-19)$ in their cognitive maps. Following the insights of ANT (Latour, 2008) that expanded the notion of actors to include not only humans, but material objects and conceptual entities, everything participants wrote on a sticky note in their cognitive maps was treated as an entity description. This decision was made in order to avoid imposing a priori criteria to these descriptions when deciding what qualified or did not qualify as an entity. At the conclusion of data coding, a total of 348 codes had been applied. Five main categories of entities that participants found salient during gameplay and described in their cognitive maps were discovered. These five categories were: formal game entities, actions, other players, learning how to play, and subjective experience.

Formal game entities. Almost all participants $(n=24)$ described entities that were part of the formal game - essentially anything contained within the game's cardboard box or described by the materials therein. In total, $37.0 \%(n=84)$ of all participants' entity descriptions referred to some formal game entity. More specifically, these entities referred to things described within the rulebook, displayed on game components, imagined during gameplay, or related to the components used to play the game. These formal game entities fell into three sub-categories: a) material objects, b) ludic concepts, and c) narrative concepts. 
Material objects. Most participants $(n=16)$ described material objects as part of their cognitive maps. In total, $16.3 \%(n=37)$ of all participants' entity descriptions referred to material objects. They referred specifically to the tangible objects that were part of the game. Because Dominion is composed solely of cards, these descriptions always referred to "cards," as when one participant wrote, "How do you know when to buy the green cards." In this example, the participant emphasized the physical quality, "green," of the card more than its function within the game, suggesting that they were paying particular attention to the physical, material characteristics of the cards. More frequently, however, material objects — cards — were mentioned in combination with other categories described below. For example, one participant wrote "Pile up copper cards." In addition to the material "card," they described an action that emphasized a material organization of physical objects: "pile up." Furthermore, they described a specific class of card, "copper," which is a ludic concept, as explained below. As other research has suggested, the movement and manipulation of material objects is the primary way in which individuals perform actions within analog games (Xu et al., 2011), so it is unsurprising that so many participants found them salient.

Ludic concepts. Often, participants $(n=23)$ described ludic concepts. In total, $28.6 \%(n$ $=65)$ of all participants' entity descriptions referred to ludic concepts. Ludic concepts are related to the rules of the game. They include game mechanics, rules, and win conditions. This subcategory of formal game entities related to entities' conceptual role or meaning within the game rules, and frequently included game-specific terms - e.g., "Victory points" or "rounds" - that were described in the rulebook or printed on the cards.

Although ludic concepts were often mentioned in tandem with material objects, these two categories were distinct. Whereas material objects referred to physical things, ludic concepts 
referred to roles, abilities, and game-specific concepts that did not necessarily have a material form. Although many participants described material "cards" in addition to ludic concepts, participants also described ludic concepts without reference to material objects. One wrote, for example: "Obtaining as many victory points as possible." Here, the ludic concept "victory points" was described in the absence of any material objects.

Descriptions of ludic concepts often mentioned the class of card (as opposed to cards as strictly material objects), as when one participant wrote simply, "Victory cards." Classification systems are a conceptual understanding of formal game objects. While "cards" referred to a material object, "Victory" referred to a ludic concept associated with that material object. Specifically, "Victory" is a part of a conceptual classification system of cards that have particular meanings, functions, and abilities within the game. In Dominion, Victory cards are worth points at the end of the game and determine the winner. Another class of cards described were Action cards, which in Dominion give players unique abilities. Sometimes participants described the function of Action cards with game-specific terminology, e.g., "Use Action cards that allow +1 Action when I have another action card." In this example, "+1 Action" was written on the card itself and described in explicit terms in the rulebook. During gameplay, Action cards with this specific text gave players the ability to play another Action card. At other times, the function of action cards were described in more generic terms, e.g., "Use action cards that add coins for you." "Coins" have a particular meaning and function in Dominion, in that they allow players to acquire more cards, and certain Action cards provide additional coins when played.

Ludic concepts also included game-defined goals and strategies for achieving these goals. As one participant wrote, "My strategy was victory points. Most victory points wins the game." Win conditions are an important part of games (Juul, 2011), and in this example, the participant 
essentially reiterated the win condition described in the rulebook: at the end of 10 rounds, the player with the most victory points wins. Further, this participant's strategy to win focused on victory points. The pervasiveness of these goals and other game-specific ludic concepts described above suggest that participants were concerned with making sense of the game as a goal-oriented and rule-based activity. As such, these findings support much of the theorizing on games that has suggested they are, at least in part, defined by rules and goals (Juul, 2011).

Narrative concepts. Participants $(n=4)$ occasionally described formal game entities that were narrative concepts - that is, in ways that pointed up the story unfolding in the fictional world represented by the game through text, image, and action. In total, $2.6 \%(n=6)$ of all participants' entity descriptions referred to narrative concepts. Unlike ludic concepts, narrative concepts are not part of a game's rules or win conditions. Narrative concepts involved imagining the meaning of game components, actions, and other players not in terms of rules, but in terms of the fictional story unfolding through gameplay. One participant wrote that they were engaged in a "Competition with fellow monarchs" to "Fight for power and money, prevent other players from surpassing your land size." The front cover of the rulebook described the theme of the game as monarchs competing to expand the lands of their domains. This theme was echoed in the graphics of the cards. By describing the other participants as "monarchs," this participant drew on the fictional story of the game. Further, by writing about "land size," this participant emphasized this fiction over the related ludic concept of Victory points. The relative infrequency of narrative concepts is likely a consequence of participants' focus on material and ludic concepts as part of their process of learning the game. Learning is discussed in further detail below. 
Co-occurrence of formal game entities. Notably, these distinct sub-categories of formal game entities - material objects, ludic concepts, and narrative concepts - were observed to cooccur within participants' entity descriptions in many instances. Sub-categories co-occurred when one entity description was coded as two or more sub-categories. As described above, a conservative approach was taken toward coding, so the frequencies of co-occurrence are also conservative. For example, it could be argued that "all the cards seemed important" is a ludic concept, because "importance" suggests an evaluation of cards in terms of their in-game value. However, due to the vagueness of the referent of "important," this entity description was coded only as a material object for its reference of "cards." Of 84 total descriptions of formal game entities, $28.7 \%(n=24)$ included two sub-categories, while none included all three. Cooccurrence primarily occurred between material objects and ludic concepts. In fact, of all entity descriptions that included a material object $(n=37), 62.2 \%(n=23)$ co-occurred with at least one ludic concept. Conversely, of all entity descriptions that included a ludic concept $(n=65)$, $35.4 \%(n=23)$ co-occurred with at least one material object. For example, ludic concepts and narrative concepts were described together when one participant wrote, "More benefit continually purchasing land. Maybe not true if more rounds." "Land" was a narrative concept because it describes what victory cards and points represented within the fiction of the game both through the images printed on cards and the text describing the game theme on the cover of the rulebook, whereas "rounds" were a ludic concept by which players' actions were meaningfully subdivided during gameplay. Rounds organized the game into discrete, meaningful chunks of action that measured the progress of the game and the approach of its conclusion. In this example, the value ("benefit") of the narrative concept of land was evaluated in terms of the ludic concept of rounds. In another example, material "cards" were also described in 
combination with ludic concepts like game-specific abilities: "Getting Action cards with the 'buy' feature." Here, the material card and its ludic classification (“Action”), as well as its affordance — the chance to buy more cards (“"buy' feature”)—-were described in combination. When formal game entity sub-categories co-occurred within entity descriptions, they often cooccurred more closely than the preceding example, as in the frequently mentioned "Victory cards." Here, "cards" referred to a material object, while "Victory" referred to a ludic classification. In this example, this word-by-word co-occurrence suggests that these subcategories, while analytically distinct, were sometimes elided in practice.

Player actions. In addition to formal game entities, most participants $(n=16)$ described entities that were player actions. In total, $17.6 \%(n=40)$ of all participants' entity descriptions referred to player actions. Player actions are behaviors participants performed during gameplay. Although actions related to the preceding formal game entities, they were distinct because these actions described what participants actually did with those formal game entities during gameplay. Within entity descriptions, player actions co-occurred with all three sub-categories of formal game entities, and $75 \%(n=30)$ of actions were described with an associated material object $(n=20)$, ludic concept $(n=20)$, or narrative concept $(n=1)$. This close relationship of player actions to ludic concepts and material objects supports theorizing on games as assemblages of interrelated conceptual, material, and human actors that interact in the process of gameplay (Taylor, 2009). The two most frequently mentioned player actions were acquiring and using. In Dominion, players acquire cards by taking them from the supply and adding them to their decks. They use cards by placing them face-up to make use of the various abilities written on them. Player actions also included discarding and trashing. Players discard cards by removing them from their hands and placing them in their discard piles. They trash cards by removing 
them from their hand and placing them out of the game. These actions corresponded to the gamedefined activities players performed during their turns. Although these actions were explained in the rulebook, they were distinct from ludic concepts because they involved a behavior. Moreover, player actions were described not only in relation to ludic concepts, but in relation to material objects and narrative concepts as well. For example, participants described acquiring in terms of ludic-material victory cards ("collect victory cards @ end"), strictly ludic victory points ("Using the multiple action cards with the "draw" and "buy" feature to buy victory point"), and strictly narrative land ("More benefit continually purchasing land. Maybe not true if more rounds"). These examples suggest that action transcended the three sub-categories of formal game entities.

Several participants $(n=7)$ described particular sequences of various kinds of actions. These sequences of actions involved performing actions in a specific order or during a specific part of the game. One participant, for example, wrote: "Collect cards early then focus on victory points." Here, the participant described a sequence of acquire actions: first, acquire cards; next, acquire victory points. Although the same action was described twice in sequence, the formal game entity with which it was associated varied. From these short descriptions, it was unclear whether participants were conceptualizing sequences of actions as systems themselves (see Latour, 2008 on objects as networks) or combining them as cognitive shortcuts.

Sociality. Many participants $(n=12)$ described some aspect of sociality in their cognitive maps. In total, $8.8 \%(n=20)$ of all participants' entity descriptions referred to sociality. This category included any mention of the other participants in the study. Although the researcher was sitting next to the participants, no participants mentioned him in any entity descriptions. Some of these descriptions only very generally referred to other players, as when participants mentioned 
the number of players in the group. In addition to other players generally, sociality included orientations to other players and surveillance of other players.

Other players. A few participants $(n=3)$ referred to other players in a general sense. In total, $2.6 \%(n=6)$ of all participants' entity descriptions referred to other players generally. One, for example, wrote, "The game is fun and easy to learn. I could see it being a lot more fun with a large group of people." This participant compared their actual experience of playing Dominion to a hypothetical experience of playing the game with a greater number of other players (i.e., "with a large group of people"). Although relatively uncommon, this general reference to other players suggested their relevance to understandings of gameplay. The following two sub-categories of sociality elaborate more specifically on the role of other players in the game.

Orientations to other players. Several participants $(n=6)$ wrote about either a competitive or a cooperative orientation toward the other participants. In total, $4.8 \%(n=11)$ of all participants' entity descriptions referred to orientations to other players. Orientations toward other players were either in terms of competition for the rulebook-defined win condition or in terms of cooperation and helping each other achieve an alternative goal. A competitive orientation involved attempting to beat other players and achieve the game-specific win state (i.e., having the most victory points at the end of 10 rounds), as well as competing for game resources generally. A cooperative orientation, in contrast, involved helping each other. One participant described a shift from cooperating with each other at the beginning of the game to competing with each other toward the end: "I think the most important factor was helping each other learn the game @ first, then creating a strategy that helped build a winning deck.” A cooperative or competitive orientation toward the game intersected with players' goals. For example, one participant preferred cooperation to pursuing other potential goals, such as the 
explicitly described victory condition in the rulebook: "Cooperation / helped each other (more fun than the object)." Here, a cooperative orientation prevailed over the competitive goals described in the rulebook. This supersession of cooperation over competition aligns with previous findings that, over time, a communicative orientation can supplant a competitive orientation even in explicitly competitive games (W. J. White, 2012).

Surveillance of other players. Besides cooperation and competition, a few participants ( $n$ $=4)$ described surveillance of other players. In total, $1.8 \%(n=4)$ of all participants' entity descriptions referred to surveillance of other players. This surveillance specifically referred to keeping track of what other players were doing in the game. A few participants wrote that they thought attending to and remembering other players' actions was important, as when one wrote: "Need to keep track of other players actions at all Times." If playing competitively, tracking other participants' actions could inform which cards to acquire and play, and when. The relative infrequency of this sub-category is likely due to that fact that participants did not have prior experience with the game, and were focused on their own understanding of how to play the game, as described in the next category.

Learning processes. Most participants $(n=16)$ described entities related to learning how to play the game. In total, $12.8 \%(n=29)$ of all participants' entity descriptions referred to learning processes. Learning to play the game involved making sense of the ludic concepts, material objects, and actions described above. Several participants also described interacting and communicating with other players as part of their learning process. Some participants described specific learning strategies that they employed during the game, such as referring to the rulebook. While some participants found the rulebook helpful for their learning, others did not. Some, for example, found specific parts of the instructions useful: "the sample turns portion of 
the instructions was useful to a beginner." In particular, this participant found the example of the first three turns helpful. Other participants, however, wanted additional clarification: "Clarify instructions in terms of when u can buy pennies." Other learning strategies, such as asking questions, centrally involved other players. In fact, collaborative communication was a frequent learning strategy, exemplified by the following: "It was important to talk to the other players to make sure we all understood." Here, "talk[ing] to the other players" served a particular learning function (i.e., "to make sure we all understood"). Although there was some overlap between collaborative learning strategies and a cooperative orientation toward other players, some participants described collaborative learning without a cooperative orientation, while others described a cooperative orientation without collaborative learning. At times, participants' focus on learning how to play subsumed any attempt to pursue other potential goals. One participant, for example, described focusing on learning before attempting to win the game: "I think the most important factor was helping each other learn the game@ first, the [sic] creating a strategy that helped build a winning deck." This participant thought that a strong group understanding of the game was an important precondition for approaching it competitively, suggesting that the distinction between competition and cooperation is not so clear cut. In analog gaming communities more broadly, players often value social relationships and social interaction more than in-game victory (Woods, 2012).

Subjective experience. Almost all participants $(n=25)$ mentioned the final entity category, subjective experience. In total, $40.1 \%(n=91)$ of all participants' entity descriptions referred to subjective experience. Subjective experience related to participants' overall experience of playing the game. It reflected participants' evaluations of and affective reactions to the game. 
Confusion and uncertainty. Because so many participants $(n=17)$ included confusion and uncertainty in their cognitive maps, a sub-category was created for this specific affective reaction. In total, $18.1 \%(n=41)$ of all participants' entity descriptions referred to confusion and uncertainty. While several players described being very confused, such as one who simply wrote, “'CONFUSING!," others wrote that their confusion was reduced over the course of the game: "game was confusing at first but became really fun at the end." While the former participant seemed to have never satisfactorily resolved his or her confusion, the latter appeared to have done so. To relieve some of this uncertainty, participants employed the learning strategies described above. As can be seen from these two examples, these learning strategies were not always successful. At times, confusion about the game influenced whether players oriented toward other players cooperatively or competitively, as with the participant who wrote: "Not really a competition / We didn't understand enough to care about competing." Here, confusion led directly to a non-competitive orientation. Again, understanding the game was seen as a precondition for approaching it competitively, and this understanding was lacking. In addition to general confusion about playing the game, some participants described uncertainty about more specific aspects of the game. One participant, for example, wrote: "How do you know when to buy the green cards."

Other reactions and evaluations. Besides confusion and uncertainty, almost all participants $(n=24)$ included some other reaction to or evaluation of the game in their cognitive maps. In total, $23.8 \%(n=54)$ of all participants' entity descriptions referred to some other reaction to or evaluation of the game. Many participants evaluated whether the game was fun or not, how easy or difficult it was to play or learn, whether they wanted to play it again, and whether they thought it seemed like another game they had experience with. One participant, for 
example, negatively evaluated the game's appearance in contrast to the fun they experienced while playing: "Game looked cheap at first but was actually really fun to play." Some participants described affective states like frustration and stress that were influenced by their confusion and uncertainty about how to play the game, such as the participant who wrote: "frustrating not knowing if we were doing it right." Here, the participant expressed uncertainty (i.e., "not knowing if we were doing it right") that led to a different affective reaction: frustration. This example, and others throughout participants' cognitive maps, suggest that understanding the game is necessary to enjoy it. While the game's challenge prevented some players from enjoying it, others found this challenge of playing part of the fun. One participant, for example, wrote that it "Would be really fun with people experienced with the game." Here, a participant thought that understanding the game - i.e., experience — would lead to more enjoyment. The broad range of subjective reactions to the game suggests that there is some individual-level — or possibly group-level—difference that leads different people to respond to the same game in quite different ways. Both understanding of the game, as well as motivations for play, likely influence whether an individual (and a group) will enjoy playing analog games, and which sorts they will enjoy (see Woods, 2012 for a discussion of analog gameplay motivations).

Miscellaneous. Some open codes that entity descriptions received were idiosyncratic and did not meaningfully pattern with other coded entities. These codes and descriptions were maintained as a separate, miscellaneous category. Some descriptions were too vague to categorize, such as single words describing broad concepts, like "power" and "control." These broad concepts may have been related to ludic concepts like victory points, to competition with other players, or to managing randomness. Not enough detail was provided, however, to 
discriminate between multiple possible interpretations. A few participants wrote about "strategy" in a generic sense, but nothing about a specific strategy. Whereas specific strategies were categorized under ludic concepts, generic "strategy" was left under miscellaneous because it was too vague to interpret. Additionally, two participants mentioned specific issues that they felt made them perform poorly in the game, but were not obviously part of their subjective experience of the game.

RQ1: Detail complexity of game-derived mental models. To answer RQ1, then, participants included five main categories of entities in their cognitive maps, interpreted here as externalizations of their mental models of the Dominion gameplay experience. These results are summarized in Table 2. One such entity category emerged related to formal game entities, with three sub-categories: material objects, ludic concepts, and narrative concepts. A second category of entities was the player actions that participants made while playing the game, which employed the aforementioned material, ludic, and narrative entities. Third, participants described sociality — not only other players generally, but also how they oriented toward other players either competitively or cooperatively and surveillance of other players' actions. The fourth key category of entity in participants' cognitive maps was their learning process, which included the strategies that they used to understand how to play the game. The final category of entity that participants found salient was their subjective experience of playing the game, including both feelings of confusion and uncertainty, as well as other reactions to, evaluations of, and reflections on the gameplay experience. 


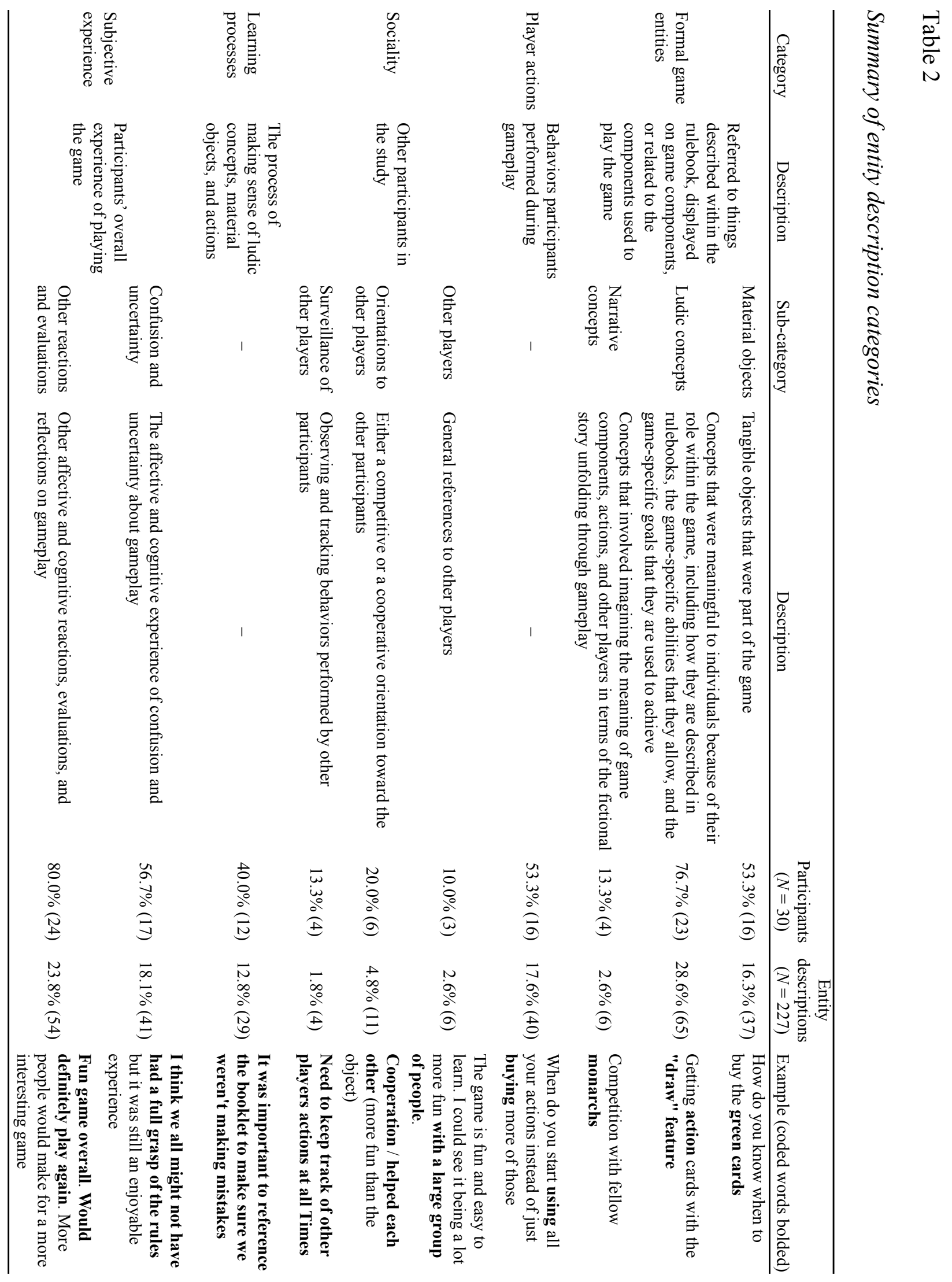




\section{Entity Relationships in Game Mental Models}

RQ2 asked what interrelationships individuals identify among the entities in their externalized mental models of analog game systems. This research question was addressed with a content analysis of the relationships between entities that participants drew and described in their cognitive maps (see RQ2 Analysis: Mental Model Entity Relationships, pp. 37 - 38, for a description of the analytical process). In participants' cognitive maps, participants drew arrows between the entity descriptions described above to represent relationships between them. Participants were also asked to describe the relationships represented by those arrows. These relationships were content analyzed by coding for five different types of relationships that are characteristic of complex systems: stochastic relationships, delayed relationships, nonlinear relationships, indirect relationships, and feedback loops (see Appendix $\mathrm{G}$ for the codebook). These codes were not exclusive, so relationships could be coded as multiple of these relationship types. These kinds of relationships are thought to contribute to the "dynamic complexity" of systems and mental models (Senge, 2006). For simplicity, these five kinds of relationships will be collectively referred to as "complex relationships" below. If a relationship was labeled and not coded as one of these five types of complex relationships, it was coded as a simple relationship.

Participants drew a total of 207 relationships between pairs of entities in their cognitive maps $(M=6.90, S D=3.78)$. Of these relationships, $28.5 \%(n=59)$ were unlabeled and so represent deviations from the participant instructions to describe relationships, with $60.0 \%(n=$ 18) of participants included at least one unlabeled relationship in their cognitive maps. Given that an arrow drawn between two entity descriptions in a cognitive map is ambiguous, it would be inappropriate to speculate what these arrows are meant to represent. A simple relationship is 
presented here as an example of the ambiguity of unlabeled arrows (see Figure 7). In this example, the left-to-right arrow in isolation suggests that the entity description on the left (confusion) influenced the entity description on the right (unclear instructions). The relationship description, however, suggests the opposite direction of influence: that unclear instructions led to confusion. In the absence of such a description, even the direction of the relationship - to say nothing of the other characteristics of that relationship — cannot be interpreted. As such, these unlabeled relationships were excluded from the remainder of this content analysis. The high prevalence of unlabeled relationships may have been due to general confusion about the game (see the above results for RQ1), confusion about the cognitive mapping instructions, or a lack of motivation to complete the task. Unlabeled relationships are addressed further in the limitations section below.

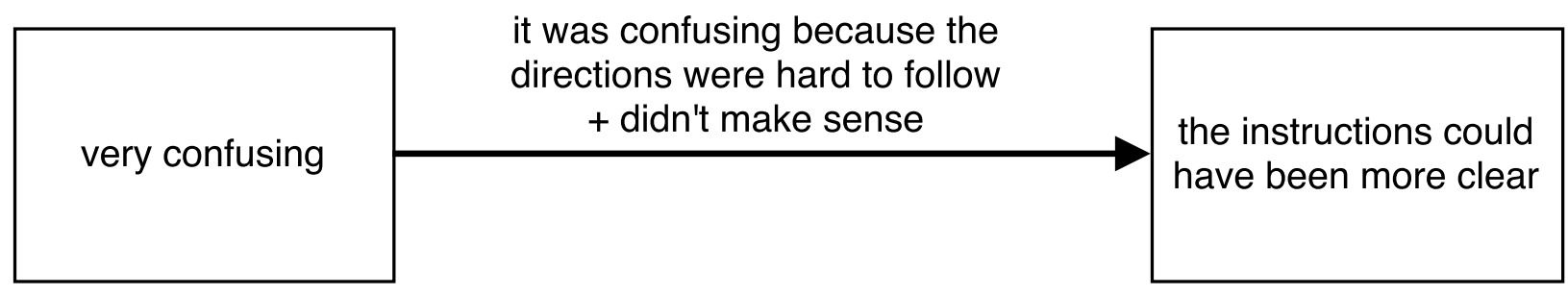

Figure 7. Example simple relationship transcribed by the researcher.

Indirect relationships. Of the complex relationships that were described, the most common type was indirect. Indirect relationships involve some entity, A, influencing another entity, C, through a third entity, B. Therefore, the most fundamental indirect relationship involves three entities and two relationships. Of the participants in this sample, $23.3 \%(n=7)$ of participants described at least two indirect relationships in their cognitive maps. Of all labeled relationships, $13.5 \%(n=20)$ were coded as indirect. See Figure 8 for an example indirect relationship. This example was coded as an indirect relationship because the participant 
explicitly described confusion influencing their thoughts about playing correctly, and explicitly described these thoughts influencing their stress level. Of the more complex relationships in this content analysis, indirect relationships were likely the most common because they had the lowest specificity, requiring only that participants explicitly describe two relationships such that entity A influenced entity $\mathrm{C}$ through entity B. As such, indirect relationships can be composed of multiple simple relationships, which are addressed below.

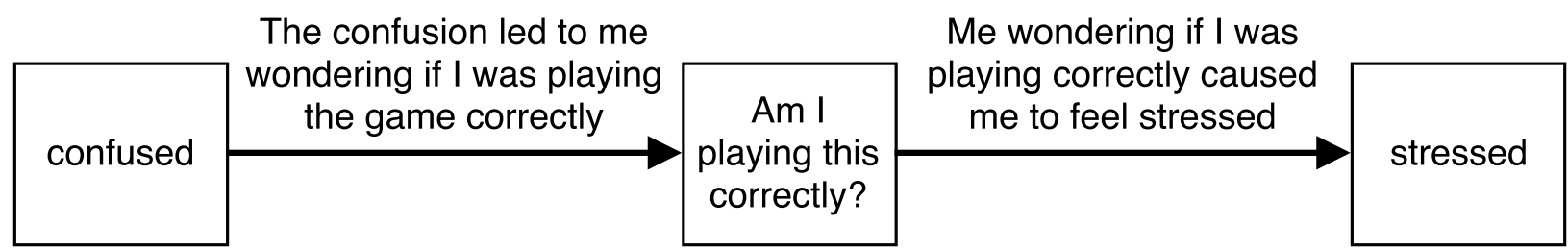

Figure 8. Example indirect relationship transcribed by the researcher.

Delayed relationships. In delayed relationships, the influence of one entity on another is not immediate, but delayed over time. This time lag itself poses a challenge to identifying delayed relationships, since outcomes are temporally separated from inputs, events, or triggers (Sweeney \& Sterman, 2007). In fact, only $6.7 \%(n=2)$ of participants described delayed relationships. Of all labeled relationships, $2.0 \%(n=3)$ were coded as delayed. See Figure 9 for an example delayed relationship. This example was coded as a delayed relationship because the relationship description in the center of the figure described a future outcome (i.e., "will provide..."). This delayed relationship was reinforced in the entity description on the left, which described a future influence ("future success") of "Action cards." Furthermore, these Action cards were explicitly connected to the "victory points" in the entity description on the right through the relationship description. As such, action cards in the entity description on the left were the input that led to the delayed output of victory points in the entity description on the 
right. Participants' inattention to delays in entity relationships were likely a result of common heuristics that conceptualize delayed influences as immediate (Sweeney \& Sterman, 2007).

\begin{tabular}{|c|c|c|}
\hline $\begin{array}{c}\text { Action cards are } \\
\text { important for } \\
\text { future success } \\
\text { in the game }\end{array}$ & $\begin{array}{c}\text { Action cards will provide you with } \\
\text { more copper, silver, and gold cards } \\
\text { which means more victory points. }\end{array}$ & $\begin{array}{c}\text { My strategy was } \\
\text { victory points. } \\
\text { Most victory } \\
\text { points wins the } \\
\text { game }\end{array}$ \\
\cline { 3 - 4 } & & \begin{tabular}{c} 
gome \\
\hline
\end{tabular}
\end{tabular}

Figure 9. Example delayed relationship transcribed by the researcher.

Stochastic relationships. Stochastic relationships are non-deterministic, i.e., they are influenced by randomness. Despite the centrality of randomness in Dominion through shuffling and drawing cards, merely $3.3 \%(n=1)$ of participants described stochastic relationships. Of all labeled relationships, $1.4 \%(n=2)$ were coded as stochastic. See Figure 10 for an example stochastic relationship. This example was coded as a stochastic relationship because randomness ("luck of the draw") was described in the description of the relationship between entity descriptions. Furthermore, randomness was mentioned in the entity description on the right. These two entity descriptions were connected by the relationship description, which mentioned drawing cards - a central activity in the "deck-building games" in the entity description on the left. The "luck of the draw" in the relationship description was the source of the " $80 \%$ randomness" in the entity description on the right. Because of common heuristics that see the world as deterministic (Resnick \& Wilensky, 1998), participants likely did not frequently consider the role of stochasticity. 


\begin{tabular}{|c|c|c|}
\hline $\begin{array}{c}\text { Having a history of } \\
\text { Catan/deck-building } \\
\text { games helped me } \\
\text { for sure }\end{array}$ & $\begin{array}{c}\text { I need to realize a lot is } \\
\text { just luck of the draw }\end{array}$ & $\begin{array}{c}\text { It's a game with like } \\
80 \% \text { randomness, but } \\
\text { I spent too much time } \\
\text { calculating the odds }\end{array}$ \\
\cline { 2 - 3 }
\end{tabular}

Figure 10. Example stochastic relationship transcribed by the researcher.

Nonlinear relationships. In nonlinear relationships, the proportion of the magnitude of an input to an output—or an event and an outcome—varies depending on the size of the input. In other words, nonlinear relationships are curvilinear, and include exponential, logarithmic, and S-curve relationships. Again, these relationships were very rare in this sample: only $3.3 \%(n=1)$ of participants described nonlinear relationships. Of all labeled relationships, $1.4 \%(n=2)$ were coded as nonlinear. See Figure 11 for an example nonlinear relationship. This example was coded as a nonlinear relationship because the relationship description included a curvilinear relationship between challenge and interest/frustration. They described how a certain amount of challenge led to interest in the game, but after a certain point, more challenge decreased interest and led instead to feelings of frustration.

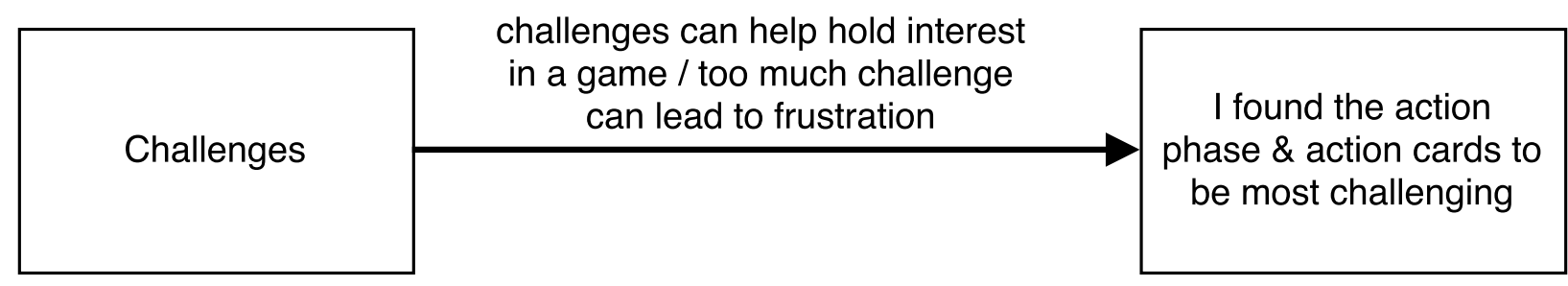

Figure 11. Example nonlinear relationship transcribed by the researcher.

Feedback loops. Feedback loops involve an entity influencing itself, either directly or indirectly (see Figure 4 in Challenges to Systems Thinking: System Complexity, p. 9). No participants described any feedback loops, echoing previous findings that individuals typically 
have great difficulty identifying feedback loops in complex systems (Sweeney \& Sterman, 2007).

Simple relationships. Overall, participants only very rarely described the above five types of complex relationships, necessitating coding of the simpler relationships indicated in the data. Of the 148 relationships with written descriptions, $81.8 \%(n=121)$ were not coded as representing any of the five types of complex relationships identified above. In other words, they represented simple relationships. Out of all 30 participants, $86.7 \%(n=26)$ described at least one simple relationship, and $66.7 \%(n=20)$ of participants exclusively described simple relationships. See Figure 12 for an example simple relationship. This example was coded as a simple relationship because although the relationship between copper cards and victory points was labeled, there was no indication of a stochastic relationship, a delayed relationship, a nonlinear relationship, an indirect relationship, or a feedback loop. The preponderance of simple relationships in participants' cognitive maps suggests that there was some barrier to participants' identification of more complex relationships. One possible explanation is that participants heuristically treated more complex relationships among entities as deterministic, immediate, linear, and direct. Participants may have used these heuristics to minimize their cognitive load while attempting to focus on learning the rules and mechanics of the game (see Sweller, 1988 on cognitive load in learning contexts).

copper/silver/gold card can be traded

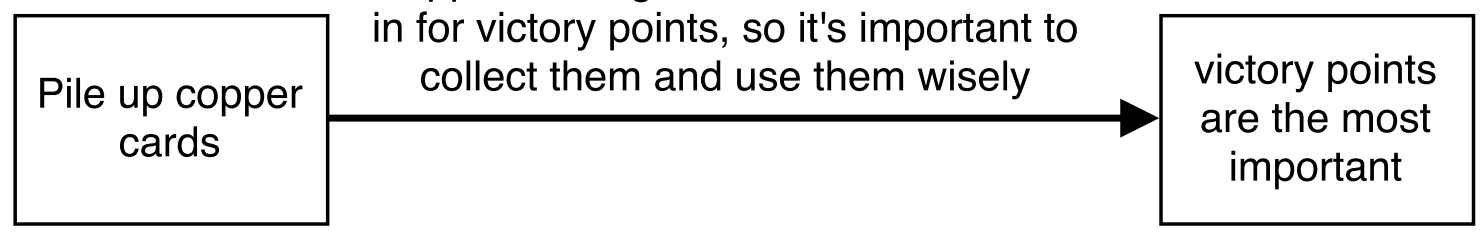

Figure 12. Example simple relationship transcribed by the researcher. 
RQ2: Dynamic complexity of game-derived mental models. To answer RQ2, then, participants primarily included simple relationships in their cognitive maps, interpreted here as externalized mental models of the Dominion gameplay experience. That is, they largely included relationships that were not typical of complex systems and did not frequently attend to stochastic relationships, delayed relationships, nonlinear relationships, indirect relationships, or feedback loops, as summarized in Table 3.

Table 3

Summary of relationship types in participants' cognitive maps

\begin{tabular}{lcc}
\hline \multicolumn{1}{c}{ Code } & Participants $(N=30)$ & Entity relationships $(\mathrm{N}=207$, labeled $\mathrm{n}=148)$ \\
\hline Indirect & $23.3 \%(7)$ & $13.5 \%(20)$ \\
Delayed & $6.7 \%(2)$ & $2.0 \%(3)$ \\
Stochastic & $3.3 \%(1)$ & $1.4 \%(2)$ \\
Nonlinear & $3.3 \%(1)$ & $1.4 \%(2)$ \\
Feedback loop & $0.0 \%(0)$ & $0.0 \%(0)$ \\
Simple & $86.7 \%(26)$ & $81.8 \%(121)$ \\
Unlabeled & $60.0 \%(18)$ & $28.5 \%(59)$ \\
\hline
\end{tabular}

Note. Percentages for unlabeled entity relationships were calculated from the total $N$; percentages

for other relationships were calculated from the $n$ of labeled relationships (148). Values in parentheses are $n$ s. Totals do not sum to $100 \%$ because only Unlabeled and Simple were exclusive codes.

\section{Discussion}

Summarily, RQ1 asked what entities individuals include in their mental models of analog game systems. Grounded theory coding of cognitive maps produced by participants identified five main categories of entities. The first of these categories were formal game entities — things that were either contained within the game's cardboard box or described therein. Formal game entities included material objects, ludic concepts, and narrative concepts. Second, participants described their own actions_- behaviors that participants performed during the game such as 
acquiring or using game components. Third, participants described sociality, which included entities related other players. Specifically, they mentioned other players generally, orientations to other players that were either competitive or cooperative, and surveillance of other players' actions. Fourth, participants described learning processes that they employed to understand how to play the game. The fifth category of entities was subjective experience, including confusion and uncertainty, as well as other reactions to and evaluations of the game.

RQ2 asked how the entities in individuals' mental models of analog game systems are interrelated. Players' descriptions of entity relationships in their cognitive maps were content analyzed for five types of relationships that are typical of complex systems: indirect relationships, delayed relationships, stochastic relationships, nonlinear relationships, and feedback loops. Other relationships were coded as simple relationships. Nearly all labeled relationships were simple relationships, with a smaller but substantial number of indirect relationships. Very few delayed, stochastic, or nonlinear relationships were identified in participants' cognitive maps. No feedback loops were identified.

\section{What Games Are Made Of}

This study provides empirical support for the subjective importance of elements that have been suggested in theoretical and critical-cultural work to be important parts of games and gameplay - in other words, the entities identified in players' cognitive maps extend what "counts" as a game and what games can be said to be made of. As elaborated below, the current findings are argued to suggest that games are not fully formed until actively engaged in play, and that these gameplay events include the interaction and intertwinement of material and semiotic, human and non-human elements. In many ways, these empirical, phenomenological findings align with recent games studies literature, but from a different epistemological and 
methodological perspective. Existing literature argues for definitions and characterizations of games from a theoretical, textual analysis, and critical analysis perspective. This study, in contrast, addressed phenomenological understandings of games and gameplay empirically through players' self-reported cognitive maps. Nevertheless, this study's phenomenological findings echo the importance of objects, players, actions, and interactions. The alignment of this study's RQ1 findings with recent games studies literature is summarized in Table 4. Games scholars have used terms like "mangle" (Steinkuehler, 2006), "assemblage" (Taylor, 2009), and “collusion" (Giddings, 2009) to describe games — both digital and analog — as interactions between heterogeneous actors (see Law, 2009). Common among this body of work has been an emphasis on material objects (Carter et al., 2014; Evans, 2013; Leino, 2012b; Ralph \& Monu, 2015; Xu et al., 2011), the agency exerted by these non-human objects on human actors (Giddings, 2009; Taylor, 2009), and the active interaction of human actors (Evans, 2013; Giddings, 2007, 2009; Ralph \& Monu, 2015; Taylor, 2009) and non-human actors during gameplay (Giddings, 2009; Ralph \& Monu, 2015; Taylor, 2009).

This study's findings depart from existing literature on the nature of games and gameplay in a number of crucial ways. First, as discussed below, certain combinations of conceptual and material objects suggest that these may be more closely connected than previously expected. Second, players' goals are not necessarily a direct reflection of the explicit goals defined in rulebooks. Third, individuals may attend less to the narrative elements of analog games than is usually assumed. Further, the present study builds on these insights into the phenomenology of analog gameplay as it may relate to using these games as instructional tools. Specifically, mental models formed during complex game play suggest their constitutive entities exist in nuanced webs of relations — "laminated together," surprisingly social, and privileging function over 
narrative. Taken together, these findings have implications for using games in instructional contexts generally, and to train systems thinking competencies specifically. These implications are discussed below in Practical Implications for Game-based Instruction.

\section{Table 4}

Summary of recent scholarship on game definitions and entities in relation to this study's findings

\begin{tabular}{|c|c|c|}
\hline Category & Sub-category & Literature \\
\hline \multirow{3}{*}{$\begin{array}{l}\text { Formal } \\
\text { game } \\
\text { entities }\end{array}$} & Material objects & $\begin{array}{l}\text { Material objects (Carter et al., 2014; Evans, 2013; Leino, 2012b; Ralph \& Monu, } \\
\text { 2015; Xu et al., 2011); Material actors and physical interaction during gameplay } \\
\text { (Giddings, 2009; Taylor, 2009) }\end{array}$ \\
\hline & Ludic concepts & $\begin{array}{l}\text { Game as designed rules (Evans, 2013; Giddings, 2009; Steinkuehler, 2006); Non- } \\
\text { human agents (Giddings, 2007, 2009); Conceptual actors (Taylor, 2009); Rules } \\
\text { and rule-defined outcomes and goals (Evans, 2013; Juul, 2011); Strategies to } \\
\text { achieve goals (Xu et al., 2011); Conceptual understandings of material game } \\
\text { objects (Leino, 2012b) }\end{array}$ \\
\hline & $\begin{array}{l}\text { Narrative } \\
\text { concepts }\end{array}$ & $\begin{array}{l}\text { Conceptual actors (Taylor, 2009); Fiction (Juul, 2011); Conceptual } \\
\text { understandings of material game objects (Leino, 2012b); Narratives (Ralph \& } \\
\text { Monu, 2015) }\end{array}$ \\
\hline $\begin{array}{l}\text { Player } \\
\text { actions }\end{array}$ & - & $\begin{array}{l}\text { Active interaction of human and non-human actors (Giddings, 2009; Ralph \& } \\
\text { Monu, 2015; Taylor, 2009); Player effort toward achieving goals (Juul, 2011) }\end{array}$ \\
\hline \multirow{3}{*}{ Sociality } & Other players & $\begin{array}{l}\text { Human actors (Evans, 2013; Giddings, 2007, 2009; Ralph \& Monu, 2015; } \\
\text { Taylor, 2009) }\end{array}$ \\
\hline & $\begin{array}{l}\text { Orientations to } \\
\text { other players }\end{array}$ & $\begin{array}{l}\text { Community norms of play (Steinkuehler, 2006); Negotiable consequences of } \\
\text { gameplay (Juul, 2011) }\end{array}$ \\
\hline & $\begin{array}{l}\text { Surveillance of } \\
\text { other players }\end{array}$ & Observing other players (Nicholson \& Begy, 2014; Xu et al., 2011) \\
\hline $\begin{array}{l}\text { Learning } \\
\text { processes }\end{array}$ & - & $\begin{array}{l}\text { Chores and enforcing rules (Juul, 2011; Leino, 2012b; Nicholson \& Begy, 2014; } \\
\text { Xu et al., 2011); Collaborative learning (Xu et al., 2011); Rulebooks (Evans, } \\
\text { 2013; Xu et al., 2011) }\end{array}$ \\
\hline \multirow{2}{*}{$\begin{array}{l}\text { Subjective } \\
\text { experience }\end{array}$} & $\begin{array}{l}\text { Confusion and } \\
\text { uncertainty }\end{array}$ & \multirow{2}{*}{$\begin{array}{l}\text { Subjective experience of play (Giddings, 2009; Ralph \& Monu, 2015); } \\
\text { Attachment to game outcomes (Juul, 2011) }\end{array}$} \\
\hline & $\begin{array}{l}\text { Other reactions } \\
\text { and evaluations }\end{array}$ & \\
\hline
\end{tabular}

Lamination of formal game elements. The frequent co-occurrence of material objects with ludic concepts in participants' cognitive maps suggests that formal game elements may exist in an even more intimate interrelationship than addressed in previous literature. While this 
literature has proposed that material objects, rules, and narratives are interrelated (e.g., Juul, 2011; Ralph \& Monu, 2015), this study suggests that they are at times inseparable. As such, these material objects and conceptual entities may more rightly be seen as "laminated." That is, participants described game entities as material and ludic — or rarely, ludic and narrativesimultaneously and inextricably. These material and conceptual layers, though they could be teased apart analytically, were fused—laminated —in participants' descriptions of salient game entities. Characterizing these material-semiotic entities (cf. Haraway, 1991) as laminated echoes theoretical treatments of games that have highlighted the "ontological hybridity" of game entities (Leino, 2012b) — that objects in games are inextricably and simultaneously both material and conceptual. There are two likely sources for this lamination: rules and action.

Rules beyond rulebooks. By defining the role of material objects, such as cards, rules contribute to the ludic conceptual meaning of material objects in analog games. It has been common to refer to rules in definitional discussions of games (e.g., Evans, 2013; Giddings, 2009; Steinkuehler, 2006). Rules define the possibilities and limitations of the material objects in the game, and this semiotic relationship between concepts and material objects laminates a conceptual layer onto these material objects. In this study, participants often referred to learning and understanding rules, and specifically referred to the "rules" or "instructions." For these participants, then, the game rules and the text describing these rules were an important part of gameplay. In analog games specifically, rulebooks are necessary and central to gameplay (Evans, 2013; Xu et al., 2011) because players are required to enforce these rules during gameplay and maintain the game through "chores" like reshuffling decks of cards (Juul, 2011; Leino, 2012b; Nicholson \& Begy, 2014; Xu et al., 2011). In analog games specifically, the full written rules are distinct from in-game text. While rulebooks are more detailed, as players come accustomed to 
them, they reference them less and less (Evans, 2013). In-game text, like that written on the cards in Dominion, serves as rules shorthand for those specific cards. This in-game text, though often too brief to be completely understood on its own, is fully explained within the rulebook, but retains its importance throughout gameplay. Every time a player plays a card, its in-game text is relevant, because it describes the consequences of having played that card. Both in-game text and rules laminate ludic concepts onto material objects, which is reinforced by the necessity for analog game players to enforce these rules themselves.

Actions that bind. Second, the action or behavior that players perform during gameplay, which are permitted and restricted by the game's rules, laminates ludic concepts onto material objects. Game scholars have often suggested that games are not complete until played (Giddings, 2009; Ralph \& Monu, 2015; Taylor, 2009). That is, games are not fully games in the absence of someone to play them. The prevalence of player actions in participants' cognitive maps in the present study further suggests that action is an important part of the subjective experience of games. As such, players' actions are key to phenomenological understandings of what counts as part of the game proper. Throughout the game, participants performed actions with materialsemiotic objects that had consequences for them and for other players. Although Dominion's rules define the possibilities of and restrictions on using cards, these rules do not tell participants how to play. Nor do these rules suggest good or bad strategies to players. Instead, participants discovered the value and uses of different cards through the actions they performed with them and the observed consequences of those actions. In this way, players attached ludic and narrative meanings to material objects (cards) that were not contained within the rules of the game as written. That players' understandings of entities arise in part through the actions they perform with them is central to the unique potential game-based learning. Otherwise, students could learn 
as much from simply reading a text like a rulebook. Instead, actively engaging with a game's objects during gameplay likely enhances learners' understanding. This link between action and understanding echoes the insight of situated cognition scholars that knowledge is a product of action, and therefore cannot be divorced from it (J. S. Brown, Collins, \& Duguid, 1989). Moreover, the importance of actions in participants' cognitive maps re-affirms the notion that games are incomplete in the absence of active play (Bowman \& Banks, in press; Giddings, 2009; Leino, 2012b; Ralph \& Monu, 2015; Steinkuehler, 2006) and that empirical study of gameplayas opposed to games as texts or artifacts - is crucial to understanding them (Leino, 2012b). As individuals actively engage with material objects during gameplay, actions and their consequences contribute to these material objects' meanings within the context of gameplay. In other words, action laminates ludic concepts onto material objects. As such, players' actionsnot only game artifacts and texts - are central to the creation and communication of meaning during the course of games-based learning.

Alternative goals. This study also departs from typical understandings of games as goaldirected activities, by revealing that their goals often departed from those described in the game's rulebook. Game scholars have discussed the importance of rule-defined goals (Evans, 2013; Juul, 2011), an affective attachment to different game outcomes (Juul, 2011), and strategies used to achieve these outcomes and goals (Xu et al., 2011). In the current study, many participants did describe game-defined goals related to winning, strategies for achieving them, and affective reactions to the game. Notably, however, several participants explicitly rejected the competitive goals written in the rulebook in favor of an alternative: cooperation and helping each other to learn. Several participants explicitly wrote in their cognitive maps that they were not attempting to compete, and therefore were not attempting to collect the most victory points in 
order to win. There is precedent for game communities to reject the designers' intended goals of the game (e.g., Steinkuehler, 2006). Indeed, among analog gaming communities, more players enjoy social interaction with other players than competition, leading most players to pursue goals other than victory in certain conditions (Woods, 2012).

There are a number of possible reasons for participants in this study to have rejected a competitive orientation toward the game and other players in favor of a cooperative orientation. Before even entering the study, participants may have already had alternative goals (see Woods, 2012) and non-competitive gameplay motivations (Sherry, Lucas, Greenberg, \& Lachlan, 2006; Yee, 2006) that they enacted during gameplay. Alternatively, participants' cooperative orientations may have been a consequence of the primacy of interpersonal and communicative orientations toward others, even in the context of competitive games (W. J. White, 2012). This notion of the primacy of the communicative - the idea that interpersonal communication is the primary goal of communication (Habermas, 1984) —-would predict a more prevalent noncompetitive orientation that focused instead on communicating with each other, so the persistence of a competitive orientation among many players in this study suggests that this explanation is unlikely. Instead, participants may have taken a cooperative orientation as part of learning how to play a new, unfamiliar game. Given participants' unfamiliarity with the game and with the other participants' potential skill at that game, participants may have felt uncertainty about their ability to compete successfully. As such, instead of competing, they may have approached the game cooperatively to gather information about the game and other players to reduce their uncertainty about their relative game competence before even attempting to compete (Berger, 1997). Additionally, when confronted with an unfamiliar and complex task, like an analog game system, cognitive load involved in merely learning the task is likely to be high 
(Sweller, 1988). As such, participants may not have had the cognitive resources available to learn how to play Dominion and attempt to compete with the other players. For some participants, the confusion they experienced when trying to learn this new game may have led them to adopt goals related to avoiding success, which is one reaction individuals have when they feel their competence is threatened (Brodish \& Devine, 2009). In this study, some participants may have felt like they were unlikely to win, and therefore tried not to win by rejecting competition entirely. Regardless of the specific reason that participants took cooperative orientations toward the game, this study affirms that players' goals cannot be inferred from a formal ruleset, but instead need to be discovered empirically. As such, when studying games, players' goals cannot be taken for granted.

Function over fantasy. This study further departs from other games scholarship because of the infrequency of narrative concepts in participants' cognitive maps. Games scholars have suggested that fiction (Juul, 2011) —including the fictional representations of material game objects (Leino, 2012b) - and the narratives that emerge through gameplay (Ralph \& Monu, 2015) are theoretically important to games. In contrast, this study's participants only rarely described these fictional and narrative concepts. It is possible that most of these individuals were not motivated by the fantasy of gameplay (Sherry et al., 2006; Yee, 2006). Alternatively, participants may not have had excess cognitive resources with which to interpret gameplay as part of a fictional narrative while devoting cognitive resources to learning how to play (Sweller, 1988). Along similar lines, this narrative level of gameplay likely relies on a certain level of facility with the ludic elements of the game. In other words, before players are able to understand gameplay narratively, they need to be able to play the game without attending to the game's rules and mechanics. This facility with the game's ludic dimensions should allow players to focus on 
and engage with the narrative unfolding via gameplay. Needing to think about the game's rules, or even reference a rulebook, would likely disrupt this narrative engagement (see Busselle \& Bilandzic, 2009). Once players are able to perform game actions without giving much thought to the game's rules, they should be able to attend to the gameplay's narrative instead. Given the rarity of narrative concepts in participants' cognitive maps, it remains to be seen whether narrative concepts are extensively laminated to ludic concepts or material objects. Because it has been found that narrative engagement can increase knowledge gained from consuming narrative media (Murphy, Frank, Moran, \& Patnoe-Woodley, 2011), the influence of narrative and narrative engagement in analog gameplay on learning outcomes should be explored.

Overall, the results of RQ1 extend theoretical and critical-cultural work on games by suggesting that similar actors, entities, objects, and concerns are important from the subjective, phenomenological perspective of game players. These entities include rules, players, and laminated material-semiotic objects; actions and behaviors through which material, conceptual, and human actors interact; group norms and orientations toward the game and other players; and subjective experiences and reactions to gameplay. In particular, the laminated quality of material objects and ludic concepts supports the uncommon assertion that heterogeneous actors can not only be interrelated (cf. Latour, 2008) but can also be inextricably intertwined (Leino, 2012b). This study challenges prevailing notions of games as activities with rule-defined goals, instead finding that players' goals may in fact contradict the goals written in a rulebook. Additionally, this study complicates the position of narrative in gameplay by suggesting that narrative features of games are not always accessible, salient, or relevant to players. The inclusion and exclusion of different categories of entities in participants' cognitive maps have implications for using 
games — and analog games specifically — in instructional contexts, which are developed below in Practical Implications for Game-Based Instruction, pp. 74-79.

Gameplay as Communicative Action. As discussed above, players' descriptions of actions frequently co-occurred with descriptions of formal game entities, material objects and ludic concepts in particular. This co-occurrence suggests that action plays a role in the creation of meaning through gameplay by laminating ludic (and possibly narrative) concepts to material objects during gameplay. Furthermore, the material objects that players manipulate during gameplay, as well as the particular behaviors that players perform, hold particular meanings to players. As such, analog gameplay can be thought of as an inherently communicative process in which meaning is communicated between players through player actions with material objects. In other words, materially manipulating game objects during gameplay is nonverbal communication. During gameplay, communication via action can take place simultaneously with verbal communication (see $\mathrm{Xu}$ et al., 2011). Communication during gameplay, then, is essentially multimodal, combining verbal communication and nonverbal communication through action.

\section{Mental Model Complexity}

The infrequency of indirect, delayed, stochastic, nonlinear, and feedback relationships in participants' cognitive maps, as externalizations of their mental models, suggests that their mental models of Dominion had relatively low dynamic complexity. Not only did participants overwhelmingly describe simple relationships, they also left a significant number of relationships unlabeled. The prevalence of unlabeled relationships in participants' cognitive maps begs an explanation. One possibility is that participants perceived, but were unable to externalize, certain relationships between entity descriptions. Therefore, they may have drawn an arrow to connect 
two entity descriptions that they thought were related, but were then incapable of describing that relationship in the next step of the cognitive mapping exercise. Alternatively, the prevalence of confusion and uncertainty in participants' cognitive maps suggests that participants were in fact confused about the game. As such, they may have foregone describing relationships that they were confused or uncertain about. This finding suggests that participants struggled to understand the relationships among entities in Dominion's game system. As such, in order to most effectively use games as instructional tools, learners need additional support to understand these relationships beyond simply playing the game. Otherwise, their understandings and mental models of the game will be underdeveloped. Specific suggestions for supporting learners' understanding of game systems are presented below in Practical Implications for Game-Based Instruction, pp. 74-79. Additional potential methodologically-related reasons for unlabeled cognitive map relationships are discussed in the limitations.

Overall, the preponderance of simple relationships in participants' cognitive maps suggests that their mental models of Dominion — as a complex game system - were relatively simple. After playing Dominion one time with no additional instruction, participants seemed not to conceive of the game as a complex system. Two possible explanations for this finding and their respective implications are presented below. First, mental model complexity may have been obscured in participants' cognitive maps because they aggregated multiple entities and complex relationships into individual entity descriptions. Second, participants may truly have not perceived these complex relationships, instead applying simple heuristics.

First, participants may have had more complex understandings than were represented by the relationships they described in their cognitive maps. Participants' entity descriptions often included multiple categories of entities. It cannot therefore be ruled out that participants' mental 
model complexity was expressed within complex entity descriptions and not in the diagrammatic relationships in their cognitive maps. For example, a number of participants described specific sequences of actions within individual entity descriptions. These descriptions may have involved a complex relationship (e.g., delayed or indirect) among included entities if each entity description had been more granular. Participants may have combined multiple ideas within individual entity descriptions because they, like most humans, were used to understanding and representing the world and themselves in terms of narratives - sequences of meaningful, connected events (Riessman, 2008). From this perspective, aggregate entity descriptions can be thought of as micro-narratives describing the game. Similarly, lamination of a material object and a ludic or narrative concept within a single entity description may indicate mental model complexity. These laminated entities may indicate complexity because players have moved beyond understanding gameplay as manipulating strictly material objects, strictly ludic concepts, or strictly narrative concepts. Instead, lamination suggests that players may understand gameplay at a material, ludic, and narrative level simultaneously. Some have suggested that more complex mental models should involve more disaggregated cognitive maps (e.g., Groesser \& Schaffernicht, 2012). For example, a single entity description like "The more supply the more victory" could have been disaggregated into two entity descriptions_- "supply" and "victory"linked by an arrow from "supply" to "victory." Nevertheless, the opposite is also possible. More aggregated entities (i.e., those including a number of interrelated, constitutive objects) may in fact be indicative of more complex mental models in which a series of relationships have been collapsed (Schaffernicht \& Groesser, 2013). Instead of representing and describing complex relationships diagrammatically in their cognitive maps, participants may have been collapsing these complex relationships into aggregated micro-narrative entity descriptions. As such, it is 
unclear whether more or less aggregated entity descriptions in general—and laminated entities or sequences of events specifically_indicate more or less complex mental models.

Alternatively, simple relationships may have been participants' prepotent mode of interpreting or understanding relationships between entities. In other words, instead of considering more complex relationships, participants may simply be prone to thinking of the world in terms of simple relationships. This interpretation aligns with research on systems thinking that has found that across age levels, individuals typically have difficulty identifying stochastic relationships (Jacobson \& Wilensky, 2006; Resnick \& Wilensky, 1998), delayed relationships (Sweeney \& Sterman, 2007), nonlinear relationships (Jacobson \& Wilensky, 2006; Penner, 2000), and feedback loops (Jacobson \& Wilensky, 2006; Sweeney \& Sterman, 2007) in systems. The less individuals are accustomed to thinking about a certain kind of relationship, the more cognitive load these individuals experience when trying to understand them (Sweller et al., 1998). As such, conceptualizing complex relationships consumes more cognitive resources than simple relationships, especially for those not trained in thinking about complex systems. Instead, individuals' prepotent conceptualizations of relationships may be based on simplifying heuristics (see, e.g., Tversky \& Kahneman, 1974) that minimize cognitive load. From a "cognitive miser" standpoint, in which individuals tend to conserve cognitive resources whenever possible (Fiske \& Taylor, 2013), most individuals will tend to use simple heuristics instead of complex relationships to minimize their cognitive load. In learning contexts, therefore, it is necessary for instructors to facilitate learners' attention to these complex relationships. Specific suggestions for doing so are presented below. 


\section{Practical Implications for Game-based Instruction}

The present study's findings have several implications for analog games' potentials as tools for systems-thinking instruction. Although these implications apply specifically to games that are complex systems and contain complex relationships, they are relevant to game-based learning more broadly. Building on the above discussion on the phenomenological experience of gameplay and mental model complexity, practical suggestions for using analog games as complex-systems-in-miniature in an instructional context - and for system-thinking instruction specifically_are presented below. These suggestions for instruction are to: a) embed instructional objectives in games in multiple ways, b) take an active facilitative role in gamebased learning activities, c) supplement other educational activities with game-based instruction, and d) use games that are as simple as possible for the instructional objective.

Embed instructional objectives. First, to ensure that mental models of the game include the intended instructional objective, this objective should be embedded in as many categories of entities as possible, including material objects, ludic concepts, narrative concepts, player actions, and game goals. Not all participants included all of these categories of entities in their cognitive maps, suggesting that there was individual variation in which of these categories of entities they found salient during gameplay. As such, if a learning objective were embedded in only one or some of these entities, it is possible that players would fail to engage with the learning objective by attending only to the other kinds of entities. If, on the other hand, all of these entities were aligned toward the learning objective, mental models that include any of them should be relevant to learning objectives. This recommendation echoes earlier findings that mental models developed through gameplay were influenced by both the physical structure of the game and the activities players performed during gameplay (Laski \& Siegler, 2014; Siegler \& Ramani, 2009). 
The present findings suggest that not only the game's physical structure and player actions (see Laski \& Siegler, 2014; Siegler \& Ramani, 2009), but also player goals, social interactions, and gameplay narratives, may influence mental models. Such an approach should engage formative evaluation during the game development process to ensure that the intended learning audience incorporates the intended educational objective into their mental models of the game (Sherry, 2013a). Potential pitfalls of this approach include the possibility that the final game would lack characteristics that would motivate the desired audience to play it (Sherry, 2013b).

Facilitate mental model development. The second recommendation for instructors is to take an active role in facilitating students' development of their mental models of the game system. In this study, participants' cognitive maps included varied entities, and they did not include many complex relationships - that is, they featured detail complexity but not dynamic complexity. This finding suggests that additional instructional support may be needed to teach systems thinking competencies that are more advanced than merely identifying entities in a system, such as understanding complex relationships between these entities (see Anderson \& Krathwohl, 2001; Hopper \& Stave, 2008). As such, instructors should orient learners toward systems' entities and relationships that are important for instructional objectives. By doing so, learners' mental models should be more likely to include those instructionally relevant entities and relationships. Several methods of facilitation have been proposed in the literature. Structural debriefing, for example, is essentially a guided cognitive mapping task through which learners identify the relevant entities, describe their relationships and behavior, build a model of the system, and test the model against their understanding of the system and its behavior (Pavlov, Saeed, \& Robinson, 2015). Through structural debriefing, learners reflect on and modify their mental model of the game system, which is thought to facilitate learning by making clearer the 
content and structure of the game or simulation itself (Pavlov et al., 2015). In fact, the discipline of System Dynamics has coalesced around the notion that diagramming complex systems—such as games — can facilitate understanding them (Lane, 2008). Besides diagramming techniques like structural debriefing, learners can also be presented with schematic diagrams of the important entities and relationships in the game system. When this kind of supporting schematic information is presented to students with a game simultaneously, however, it risks both straining cognitive capacities (Kester, Lehnen, Van Gerven, \& Kirschner, 2006) and diminishing learner motivation to play by making the game less fun (Charsky \& Ressler, 2011). As such, instructormade diagrams of the game system should be presented to learners only after a gameplay session, not during.

Another way instructors can promote learners' mental model development is by making learning how to play the game as easy as possible, specifically by communicating game rules in multiple modalities. In this study, several participants wrote in their cognitive maps that they were confused by the written game instructions and that they had trouble learning from it. In the present study, players' only instruction was a written rulebook. During study sessions, several participants attempted to seek verbal instruction or rules clarification from the researcher, which was denied to ensure all participants learned from the same written rules. In an instructional setting, however, verbal instruction should supplement written instructions because learning from written instructions does not suit all learning styles (Kolb, 2014). As such, instructors should target multiple learning styles while teaching a game by providing learners written rulebooks, giving a verbal explanation of the game, demonstrating how the game works, and giving learners risk-free learning rounds before playing the game in full. By facilitating students' learning of the game in this way, instructors will reduce students' cognitive load associated with 
learning the game (see Sweller et al., 1998), enabling them to better understand the game and its connection to class topics.

Connect gameplay to other instruction. As discussed above, few participants in this study described complex relationships in their cognitive maps, supporting the view that individuals' prepotent understandings of relationships between entities in systems tend to rely on simple heuristics. As such, playing an analog game in and of itself is not enough to develop an understanding of a complex system. In the absence of further instruction, learners will likely not identify the complex relationships in a complex system that are necessary for systems thinking. Instead, additional instruction is necessary. In order to successfully train systems thinking, it is necessary for instructors to help students connect their understandings of an instructional game to systems thinking concepts developed in other contexts. In other words, games should be used to supplement—not supplant—other instructional methods. Furthermore, connections between game-based learning and other learning contexts should be attended to directly, so as to promote learning transfer between them. This suggestion is bolstered by findings that students learn more when they encounter the same topics across multiple learning activities (Fisch, Lesh, Motoki, Crespo, \& Melfi, 2014), possibly because learners transfer mental models developed in one learning context to another, providing a foundation for further mental model development (Fisch, 2013). As such, systems-thinking instruction is best delivered through multiple activities and modalities, including games. Nevertheless, the ideal method of facilitating this sort of cumulative cross-platform/activity learning transfer is currently unknown.

Make systems thinking games as simple as possible. Fourth, games for learning broadly_ and systems-thinking instruction specifically_ should be as simple and focused on as discrete instructional objectives as possible. This recommendation echoes recent suggestions that 
students may learn more from playing multiple simple business simulations than one large, complex business simulation (Teach \& Murff, 2014). Along these lines, gradually introducing learners to parts of a system before interacting with the whole system has been found to improve their ability to identify relationships between the entities in that system (Mulder, Lazonder, \& Jong, 2015). In this study, participants described very few complex relationships in their cognitive maps. As such, introducing these individuals to a learning game involving all five of the types of complex relationships studied here may strain cognitive capacities. Instead, learners may be better served by playing several simpler games that involve only one type of complex relationship, allowing them to incrementally build their systems thinking capabilities.

\section{Limitations and Future Directions}

As with most exploratory, qualitative research, this study's grounded and content analyses was subject to the limitations of a small sample size and the interpretive lens of a single researcher. While this study's sample size was small, the objectives of the study were not representative or generalizable findings. Rather, the goal was to identify the breadth of potential entities individuals might include in their mental models of an analog game. Although data were collected at the individual level, via cognitive mapping, it was analyzed at the level of individual entities and relationships in these cognitive maps. Maximal breadth of cognitive map entities was reached, as demonstrated by satisfying the criteria for saturation (Bowen, 2008b). Additionally, the subjective influence of the researcher was minimized during grounded coding by following a process for coding that involved constant checking and re-checking for invalidating data both within and across categories. Furthermore, the concepts that influenced the researcher's perspective were made explicit prior to data collection and analysis, such that they could be set aside to allow other themes to emerge - a technique known as bracketing (Ahern, 1999). Given 
time constraints associated with completion of this thesis, the researcher's supervisor independently reviewed the content analysis for face validity in lieu of conducting coder training and establishing intercoder reliability. Additional analysis of this data is planned in which formal content analysis (including reliability evaluations) will be conducted.

Some limitations of this study have been partially addressed above. Some participants expressed confusion, frustration, stress, and a lack of enjoyment in their cognitive maps. These negative affective states may have influenced the entities and relationships that they apprehended during gameplay, as well as those that they included in their cognitive maps. This is a realistic circumstance for instructors attempting to use games as instructional tools, and recommendations for facilitating learning have been suggested above. One possible source of participants' frustration with the game may have been that Dominion is a competitive game, even though some participants approached it from a cooperative standpoint both in their cognitive maps and as observed during study sessions. Competitive or cooperative games may function better as instructional tools for different people in different contexts.

Individual differences and group composition may have influenced study outcomes. Although this study employed both mixed- and same-sex groups, it had too small a sample size to identify systematic variation by sex and group composition. Nevertheless, previous research has found that the performance of men and women on different kinds of tasks, in groups of different sex mixes, and in competitive or noncompetitive environments is quite varied (Gneezy, Niederle, \& Rustichini, 2003; Günther, Ekinci, Schwieren, \& Strobel, 2010). Furthermore, men more than women self-report that they enjoy competitive games and are motivated to play competitive video games (Lucas \& Sherry, 2004). Future research should examine a) the effect of sex-based stereotype threat, competition, and cooperation on learning outcomes from playing 
educational games and b) sex differences in the effect of competitive and cooperative games on affective dimensions of learning like motivation. Drawing from the above discussion, future research should also address c) the relative effectiveness of different methods for facilitating learning transfer between contexts and platforms and d) the optimal ordering of different types of learning media and activities, which in other contexts has been shown to influence narrative engagement (Sangalang, Quintero Johnson, \& Ciancio, 2013).

As discussed above, participants' unlabeled relationships in their cognitive maps were not analyzed. Because of the ambiguity of arrows drawn between entity descriptions, interpreting these relationships was not possible. Some reasons for the prevalence of unlabeled relationships in participants' cognitive maps have been proposed above. Specifically, participants may not have known how to describe relationships that they perceived, or they may have been confused about the nature of these relationships. There are potential methodological reasons that participants may have included so many unlabeled relationships in their cognitive maps: they may have drawn extra arrows as a demand effect of the cognitive mapping exercise, may have been tired or unmotivated, or may not have realized that they were supposed to describe every relationship. Participants may have drawn unlabeled arrows as due to demand effects of the cognitive mapping exercise. That is, in response to instructions to draw arrows to represent relationships, they may have felt compelled to draw arrows in the absence of any conception of such relationships. Additionally, participants were asked to describe these relationships at the end of the study, at which point they may have been tired or unmotivated to complete the task. Finally, participants may have included unlabeled relationships in their cognitive maps because they were confused about the cognitive mapping instructions or about the game itself. It is possible that participants did not realize they were supposed to write a description for every 
arrow in their cognitive map. Given the preponderance of simple relationships in the rest of participants' cognitive maps, it is likely that the majority of unlabeled relationships, had they been described, would also have been simple relationships. In future studies, attempts should be made to minimize unlabeled relationships that are caused by research methods by pretesting cognitive mapping instructions to ensure they are as clear as possible. Future studies should also seek to understand the causes of unlabeled relationships that are not due to methodology. For example, game complexity could be manipulated to identify whether greater game complexity leads to a greater proportion of unlabeled relationships in participants' cognitive maps.

This study attempted to study mental models of game systems indirectly. Because mental models are cognitive representations, they are not directly accessible to investigation. As such, some indirect approach is necessary. In the present study, participants were guided through a cognitive mapping task designed to externalize their mental models. Operationally, participants wrote and drew cognitive maps that were diagrams of the entities and relationships between entities that they perceived in Dominion's game system. In many ways, this method was successful. Participants described entities and relationships, as intended. Nevertheless, some of the cognitive map data was unexpected. Specifically, entity descriptions were richer and more aggregated than anticipated, while entity relationship descriptions were sparser. Instead of describing discrete things within their entity descriptions, many participants described aggregated narratives of what could have been several distinct entities. These narrative entity descriptions were possibly a product of narrative understandings of the world (Riessman, 2008).

More generally, eliciting responses from study participants through novel kinds of tasks — such as cognitive mapping — always raises the question of whether differences in data are due to the variable under study (e.g., systems thinking competency) or participants' skill at 
performing the elicitation task (e.g., diagramming capability). The cognitive mapping procedure in this study was designed specifically to address the research questions by a) eliciting entities in as open-ended a way as possible so as not to lead participants into including or excluding anything in particular and b) eliciting entity relationships diagrammatically to allow for complex interrelationships and feedback loops. Other methods of studying mental models are possible. Some researchers, for example, have attempted to make inferences about mental models based on participants' performances in tasks thought to be related to mental models (e.g., Goldstone \& Sakamoto, 2003; Laski \& Dulaney, 2015). These inferential methods avoid the difficulties of elicitation tasks entirely, but do not provide insight into the content or nature of mental models. An alternative method is to elicit individuals' understandings of games in the way they are already prone to present them: narratively (see Riessman, 2008). Several researchers have elicited narrative descriptions or explanations from gameplayers and then applied formal rules to tease apart the entities and entity relationships in these narrative descriptions via object-relation mapping (ORM; Banks, 2014; see also Doyle, Radzicki, \& Trees, 1996; Doyle et al., 2008; Wrightson, 1976). Whereas cognitive mapping involves participants constructing their own diagrams of a system, in ORM, researchers transform participants' linear, narrative accounts of a system into a diagram for analysis. Because ORM involves eliciting narratives from participants, participants' relationships between entities are necessarily sequential. As discussed above, feedback loops — which are not strictly sequential—are crucial features of complex systems. As such, ORM is not as aligned with the conception of mental models outlined above as cognitive mapping. Future research should evaluate the validity of these three methods for measuring mental models - cognitive mapping, ORM, and inferential techniques. Comparing the outputs of these three mental model measurement methods to other measurements that should be related to 
systems thinking, such as the accuracy of predictions about a system's behavior, is crucial for developing a better understanding of the relative strengths and weaknesses of these methods.

Finally, participants included few complex relationships in their cognitive maps. As such, few conclusions can be drawn about these kinds of relationships from this study. However, it can be said that in the absence of any systems-thinking instruction or any instructor assistance, several participants did identify a small number of indirect, delayed, stochastic, and nonlinear relationships. With appropriate instruction, learners should be able to understand and identify more of these relationships. Given how much participants included within their entity descriptions, future research should investigate if more or less aggregated entity descriptions indicate more or less mental model complexity. Additionally, future research should identify the antecedents of entity aggregation. Specific attention should be paid to lamination of entitieswhen and why does it happen, and what are the implications of when it does not?

\section{Conclusion}

The present study began with the problem of understanding whether and how games might be able to be used as instructional tools for teaching about systems and systems thinking. Despite some findings that suggest that games in general—and analog games specifically—may be effective instructional tools, there were gaps in the literature. Specifically, it was unknown what elements of games individuals found salient in their phenomenological experience of gameplay. Furthermore, it was unknown what, if any, kinds of relationships individuals would be

able to identify in a game system without training. Overall, the present study suggests that analog games may have untapped potential as instructional tools for training systems thinking: even in the absence of instructor facilitation or systems thinking training, several participants were able to identify complex relationships in an analog game system. Moreover, the richness of 
participants' descriptions of system entities suggests that they may have perceived even more relationships between entities than they diagrammed and described.

Nevertheless, using analog games as instructional tools will not be without its challenges. Many participants found the analog game used in this study, Dominion, confusing, challenging, or frustrating. Given these experiences, and given the difficulty of systems thinking generally, appropriate instructor facilitation is crucial. Furthermore, participants did not attend to the narrative aspects of this analog game, suggesting the need for additional investigation into the role of narrative in analog games. 


\section{References}

Afifi, W. A., \& Weiner, J. L. (2004). Toward a theory of motivated information management. Communication Theory, 14, 167-190. doi:10.1111/j.1468-2885.2004.tb00310.x

Ahern, K. J. (1999). Ten tips for reflexive bracketing. Qualitative Health Research, 9, 407-411. doi:10.1177/104973239900900309

Anderson, L. W., \& Krathwohl, D. R. (2001). A taxonomy for learning, teaching, and assessing: A revision of Bloom's taxonomy of educational objectives: Abridged edition. New York: Addison Wesley Longman.

Banks, J. (2014). Object-relation mapping: A method for analysing phenomenal assemblages of play. Journal of Gaming \& Virtual Worlds, 6, 235-254. doi:10.1386/jgvw.6.3.235_1

Berger, C. R. (1997). Message production under uncertainty. In G. Philipsen \& T. L. Albrecht (Eds.), Developing communication theories. New York: SUNY Press.

Bergman, M., \& Paavola, S. (Eds.). (n.d.). Sign. The commens dictionary: Peirce's terms in his own words. Retrieved from http://www.commens.org/dictionary/term/sign

Berland, M. (2011). Understanding strategic boardgames as computational-thinking training machines. In G. Costikyan \& D. Davidson (Eds.), Tabletop: Analog game design (pp. 167-173). Pittsburgh, PA: ETC Press.

Berland, M., \& Lee, V. R. (2011). Collaborative strategic board games as a site for distributed computational thinking. International Journal of Game-Based Learning, 1, 65-81. doi:10.4018/ijgbl.2011040105

Biesta, G. (2010). Pragmatism and the philosophical foundations of mixed methods research. In A. Tashakkori \& C. Teddlie (Eds.), SAGE handbook of mixed methods in social \& behavioral research (pp. 95-118). Thousand Oaks, CA: SAGE. 
BoardGameGeek. (n.d.). Retrieved August 12, 2015, from https://boardgamegeek.com/

Bowen, G. A. (2008a). Grounded theory and sensitizing concepts. International Journal of Qualitative Methods, 5, 12-23. doi:10.1177/160940690600500304

Bowen, G. A. (2008b). Naturalistic inquiry and the saturation concept: A research note. Qualitative Research, 8, 137-152. doi:10.1177/1468794107085301

Bowman, N. D., \& Banks, J. (in press). Playing with a zombie author? Machinima through the lens of Barthes. In K. Kenney (Ed.), Philosophy for multisensory communication. New York: Peter Lang.

Boyle, E. A., Hainey, T., Connolly, T. M., Gray, G., Earp, J., Ott, M., ... Pereira, J. (2016). An update to the systematic literature review of empirical evidence of the impacts and outcomes of computer games and serious games. Computers \& Education, 94, 178-192. doi:10.1016/j.compedu.2015.11.003

Brandstädter, K., Harms, U., \& Großschedl, J. (2012). Assessing system thinking through different concept-mapping practices. International Journal of Science Education, 34, 2147-2170. doi:10.1080/09500693.2012.716549

Bransford, J. D., \& Schwartz, D. L. (1999). Rethinking transfer: A simple proposal with multiple implications. Review of Research in Education, 24, 61-100. doi:10.2307/1167267

Brodish, A. B., \& Devine, P. G. (2009). The role of performance-avoidance goals and worry in mediating the relationship between stereotype threat and performance. Journal of Experimental Social Psychology, 45, 180-185. doi:10.1016/j.jesp.2008.08.005

Brown, A. L., \& Campione, J. C. (1996). Communities of learning and thinking, or a context by any other name. In P. Woods (Ed.), Contemporary issues in teaching and learning (pp. 120-126). London, UK: Routledge. 
Brown, J. S., Collins, A., \& Duguid, P. (1989). Situated cognition and the culture of learning. Educational Researcher, 18, 32-42. doi:10.3102/0013189X018001032

Bryant, J., \& Fondren, W. (2009). Psychological and communicological theories of learning and emotion underlying serious games. In U. Ritterfeld, M. Cody, \& P. Vorderer (Eds.), Serious games: Mechanisms and effects (pp. 103-116). Routledge.

Busselle, R., \& Bilandzic, H. (2009). Measuring narrative engagement. Media Psychology, 12, 321-347. doi:10.1080/15213260903287259

Carter, M., Harrop, M., \& Gibbs, M. (2014). The roll of the dice in Warhammer 40,000. Transactions of the Digital Games Research Association, 1(3). Retrieved from http://todigra.org/index.php/todigra/article/view/20

Castronova, E., \& Knowles, I. (2015). A model of climate policy using board game mechanics. International Journal of Serious Games, 2, 41-62. doi:10.17083/ijsg.v2i3.77

Charsky, D., \& Ressler, W. (2011). “Games are made for fun”: Lessons on the effects of concept maps in the classroom use of computer games. Computers \& Education, 56, 604-615. doi:10.1016/j.compedu.2010.10.001

Checkland, P. (1999). Systems thinking, systems practice: Includes a 30-year retrospective. New York: Wiley.

Civikly, J. . (1992). Clarity: Teachers and students making sense of instruction. Communication Education, 41, 138-152. doi:10.1080/03634529209378876

Clark, D. B., Tanner-Smith, E. E., \& Killingsworth, S. S. (2016). Digital games, design, and learning: A systematic review and meta-analysis. Review of Educational Research, 86, 79-122. doi:10.3102/0034654315582065 
Corredor, J., Gaydos, M., \& Squire, K. (2013). Seeing change in time: Video games to teach about temporal change in scientific phenomena. Journal of Science Education and Technology, 23, 324-343. doi:10.1007/s10956-013-9466-4

Craig, A. (2003). Interoception: The sense of the physiological condition of the body. Current Opinion in Neurobiology, 13, 500-505. doi:10.1016/S0959-4388(03)00090-4

Dall, W. H., \& Boas, F. (1887). Museums of ethnology and their classification. Science, 9, 587589. doi:10.1126/science.ns-9.229.612

Denzin, N. K., \& Lincoln, Y. S. (2011). The discipline and practice of qualitative research. In N. K. Denzin \& Y. S. Lincoln (Eds.), The SAGE handbook of qualitative research (pp. 119). Los Angeles, CA: SAGE.

Doyle, J. K., \& Ford, D. N. (1998). Mental models concepts for system dynamics research. System Dynamics Review, 14, 3-29. doi:10.1002/(SICI)1099-1727(199821)14:1<3::AIDSDR140>3.0.CO;2-K

Doyle, J. K., \& Ford, D. N. (1999). Mental models concepts revisited: Some clarifications and a reply to Lane. System Dynamics Review, 15, 411-415. doi:10.1002/(SICI)10991727(199924)15:4<411::AID-SDR181>3.0.CO;2-R

Doyle, J. K., Radzicki, M. J., \& Trees, S. (1996). Measuring the effect of system thinking interventions on mental models. In Proceedings of the 1996 International System Dynamics Conference (pp. 129-132). Cambridge, MA.

Doyle, J. K., Radzicki, M. J., \& Trees, W. S. (2008). Measuring change in mental models of complex dynamic systems. In H. Qudrat-Ullah, J. M. Spector, \& P. I. Davidsen (Eds.), Complex decision making: Theory and practice (pp. 269-294). Berlin, Germany: Springer Berlin Heidelberg. 
Duncan, S. C., \& Berland, M. (2012). Uncovering play through collaboration and computation in tabletop gaming. Presented at the Meaningful Play 2012, East Lansing, MI.

Eastin, M. S. (2007). The influence of competitive and cooperative group game play on state hostility. Human Communication Research, 33, 450-466. doi:10.1111/j.14682958.2007.00307.x

Eden, C., Ackermann, F., \& Cropper, S. (1992). The analysis of cause maps. Journal of Management Studies, 29, 309-324. doi:10.1111/j.1467-6486.1992.tb00667.x

Evans, J. (2013). Translating board games: Multimodality and play. The Journal of Specialised Translation, (20), 15-32.

Fisch, S. M. (2013). Cross-platform learning: On the nature of children's learning from multiple media platforms. New Directions for Child and Adolescent Development, 2013, 59-70. doi:10.1002/cad.20032

Fisch, S. M., Lesh, R., Motoki, E., Crespo, S., \& Melfi, V. (2014). Cross-platform learning: How do children learn from multiple media? In F. C. Blumberg (Ed.), Learning by playing: Video gaming in education (pp. 207-219). New York: Oxford University Press.

Fiske, S. T., \& Taylor, S. E. (2013). Social cognition: From brains to culture (2nd ed., Vol. xviii). Thousand Oaks, CA: SAGE Publications.

Foster, A. N. (2011). The process of learning in a simulation strategy game: Disciplinary knowledge construction. Journal of Educational Computing Research, 45, 1-27. doi:10.2190/EC.45.1.a

Frontier Developments. (2004). RollerCoaster Tycoon 3. New York: Atari.

Garson, G. D. (2009). Computerized simulation in the social sciences: A survey and evaluation. Simulation \& Gaming, 40, 267-279. doi:10.1177/1046878108322225 
Gee, J. P. (2003). What video games have to teach us about learning and literacy. New York: Palgrave Macmillan.

Giddings, S. (2007). Playing with nonhumans: Digital games as technocultural form. In S. de Castell \& J. Jenson (Eds.), Worlds in play: International perspectives on digital games research. New York: Peter Lang.

Giddings, S. (2009). Events and collusions: A glossary for the microethnography of video game play. Games and Culture, 4, 144-157. doi:10.1177/1555412008325485

Glaser, B. G. (1965). The constant comparative method of qualitative analysis. Social Problems, 12, 436-445. doi:10.1525/sp.1965.12.4.03a00070

Glaser, B. G., \& Strauss, A. L. (1967). The discovery of grounded theory: Strategies for qualitative research. Chicago, IL: Aldine Publishing Company.

Gleick, J. (1988). Chaos: Making a new science. New York: Penguin.

Gneezy, U., Niederle, M., \& Rustichini, A. (2003). Performance in competitive environments: Gender differences. The Quarterly Journal of Economics, 118, 1049-1074. doi:10.1162/00335530360698496

Goldstone, R. L., \& Sakamoto, Y. (2003). The transfer of abstract principles governing complex adaptive systems. Cognitive Psychology, 46, 414-466. doi:10.1016/S00100285(02)00519-4

Gray, S. A., Zanre, E., \& Gray, S. R. J. (2014). Fuzzy cognitive maps as representations of mental models and group beliefs. In E. I. Papageorgiou (Ed.), Fuzzy cognitive maps for applied sciences and engineering (pp. 29-48). Berlin, Germany: Springer Berlin Heidelberg. 
Grenier, R. S., \& Dudzinska-Przesmitzki, D. (2015). A conceptual model for eliciting mental models using a composite methodology. Human Resource Development Review, 14, 163184. doi:10.1177/1534484315575966

Groesser, S. N., \& Schaffernicht, M. F. G. (2012). Mental models of dynamic systems: Taking stock and looking ahead. System Dynamics Review, 28, 46-68. doi:10.1002/sdr.476

Günther, C., Ekinci, N. A., Schwieren, C., \& Strobel, M. (2010). Women can’t jump?—An experiment on competitive attitudes and stereotype threat. Journal of Economic Behavior \& Organization, 75, 395-401. doi:10.1016/j.jebo.2010.05.003

Habermas, J. (1984). Theory of communicative action (Vol. 1, Reason and the rationalization of society). Boston, MA: Beacon.

Haraway, D. (1988). Situated knowledges: The science question in feminism and the privilege of partial perspective. Feminist Studies, 14, 575-599. doi:10.2307/3178066

Haraway, D. (1991). Simians, cyborgs, and women: The reinvention of nature. New York: Routledge.

Heller, P., \& Hollabaugh, M. (1992). Teaching problem solving through cooperative grouping. Part 2: Designing problems and structuring groups. American Journal of Physics, 60, 637-644. doi:10.1119/1.17118

Hmelo-Silver, C. E., \& Pfeffer, M. G. (2004). Comparing expert and novice understanding of a complex system from the perspective of structures, behaviors, and functions. Cognitive Science, 28, 127-138. doi:10.1207/s15516709cog2801_7

Hopper, M., \& Stave, K. A. (2008). Assessing the effectiveness of systems thinking interventions in the classroom. In Proceedings of the 26th International Conference of the System Dynamics Society. Athens, Greece. 
Horn, M. S., Weintrop, D., Beheshti, E., \& Olson, I. D. (2012). Spinners, dice, and pawns: Using board games to prepare for agent-based modeling activities. Presented at the American Educational Research Association annual meeting, Vancouver, BC.

Ip, J., \& Cooperstock, J. (2011). To virtualize or not? The importance of physical and virtual components in augmented reality board games. In J. C. Anacleto, S. Fels, N. Graham, B. Kapralos, M. S. El-Nasr, \& K. Stanley (Eds.), Entertainment computing - ICEC 2011 (pp. 452-455). Berlin, Germany: Springer Berlin Heidelberg.

Jacobson, M. J., \& Wilensky, U. (2006). Complex systems in education: Scientific and educational importance and implications for the learning sciences. The Journal of the Learning Sciences, 15, 11-34. doi:10.1207/s15327809j1s1501_4

Jiménez, O., Acholonu, U., \& Arena, D. (2014). Tug-of-War: Seeking help while playing an education card game. In F. C. Blumberg (Ed.), Learning by playing: Video gaming in education (pp. 232-245). New York: Oxford University Press.

Jiménez, O., Arena, D., \& Acholonu, U. (2011). Tug-of-War: A card game for pulling students to fractions fluency. In C. Steinkuehler, C. Martin, \& A. Ochsner (Eds.), Proceedings of the 7th International Conference on Games + Learning + Society Conference (pp. 119127). Pittsburgh, PA: ETC Press.

Johnson, D. W., Johnson, R. T., Holubee, E. J., \& Roy, P. (1984). Circles of learning: Cooperation in the classroom. Edina, MN: Interaction.

Jones, N., Ross, H., Lynam, T., Perez, P., \& Leitch, A. (2011). Mental models: An interdisciplinary synthesis of theory and methods. Ecology and Society, 16(1), 46.

Juul, J. (2011). Half-real: Video games between real rules and fictional worlds. Cambridge, MA: MIT Press. 
Kearney, A. R., \& Kaplan, S. (1997). Toward a methodology for the measurement of knowledge structures of ordinary people: The conceptual content cognitive map (3CM). Environment and Behavior, 29, 579-617. doi:10.1177/0013916597295001

Keller, J. D. (2015). The limits of the habitual: Shifting paradigms for language and thought. In D. B. Kronenfeld (Ed.), A companion to cognitive anthropology (pp. 61-81). John Wiley \& Sons.

Kester, L., Lehnen, C., Van Gerven, P. W. M., \& Kirschner, P. A. (2006). Just-in-time, schematic supportive information presentation during cognitive skill acquisition. Computers in Human Behavior, 22, 93-112. doi:10.1016/j.chb.2005.01.008

Kolb, D. (2014). Experiential learning: Experience as the source of learning and development (2nd ed.). Upper Saddle River, NJ: Pearson Education.

Kramers, H. A. (1940). Brownian motion in a field of force and the diffusion model of chemical reactions. Physica, 7, 284-304. doi:10.1016/S0031-8914(40)90098-2

Landriscina, F. (2013). Simulation and learning: A model-centered approach. New York: Springer.

Lane, D. C. (1995). Trying to think systematically about "systems thinking." The Journal of the Operational Research Society, 46, 1158-1162. doi:10.2307/2584506

Lane, D. C. (2008). The emergence and use of diagramming in system dynamics: A critical account. Systems Research and Behavioral Science, 25, 3-23. doi:10.1002/sres.826

Lang, A. (2000). The limited capacity model of mediated message processing. Journal of Communication, 50, 46-70. doi:10.1111/j.1460-2466.2000.tb02833.x 
Laski, E. V., \& Dulaney, A. (2015). When prior knowledge interferes, inhibitory control matters for learning: The case of numerical magnitude representations. Journal of Educational Psychology. doi:10.1037/edu0000034

Laski, E. V., \& Siegler, R. S. (2014). Learning from number board games: You learn what you encode. Developmental Psychology, 50, 853-864. doi:10.1037/a0034321

Latour, B. (2008). Reassembling the social: An introduction to actor-network-theory. New York: Oxford University Press.

Law, J. (2009). Actor-network theory and material semiotics. In B. S. Turner (Ed.), The new Blackwell companion to social theory (pp. 141-58). Malden, MA: Blackwell Publishers.

Leacock, M. (2007). Pandemic. Mahopac, NY: Z-Man Games.

Leino, O. T. (2012a). Death loop as a feature. Game Studies, 12(2). Retrieved from http://gamestudies.org/1202/articles/death_loop_as_a_feature

Leino, O. T. (2012b). Untangling gameplay: An account of experience, activity and materiality within computer game play. In J. R. Sageng, H. Fossheim, \& T. Mandt Larsen (Eds.), The philosophy of computer games (Vol. 7, pp. 57-75). Dordrecht, NL: Springer Netherlands.

Levine, R. L., \& Doyle, J. K. (2002). Modeling generic structures and patterns in social psychology. In Proceedings of the 20th International Conference of the System Dynamics Society. Palermo, IT.

Lieberoth, A. (2015). Shallow gamification: Testing psychological effects of framing an activity as a game. Games and Culture, 10, 229-248. doi:10.1177/1555412014559978

Lucas, K., \& Sherry, J. L. (2004). Sex differences in video game play: A communication-based explanation. Communication Research, 31, 499-523. doi:10.1177/0093650204267930 
McVeigh, D. P., Black, J., \& Flimlin, G. (2008). How system simulations improve student learning by assisting in the creation of clear mental models. In Proceedings of Society for Information Technology \& Teacher Education (pp. 1767-1773). Charlottesville, VA: AACE.

Mladenov, I. (2001). Unlimited semiosis and heteroglossia (C. S. Peirce and M. M. Bakhtin). Sign Systems Studies, 29(2), 441-460.

Mosca, I. (2011). Just a cyberplace. The rules in videogames: Between ontology and epistemology. In Proceedings of the DiGRA 2011 Conference: Think Design Play (Vol. $6)$.

Mulder, Y. G., Lazonder, A. W., \& Jong, T. de. (2015). Simulation-based inquiry learning and computer modeling pitfalls and potentials. Simulation \& Gaming, 46, 322-347. doi: $10.1177 / 1046878115577159$

Murphy, S. T., Frank, L. B., Moran, M. B., \& Patnoe-Woodley, P. (2011). Impact of narratives on persuasion in health communication: A meta-analysis. Journal of Communication, 61, 407-431. doi:10.1111/j.1460-2466.2011.01554.x

National Research Council. (2011). Learning science through computer games and simulations. (M. A. Honey \& M. L. Hilton, Eds.). Washington, D.C.: National Academies Press.

National Research Council. (2012). A framework for k-12 science education: Practices, crosscutting concepts, and core ideas. Washington, D.C.: National Academies Press.

Nehring, W. M., \& Lashley, F. R. (2009). Nursing simulation: A review of the past 40 years. Simulation \& Gaming, 40, 528-552. doi:10.1177/1046878109332282 
Nicholson, S., \& Begy, J. (2014). A framework for exploring tablet-based tabletop games. In Proceedings of the Canadian Game Studies Association Annual Conference: Borders without Boundaries.

Nishikawa, K. A., \& Jaeger, J. (2011). A computer simulation comparing the incentive structures of dictatorships and democracies. Journal of Political Science Education, 7, 135-142. doi:10.1080/15512169.2011.564915

Okitika, T. A., Barnabas, R. V., Rue, T., Weisman, J., Harris, N. A., Orenstein, W. A., \& Wasserheit, J. N. (2015). "Polio Eradication” game may increase public interest in global health. Games for Health Journal, 4, 195-201. doi:10.1089/g4h.2014.0045

Özesmi, U., \& Özesmi, S. L. (2004). Ecological models based on people's knowledge: A multistep fuzzy cognitive mapping approach. Ecological Modelling, 176, 43-64. doi:10.1016/j.ecolmodel.2003.10.027

Patten, J., \& Ishii, H. (2000). A comparison of spatial organization strategies in graphical and tangible user interfaces. In Proceedings of DARE 2000 on Designing Augmented Reality Environments (pp. 41-50). New York: ACM. doi:10.1145/354666.354671

Pavlov, O. V., Saeed, K., \& Robinson, L. W. (2015). Improving instructional simulation with structural debriefing. Simulation \& Gaming, 46, 383-403. doi: $10.1177 / 1046878114567980$

Penner, D. E. (2000). Explaining systems: Investigating middle school students' understanding of emergent phenomena. Journal of Research in Science Teaching, 37, 784-806. doi:10.1002/1098-2736(200010)37:8<784::AID-TEA3>3.0.CO;2-E

Ralph, P., \& Monu, K. (2015). Toward a unified theory of digital games. The Computer Games Journal, 4, 81-100. doi:10.1007/s40869-015-0007-7 
Ramani, G. B., \& Siegler, R. S. (2008). Promoting broad and stable improvements in lowincome children's numerical knowledge through playing number board games. Child Development, 79, 375-394. doi:10.1111/j.1467-8624.2007.01131.x

Resnick, M. (1996). Beyond the centralized mindset. The Journal of the Learning Sciences, 5, 122. doi:10.1207/s15327809j1s0501_1

Resnick, M., \& Wilensky, U. (1998). Diving into complexity: Developing probabilistic decentralized thinking through role-playing activities. The Journal of the Learning Sciences, 7, 153-172. doi:10.1207/s15327809j1s0702_1

Riessman, C. K. (2008). Narrative methods for the human sciences. Los Angeles, CA: SAGE. Robin, H., Marc, L., \& Robert, Z. (2004). MDA: A formal approach to game design and game research. In Proceedings of the Challenges in Games AI Workshop, Nineteenth National Conference of Artificial Intelligence. doi:10.1.1.79.4561

Rogerson, M. J., Gibbs, M., \& Smith, W. (2015). Digitising boardgames: Issues and tensions. In Proceedings of DiGRA 2015: Diversity of play: Games - Cultures - Identities.

Roskos-Ewoldsen, D. R., Roskos-Ewoldsen, B., \& Dillman Carpentier, F. R. (2002). Media priming: A synthesis. In J. Bryant \& D. Zillmann (Eds.), Media effects: Advances in theory and research (Vol. 2, pp. 97-120). Mahwah, NJ: Erlbaum.

Sangalang, A., Quintero Johnson, J. M., \& Ciancio, K. E. (2013). Exploring audience involvement with an interactive narrative: Implications for incorporating transmedia storytelling into entertainment-education campaigns. Critical Arts: A South-North Journal of Cultural \& Media Studies, 27, 127-146. doi:10.1080/02560046.2013.766977

Schaffernicht, M. F. G., \& Groesser, S. N. (2013). Absent or distant? On the use of indirect causal links and chains of causal links to compare mental models of dynamic systems. In 
R. Eberlein \& I. J. Martínez-Moyano (Eds.), Proceedings of the 31st International Conference of the System Dynamics Society. Cambridge, MA.

Senge, P. M. (2006). The fifth discipline: The art and practice of the learning organization. New York: Doubleday/Currency.

Seven years of plenty in the hobby games business. (2016, March 9). Retrieved from http://icv2.com/articles/markets/view/33916/seven-years-plenty-hobby-games-business

Shah, M., \& Foster, A. (2014). Undertaking an ecological approach to advance game-based learning: A case study. Journal of Educational Technology \& Society, 17(1), 29-41.

Shannon, C. E., \& Weaver, W. (1949). The mathematical theory of communication. Urbana, IL: University of Illinois Press.

Shapiro, J. (2013, February 18). How game-based learning can save the humanities. Retrieved May 12, 2016, from http://www.forbes.com/sites/jordanshapiro/2013/02/18/how-gamebased-learning-can-save-the-humanities/

Sherry, J. L. (2013a). Formative research for STEM educational games. Zeitschrift Für Psychologie, 221, 90-97. doi:10.1027/2151-2604/a000134

Sherry, J. L. (2013b). The challenge of audience reception: A developmental model for educational game engagement. New Directions for Child and Adolescent Development, 2013, 11-20. doi:10.1002/cad.20027

Sherry, J. L., Lucas, K., Greenberg, B. S., \& Lachlan, K. (2006). Video game uses and gratifications as predictors of use and game preference. In P. Vorderer \& J. Bryant (Eds.), Playing video games: Motives, responses, and consequences (pp. 213-224). New York: Routledge. 
Siegler, R. S., \& Ramani, G. B. (2009). Playing linear number board games—-but not circular ones_-improves low-income preschoolers' numerical understanding. Journal of Educational Psychology, 101, 545-560. doi:10.1037/a0014239

Spiel des Jahres: Dominion. (2015). Retrieved December 27, 2015, from http://www.spiel-desjahres.com/en/dominion

Stave, K. A., Beck, A., \& Galvan, C. (2015). Improving learners' understanding of environmental accumulations through simulation. Simulation \& Gaming, 46, 293-321. doi:10.1177/1046878114531764

Steinkuehler, C. (2006). The mangle of play. Games and Culture, 1, 199-213. doi: $10.1177 / 1555412006290440$

Sterman, J. D. (1994). Learning in and about complex systems. System Dynamics Review, 10, 291-330. doi:10.1002/sdr.4260100214

Sweeney, L. B., \& Sterman, J. D. (2007). Thinking about systems: Student and teacher conceptions of natural and social systems. System Dynamics Review, 23, 285-311. doi:10.1002/sdr.366

Sweller, J. (1988). Cognitive load during problem solving: Effects on learning. Cognitive Science, 12, 257-285. doi:10.1207/s15516709cog1202_4

Sweller, J., van Merrienboer, J. J. G., \& Paas, F. G. W. C. (1998). Cognitive architecture and instructional design. Educational Psychology Review, 10, 251-296.

doi:10.1023/A:1022193728205

Taylor, T. L. (2009). The assemblage of play. Games and Culture, 4, 331-339. doi:10.1177/1555412009343576 
Teach, R. D., \& Murff, E. (2014). Are the business simulations we play too complex? Developments in Business Simulation and Experiential Learning, 35, 205-211.

Teuber, K. (1995). Settlers of Catan. Skokie, IL: Mayfair Games.

The Settlers of Catan ${ }^{\circ}: 20$ years of settling, trading and building. (2015, January 15). Retrieved August 12, 2015, from http://mayfairgames.com/news.php?id=316

Tversky, A., \& Kahneman, D. (1974). Judgment under uncertainty: Heuristics and biases. Science, 185, 1124-1131. doi:10.1126/science.185.4157.1124

Vaccarino, D. X. (2008). Dominion. Rio Rancho, NM: Rio Grande Games.

Webb, N. M. (1989). Peer interaction and learning in small groups. International Journal of Educational Research, 13, 21-39. doi:10.1016/0883-0355(89)90014-1

Weber, M. (2011). The meaning of "ethical neutrality" in sociology and economics. In E. A. Shils \& H. A. Finch (Eds.), E. A. Shils \& H. A. Finch (Trans.), Methodology of social sciences (pp. 1-47). Piscataway, US: Transaction Publishers.

Wegner, D. M. (1987). Transactive memory: A contemporary analysis of the group mind. In B. Mullen \& G. R. Goethals (Eds.), Theories of group behavior (pp. 185-208). New York: Springer New York.

White, B. Y. (1984). Designing computer games to help physics students understand Newton's laws of motion. Cognition and Instruction, 1, 69-108. doi:10.1207/s1532690xci0101_4

White, W. J. (2012). Communicative rationality, strategy, and intersubjectivity: Results from a quasi-experimental investigation. Atlantic Journal of Communication, 20, 130-139. doi: $10.1080 / 15456870.2012 .665348$

Whorf, B. L. (1944). The relation of habitual thought and behavior to language. ETC: A Review of General Semantics, 1(4), 197-215. 
Woods, S. (2012). Eurogames: The design, culture and play of modern European board games. Jefferson, NC: McFarland.

Wrightson, M. T. (1976). The documentary coding method. In R. Axelrod (Ed.), Structure of decision: The cognitive maps of political elites (pp. 291-332). Princeton, NJ: Princeton University Press.

Xu, Y., Barba, E., Radu, I., Gandy, M., \& MacIntyre, B. (2011). Chores are fun: Understanding social play in board games for digital tabletop game design. In Proceedings of DiGRA 2011 Conference: Think Design Play.

Yee, N. (2006). Motivations for play in online games. CyberPsychology \& Behavior, 9, 772775. doi:10.1089/cpb.2006.9.772 


\section{Appendix A: Recruitment Announcement/Text}

Script that was read in classes or posted by instructors to eCampus:

Subject: Play a board game and share your thoughts about it (Research Study)

Body: Dr. Jaime Banks and Mr. Joe Wasserman from the Department of Communication Studies here at West Virginia University are inviting students to participate in a research study about how students think about board games - as a member of this class, you are invited to participate. If you decide to participate, you will be asked to first complete an online survey about yourself, and then to schedule a time to come into the lab. During this lab session, you'll be asked to play a board game with two-to-three other students and then do some writing and drawing to share how you thought about the game. The survey should take about 15 minutes to complete, and the lab session should take about $1.5-2$ hours to complete.

If you are interested in participating in this study, please begin by completing the initial online survey by visiting this URL:

If you decide to participate in the study, your participation will be completely confidential—we will not share details of your participation with anyone. WVU IRB approval for this research study is on file (\#TBD). Participation in the study is completely voluntary and your class and university standing will not be affected in any way if you choose not to participate. 
Questions about the study can be directed to the researchers, Dr. Jaime Banks and Mr.

Joe Wasserman, at jabanks@mail.wvu.edu or jowasserman@mix.wvu.edu

Thanks so much for your interest in the study, and we look forward to seeing you in the Lab. =) 


\section{Appendix B: Online Cover Letter and Initial Survey}

Greetings!

You are being invited to participate in a confidential study — an online survey and in-lab research session in Armstrong Hall—conducted by Principal Investigator Dr. Jaime Banks. This research examines how people think about board games. In order to participate, you must be 18 years of age or older and currently enrolled at WVU. After participating in both parts of the study, you will be entered into a drawing for one of three $\$ 100$ Amazon gift cards.

The study will require just under two hours to complete, in total. This may seem like a long time, but we think you'll find it goes quickly since you're playing a game. This survey is the first part, and includes questions about yourself and how you play games (10 minutes). The second part is an in-lab session where you'll be asked to play a board game with up to three other students and to write and draw some responses to the game (about 90 minutes). If you decide to participate, you'll be asked to indicate your availability for your lab session after you complete this initial survey. You will then be emailed to confirm your scheduled session.

Your participation in this research is completely confidential, meaning that any of your responses will not be tied to you individually. Your email address will only be used for scheduling and distributing gift cards, and will be erased from our files at the conclusion of the study. Your responses will be used only for the purposes of this study, and will not be shared outside of our research team (the two individuals listed at the bottom of this document). You may skip any question(s) that you do not care to answer, or feel comfortable answering. Also, given that some 
of the questions in this survey will require you to type in small amounts of text, we suggest completing this survey on a laptop or desktop computer with keyboard entry device, rather than a smartphone or tablet.

Participation in this study is voluntary. Unless otherwise indicated, you may skip certain questions if you want, and/or you may stop completing the questionnaire at any time without penalty. Your actual performance in this study or your refusal to participate or withdrawal from this study will in no way affect your class standing, grades, job status, or status in any activity associated with the University.

There are no known risks associated with participation in this study. If, however, you feel any discomfort resulting from your participation, please contact the WVU Carruth Center at (304) 393-4431 for any counseling needs. If you have other concerns about the study itself, you may contact the WVU Office of Research Integrity and Compliance at (304) 293-7073.

If you would like more information about this research project, feel free to contact the WVU Principal Investigator, Dr. Banks, at jabanks@mail.wvu.edu. This study has been acknowledged by West Virginia University's Institutional Review Board, and is on file as Protocol \#__. You also encouraged to print a copy of this page for your personal records; you may also request a copy of this information by contacting Dr. Banks.

Thank you in advance for your time, and for your valuable contribution to our project! 
Sincerely,

Dr. Jaime Banks jabanks@mail.wvu.edu

Joe Wasserman jowasserman@mix.wvu.edu

[ ] I acknowledge the information above and willingly agree to participate in this research. (directs users to the first page of the survey)

[ ] I do not wish to participate in this research.

(directs users to a page that instructs them to close the browser window to stop participating)

[next page]

\section{Intro: Study about Board Games and Thinking}

On behalf of our research team, thanks again for taking the time to participate in our research on how people think about board games. Your answers to the questions in this survey and your participation in the lab portion of the research will help us better understand how board games play a role in everyday life.

In the following screens, you will be asked a series of questions about playing board games and then some questions about you, personally. Please answer all questions honestly — there are no 
right or wrong answers - as they are important in understanding the types of people who are participating in the research.

After the last section of questions, you will reach a page titled "Scheduling Your Research Session," with some instructions and a form for indicating your availability for an in-person session in the Lab, as well as a request for your email address. Please read the instructions carefully and indicate your availability for days and times you can come into the lab. You will be asked to come into the lab for one of these days. Please note you will not be eligible to participate in the second part of the research if you do not complete that scheduling form and share your email address so we can contact you. Your email address will only be used for scheduling and distributing gift cards, and will be deleted from all of our files at the end of data collection.

Please click 'next' below to continue with the survey.

[next page]

\section{Section 1/3: Board game experience}

Thank you for taking our survey! 
We are interested in finding out a little bit about the board games you may have played. This information allows us to get a general sense for the different kinds of games the people participating in this research may have played.

If you haven't played any of these games, that's okay. Please read and respond to each statement by selecting the answer that best represents your opinion. Just use your best judgment.

Consider the following list of board games. Using the slider, please indicate how experienced you are with each game. If you have never played any of these games, that's okay. Just leave the sliders at 0.

- 7 Wonders [slider: $0=$ Never played, $10=$ Expert]

- Agricola [slider: $0=$ Never played, $10=$ Expert $]$

- $\quad$ Carcassonne [slider: $0=$ Never played, $10=$ Expert $]$

- Dominion [slider: $0=$ Never played, $10=$ Expert

- $\quad$ Pandemic [slider: $0=$ Never played, $10=$ Expert $]$

- Power Grid [slider: $0=$ Never played, $10=$ Expert

- Puerto Rico [slider: $0=$ Never played, $10=$ Expert]

- The Settlers of Catan [slider: $0=$ Never played, $10=$ Expert]

- $\quad$ Small World [slider: $0=$ Never played, $10=$ Expert]

- $\quad$ Ticket to Ride [slider: $0=$ Never played, $10=$ Expert

[next page] 
Section 2/3-A bit about you

\begin{abstract}
Almost done! For this section, we would like to ask you some very basic demographic information about yourself. This information allows us to get a general sense for the different characteristics of people participating in this research.
\end{abstract}

- How old are you? [open]

- What is your gender? [open]

- What is your ethnicity? [open]

- What is your major? [open]

- How many years have you been in college? [open]

[next page]

\title{
Section 3/3 - Scheduling your research schedule
}

That's it for this survey, but there's still one more step ...

In order to participate in the full research session, you must indicate your availability for days and times to come in-person to the lab (located in Armstrong Hall at the downtown WVU campus, room 115). In that session, you'll be asked to play a board game with two-to-three other 
students, and then to do some writing and drawing to get at how you thought about the game. This session will take between 1.5 to 2 hours.

But first, in order to contact you with a time for you to come to the lab, we need you to enter your email address. Please note that if you do not complete this step, we will not be able to confirm that you have completed the survey and you will not be able to participate in the remainder of the study. After the study is complete, we will destroy all records of your email address so nobody will be able to tell that you participated in the study.

Please enter your email address here: [open response]

[next page]

Please look over the following days and times, and check any that you are available for.

Remember that Spring Break is March 21-25, so make sure you will be in town those days if you sign up for them! We will contact you as soon as possible to let you know the day and time you are scheduled for.

\begin{tabular}{|l|l|l|l|}
\hline & 9 a.m. -11 a.m. & 12 p.m. -2 p.m. & 3 p.m. -5 p.m. \\
\hline Saturday, March 5 & & & \\
\hline Sunday, March 6 & & & \\
\hline Saturday, March 12 & & & \\
\hline Sunday, March 13 & & & \\
\hline Saturday, March 19 & & & \\
\hline Sunday, March 20 & & & \\
\hline
\end{tabular}


That's it! Thanks again for your participation in this study. We will email you as soon as possible with your scheduled lab time and a few additional details.

[submit and exit survey] 


\title{
Appendix C: Consent Form
}

\author{
Only Minimal Risk \\ Consent Information Form (without HIPAA) \\ Principal Investigator \\ Jaime Banks, Ph.D. \\ Department \\ Communication Studies \\ Protocol Number \\ Study Title \\ Understanding How Players Think about Board Games \\ Co-Investigator(s) \\ Joe Wasserman, B.A.
}

\section{Contact Persons}

Jaime Banks, Ph.D. and Joe Wasserman, B.A.

In the event you experience any side effects or injury related to this research, you should contact Dr. Banks (Assistant Professor, Communication Studies) at (304) 293-3905 or jabanks@mail.wvu.edu. If you have any questions, concerns, or complaints about this research, you can contact Dr. Banks directly, or her co-investigator Mr. Wasserman (MA student, Communication Studies) at (304) 293-3905. For information regarding your rights as a research subject, to discuss problems, concerns, or suggestions related to the research, to obtain information or offer input about the research, contact the Office of Research Integrity \& Compliance at (304) 293-7073.

In addition if you would like to discuss problems, concerns, have suggestions related to research, or would like to offer input about the research, contact the Office of Research Integrity and Compliance at 304-293-7073.

\section{Introduction}

You have been asked to participate in this research study, which has been explained to you by Joe Wasserman. This study is being conducted by Dr. Jaime Banks and Mr. Joe Wasserman in the Department of Communication Studies at West Virginia University in partial fulfillment of Mr. Wasserman's MA thesis. This project is not funded by any outside organization.

\section{Purpose(s) of the Study}

The purpose of this study is to examine how people think about board games.

\section{Description of Procedures}

In this study, you will be asked to learn and play a board game with two to three other people. Then you will be asked to complete an activity related to how you thought about the game that will involve writing and drawing. Playing the game will take no longer than 90 minutes. The activity afterward will take no longer than 30 minutes.

\section{Discomforts}

There are no known or expected risks from participating in this study, except for an unlikely frustration associated with playing the board game and the activity afterward. If at any time you feel uncomfortable in the study, you may request to leave study without any sort of penalty. Your class and university standing will not be affected.

\section{Benefits}

You may not receive any direct benefit from this study. The knowledge gained from this study may eventually benefit others.

\section{Financial Considerations}


There are no special fees for participating in this study.

\section{Confidentiality}

Any information about you that is obtained as a result of your participation in this research will be kept as confidential as legally possible. Your research records and test results, just like hospital records, may be subpoenaed by court order or may be inspected by the study sponsor or federal regulatory authorities without your additional consent. In any publications that result from this research, neither your name nor any information from which you might be identified will be published without your consent.

\section{Voluntary Participation}

Participation in this study is voluntary. You are free to withdraw your consent to participate in this study at any time.

Refusal to participate or withdrawal will not affect your class standing or grades and will involve no penalty to you.

In the event new information becomes available that may affect your willingness to participate in this study, this information will be given to you so that you can make an informed decision about whether or not to continue your participation.

You have been given the opportunity to ask questions about the research, and you have received answers concerning areas you did not understand. Upon signing this form, you will receive a copy.

I willingly consent to participate in this research.

Signatures

Signature of Subject

Printed Name

Date

Time

The participant has had the opportunity to have questions addressed. The participant willingly agrees to be in the study.

Signature of Investigator or Co-Investigator

Printed Name

Date

Time 
Appendix D: Playmat

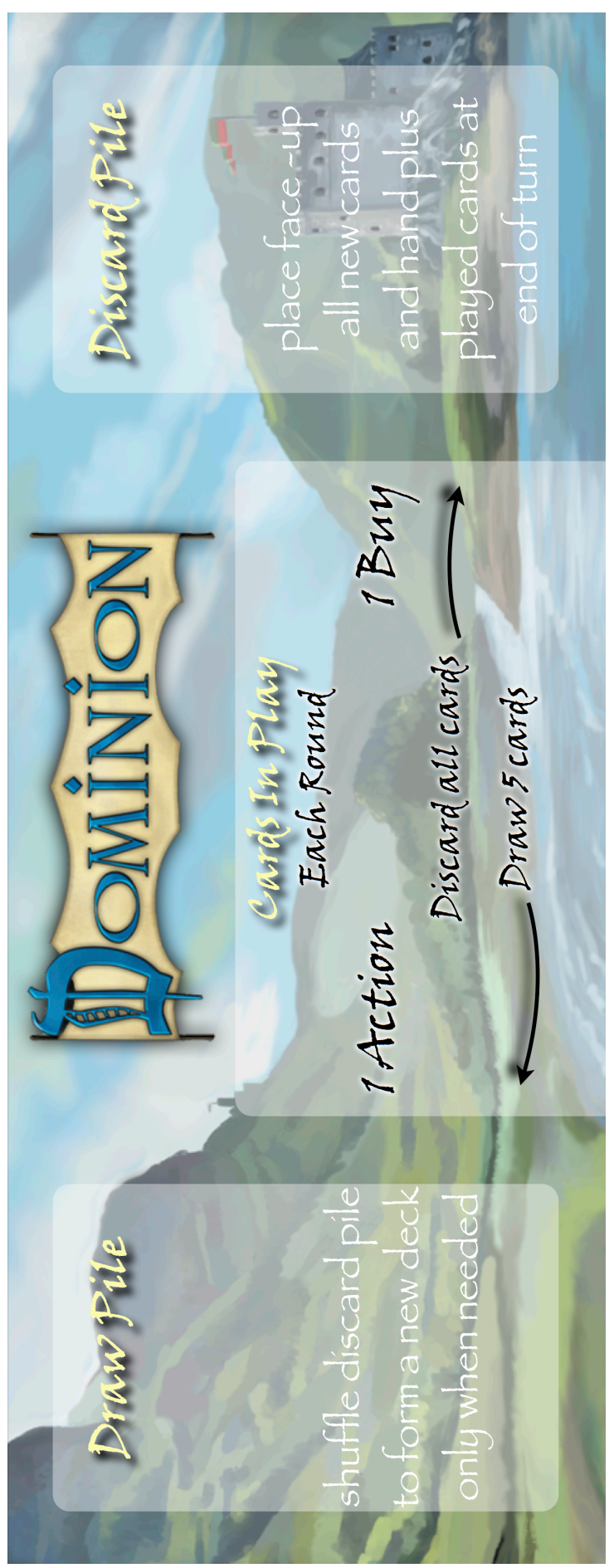




\section{Appendix E: Study Procedure Script}

1. Prior to participant arrival at Armstrong Hall 115, all stimulus materials were set up and covered on a table in the center of the room that had five chairs around it. Four tables were arranged in the corners of the room with one chair for each. The materials necessary for the first step of cognitive mapping — a pad of small sticky notes and a medium-point marker - were set in the corner of these corner tables.

2. Each participant arrived at the study room in Armstrong Hall at his/her scheduled time. The participant was greeted, and given an Informed Consent document to read and consider. The key points of informed consent were reviewed verbally by the researcher. They were asked if they have any questions about informed consent, which the researcher will answer. They could grant consent by signing the document and giving it to the investigator. Should a participant not wish to participate or grant written consent, s/he were be told s/he may leave without penalty.

3. If consent was granted, the investigator read to the participant the following prompt: "Thanks for agreeing to participate in my study. Over the next one-and-a-half to two hours, I'm going to ask you to play a board game with two-to-three other students and then do some writing and drawing to share how you thought about the game. Please follow me into the room so you can get seated (while we wait for the other participants/so we can get started)."

4. Participants were led into the room, which was equipped with a table in the center of the room with five chairs, as well as tables in the four corners of the room with one chair each. The game was setup on the center table, but covered until all participants arrive. 
5. Sessions were started no later than 10 minutes after the scheduled start time.

6. Once all participants arrived and were seated, or 10 minutes had elapsed since the scheduled start time, the researcher read the following prompt: "As was discussed in the consent document you just read, I'm conducting a research study on how people think about board games. In just a moment, I'm going to uncover the game and ask you to learn and play the game from the materials provided. I won't be able to answer questions about the game, as it's important that you learn to play on your own. I'll let you know when you've completed 5 rounds to help you keep track of them. Do you have any questions before we get started? " [Pause and address any questions or concerns.]

7. Next, the researcher uncovered the game stimulus and read the following prompt: "This is the game that you will be learning and playing. It is called 'Dominion' and you all play as 'medieval rulers' trying to build your kingdom through different kinds of cards. Please use this rulebook [points to the rulebook] and these materials to learn how to play. The rulebook describes the rules, sample cards, and an example of the first few turns. Feel free to read and discuss with each other, whatever works for you. Whenever you are ready, you can start playing."

8. The researcher seated himself in his chair placed at a slight distance from the tableclose enough to observe game events but far enough that he wouldn't be seen as part of gameplay. Throughout the gameplay session, he tracked the number of rounds that participants played.

9. As participants learned and played the game, the researcher followed a strict set of rules for behavior. He: 
- Maintained a neutral facial expression the entire time.

- Did not make eye contact with participants during gameplay unless directly addressed by participants.

- If participants ask the researcher about the game, he said, "I actually can't answer that question, since it might unfairly influence how you play the game. Everything you need to know should be covered in the rulebook, so please check that for the answer."

- If participants expressed discomfort about any aspect of the way the session was proceeding, the researcher said, "You may leave at any time without penalties of any sort, as described at the beginning of the session."

10. Once 5 rounds had been played, the researcher said, "That's the end of the fifth round, so you're halfway done."

11. Once 10 rounds had been played, as described in the modified rulebook, the researcher rang a bell and read the following, "Okay, it looks like you've completed 10 rounds. Please leave your cards here and sit at the table in the corner closest to you. You'll come back to the game before you leave, so you can leave the rest of your things as well.”

12. Once participants were seated at the corner tables, the researcher read the following script, "Great, now we're interested in finding out how you thought about the game you just played. I'm going to give you some written instructions that will guide you through an activity designed to get at your thoughts about the game. Throughout this process, go at your own pace and write whatever comes to your mind. There are no 
right or wrong answers, and no time limit. Before we begin, do you have any

questions?" [Pause and address any questions or concerns.]

13. The researcher then handed participants the written prompt for the first part of the cognitive mapping task, which read, "We are interested in how you think about the game you just played and what you think is important. When you think about the game you just played, what are the things that come to your mind? Reflect on this question for a moment, and then write each thing on a separate sticky note and set them aside. Write as many as you'd like. Just make sure to note the things that you thought were important while you were playing. Go at your own pace. It's okay to make any changes you want as you go along. Wave to the researcher when you feel satisfied with what you have written."

14. While participants worked on both this prompt and the next, the researcher quietly organized participants' cards both so that participants would be able to easily see what cards they had acquired by the time the game was stopped, and to facilitate recording of those cards once participants had left the study session. When finished, the table was re-covered to prevent participants from individually viewing the cards. At the same time, he watched for participants waving him over.

15. As participants waved over the researcher, he give them the materials for the next step of cognitive mapping: a large blank piece of paper, a replacement pad of small sticky notes in a slightly different color, and a flip book of prompts on several pages that read:

1. Now we are interested in how you think the things you've just written relate to each other. Essentially, you're going to draw a diagram or a model of the game 
using your sticky notes. This booklet will ask you to do five different things related to this. Please complete the task on each page before turning to the next. First, reflect on how the things you've written down might be related to each other. Then flip to the next page for the next step.

2. Now, arrange the sticky notes on the paper, placing related things near each other. Be sure to leave some room in between them for the next step. As you do this, feel free to edit, subtract, or add new sticky notes. When you are satisfied, flip to the next page.

3. Now that your sticky notes are laid out, we are interested in how you think the things on your sticky notes relate to each other. Please draw arrows connecting your sticky notes to indicate the things that relate to each other. Feel free to rearrange sticky notes as much as you'd like, add new things on new sticky notes, and remove or alter anything you've already written-including erasing arrows. Draw as many arrows as you please. When you are satisfied with the arrangement of your sticky notes and the arrows you've drawn between them, flip the page.

4. Now we'd like to know more about how you think the things you've written are related to each other. Next to each arrow, please write a description of why the two things connected by the arrow matter to each other. Write as much as you think is necessary to describe their relationships. Feel free to add, remove, and change both sticky notes and arrows while you do this. Then flip the page for the last step. 
5. Finally, circle the part of your diagram that you think is most important. Wave to the researcher when you are satisfied with all of your notes, arrows, and descriptions.

16. As participants waved the researcher over, he quietly told them individually, "Thanks. Please go back to your seat in the center. [If others have not yet finished:] You may use your phone on silent if you like while the others finish."

17. Once all participants finished and were seated at the center table, the researcher read the following script: "That's about all there is to it! Thank you all for time. Feel free to take a look at the cards you all got, and to compare how many points you had at the end of 10 rounds. So it looks like ... you have [X] points so you were the winner of the game. Congratulations! Before we wrap up, can I answer any questions at this time?" [Pause and address any questions or concerns.]

18. After answering any potential questions, the researcher read the following script: "If you don't have any more questions for me, we'll end the study session now. As we wrap up, I do have one more favor to ask of you: as I'm still in the process of collecting data, I would very much appreciate if you could not talk about the study with anyone else. In particular, please do not tell people anything specific about the game. You might have friends or classmates who have signed up for the study, and if they knew about the details of the study ahead of time, it might change the way they play the game or approach the questions. Once we finish data collection in April, it will be okay to talk about the study then, and I will even be able to come in and tell your class about the results." 
19. The investigator then closed the study session: "With that, you have completed your participation in this study. Thank you so much for your time."

20. Once participants left, the researcher photographed participants' cognitive maps. Notecards that displayed the session date and time as well as the participants' identification number were included in the photo to track which map and which cards correspond to which participant. The researcher then reset the room for the next session or, if it was the last session of the day, reverted the room to its normal arrangement and collected all study materials. 


\section{Appendix F: Anonymized Cognitive Maps}

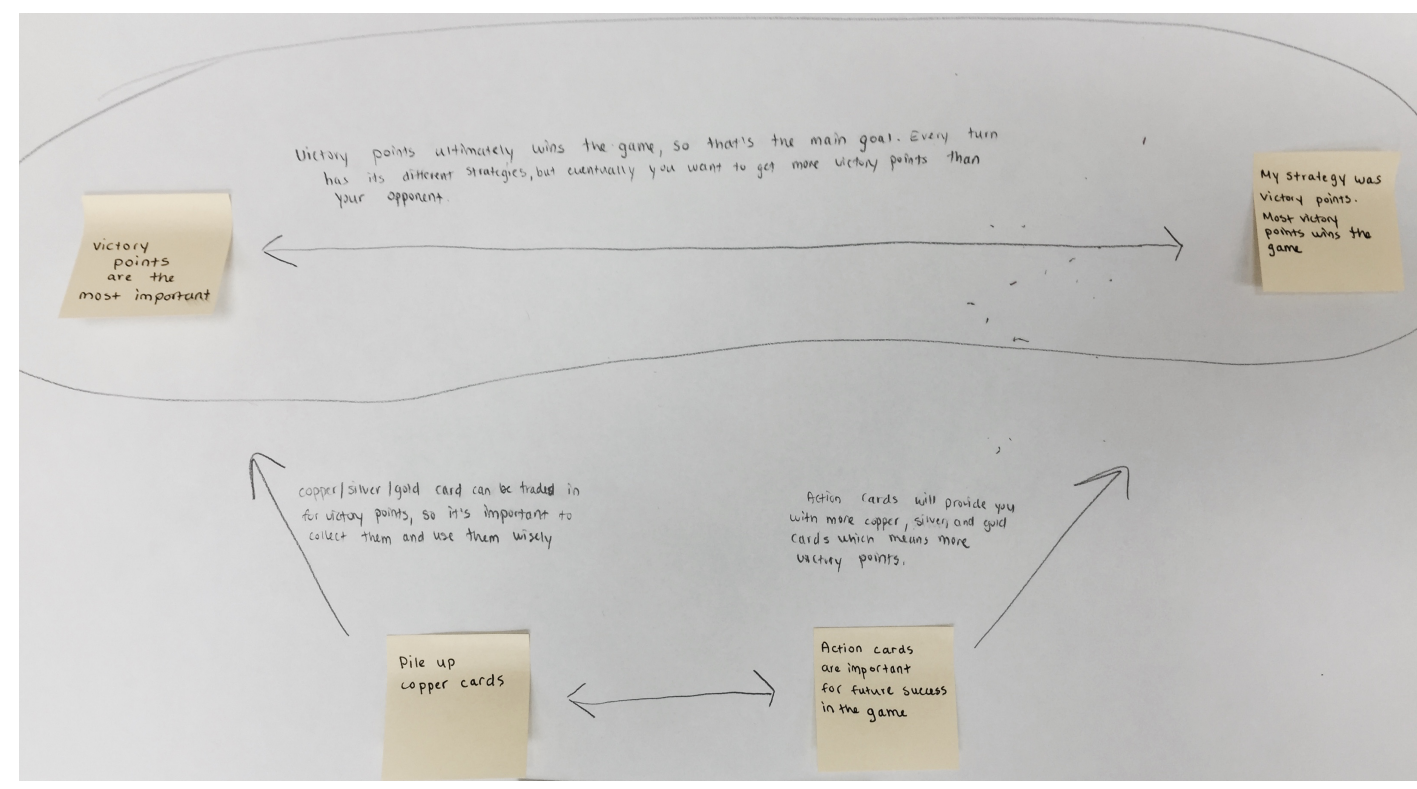

\section{Cognitive map 1}

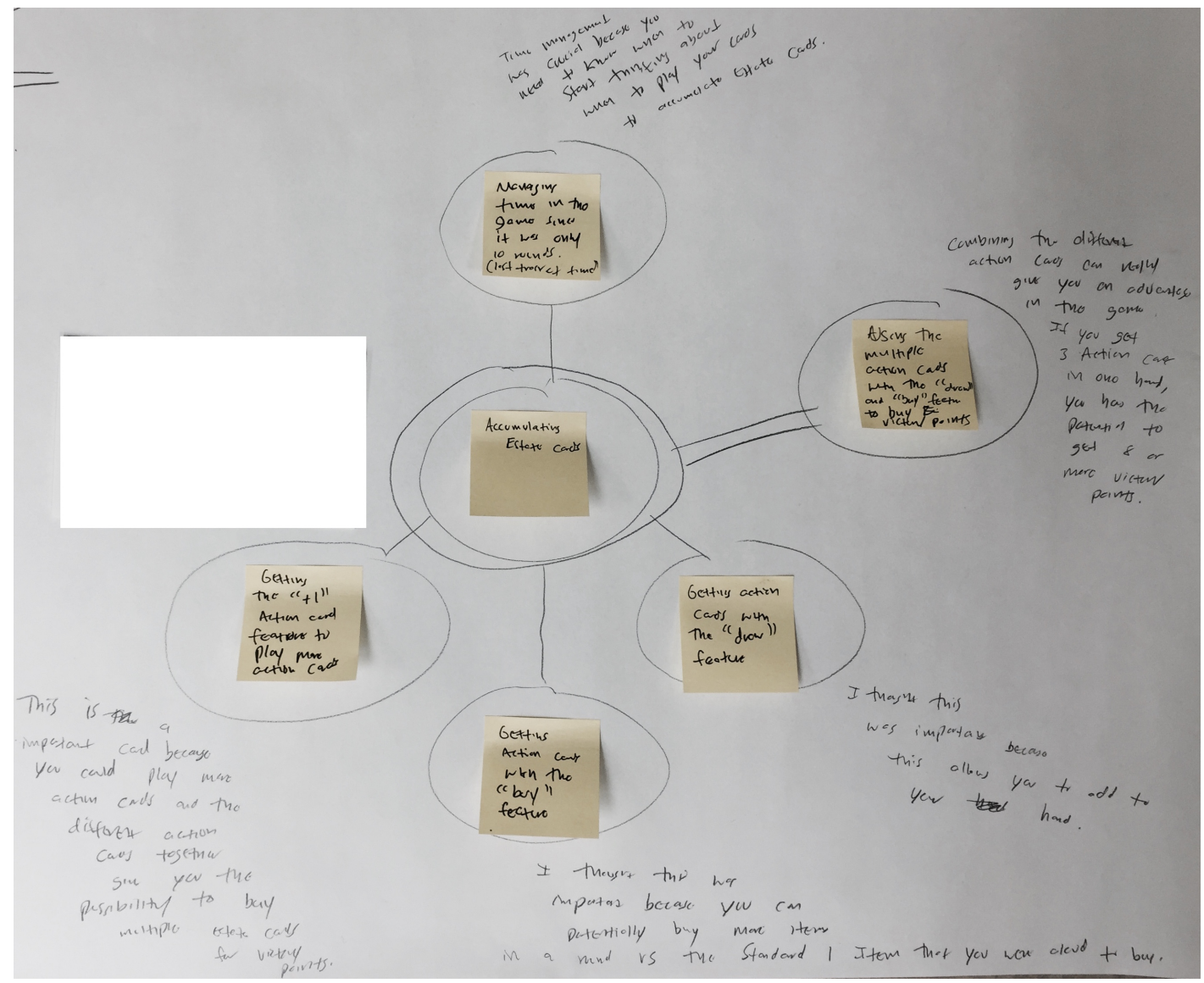

Cognitive map 2 


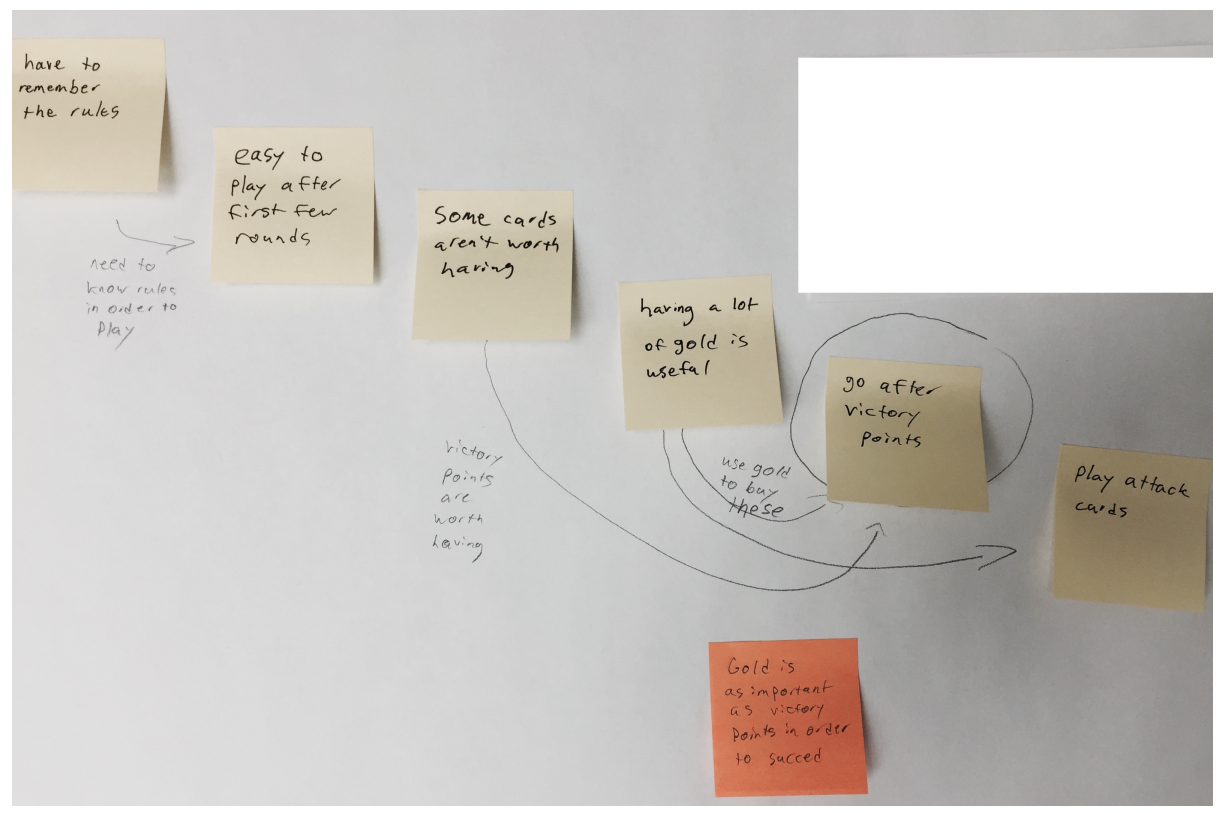

Cognitive map 3

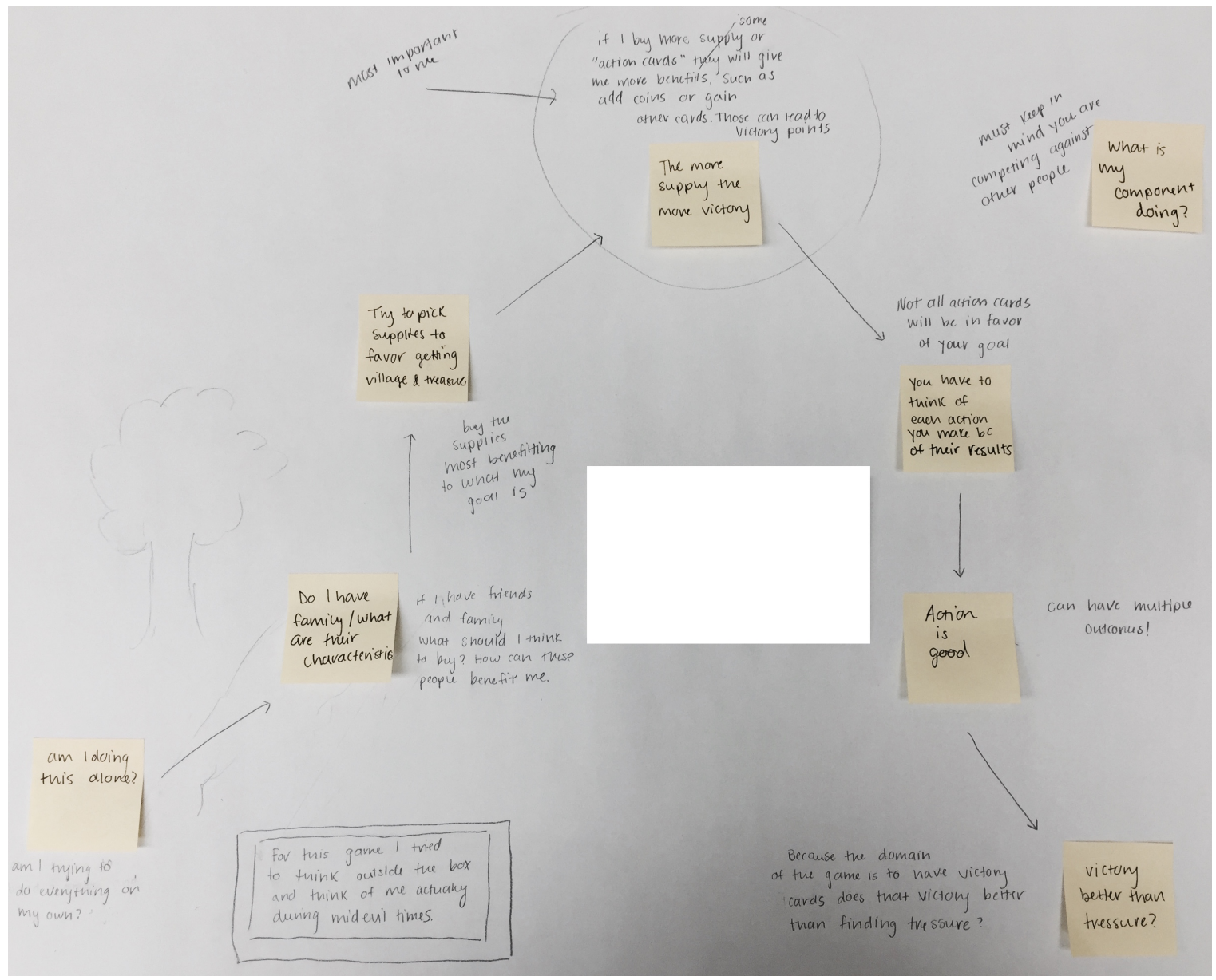

Cognitive map 4 


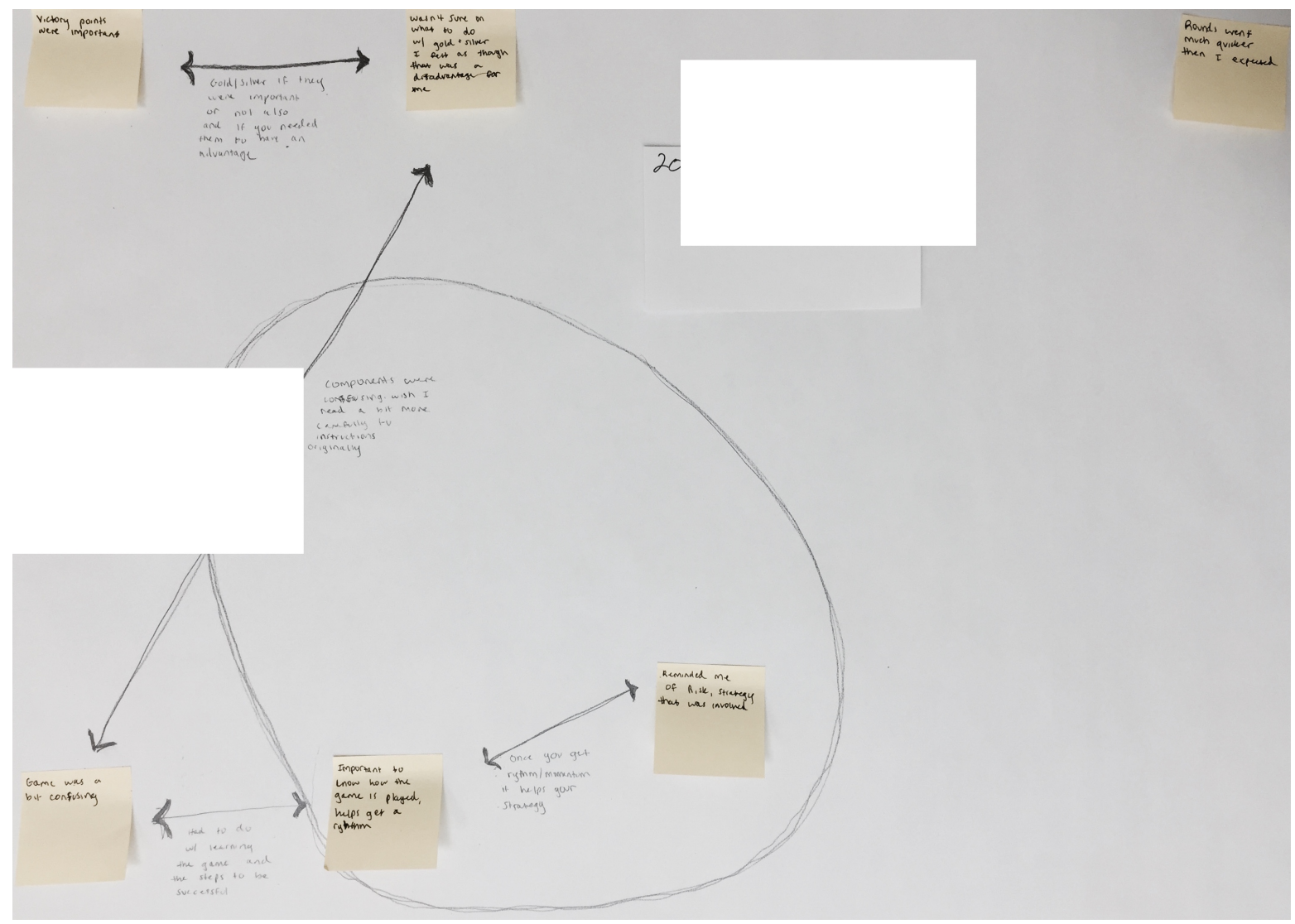

Cognitive map 5

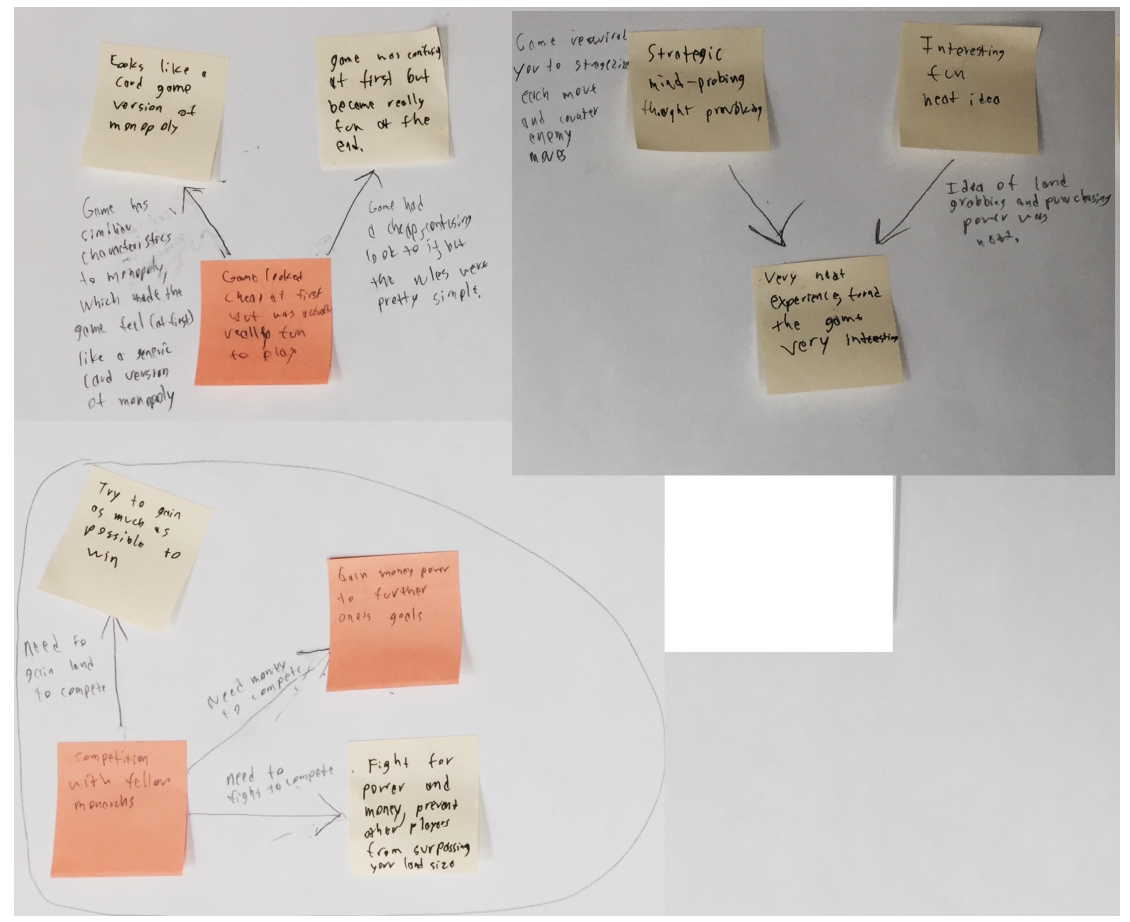

Cognitive map 6 


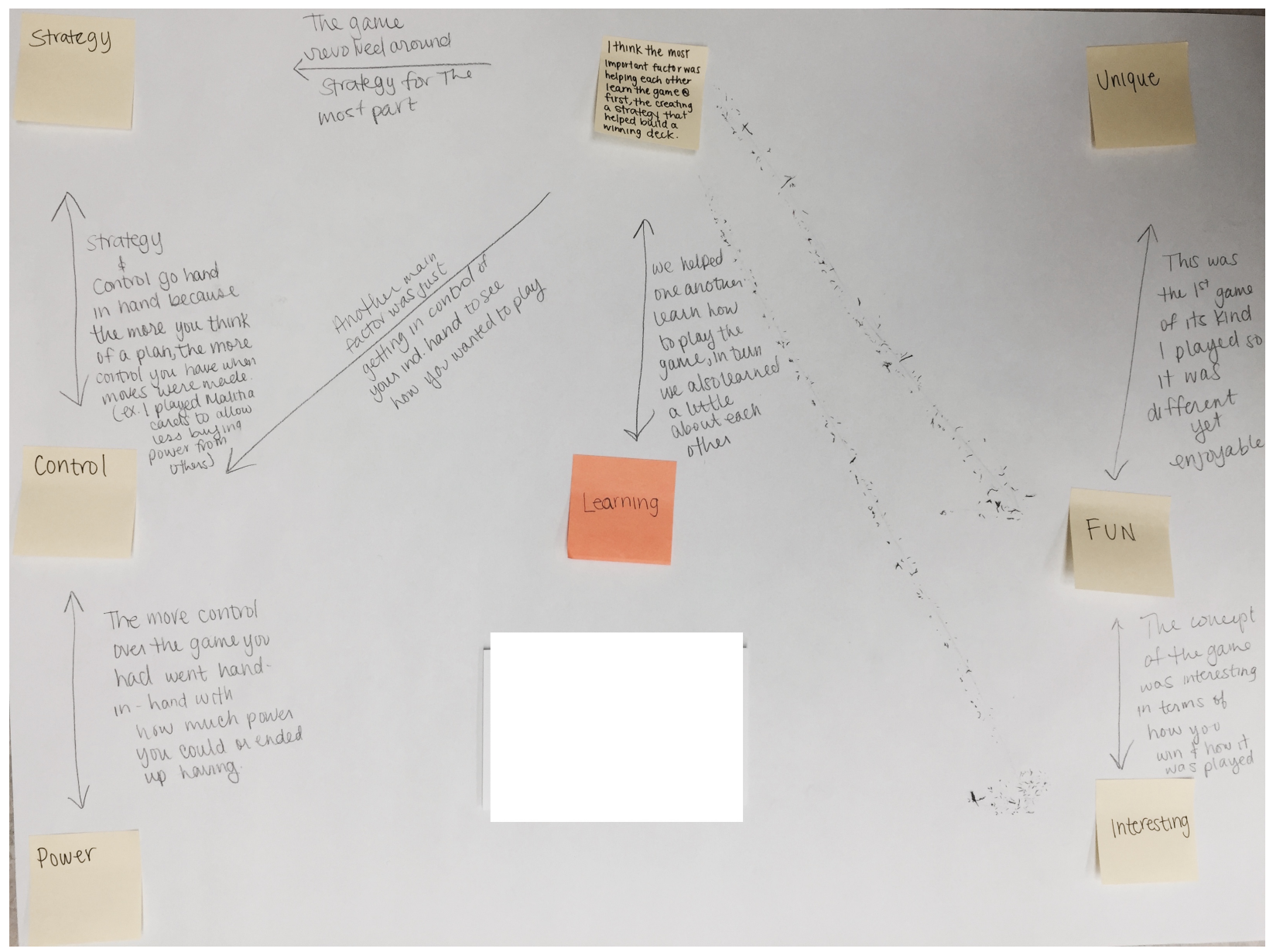

Cognitive map 7 


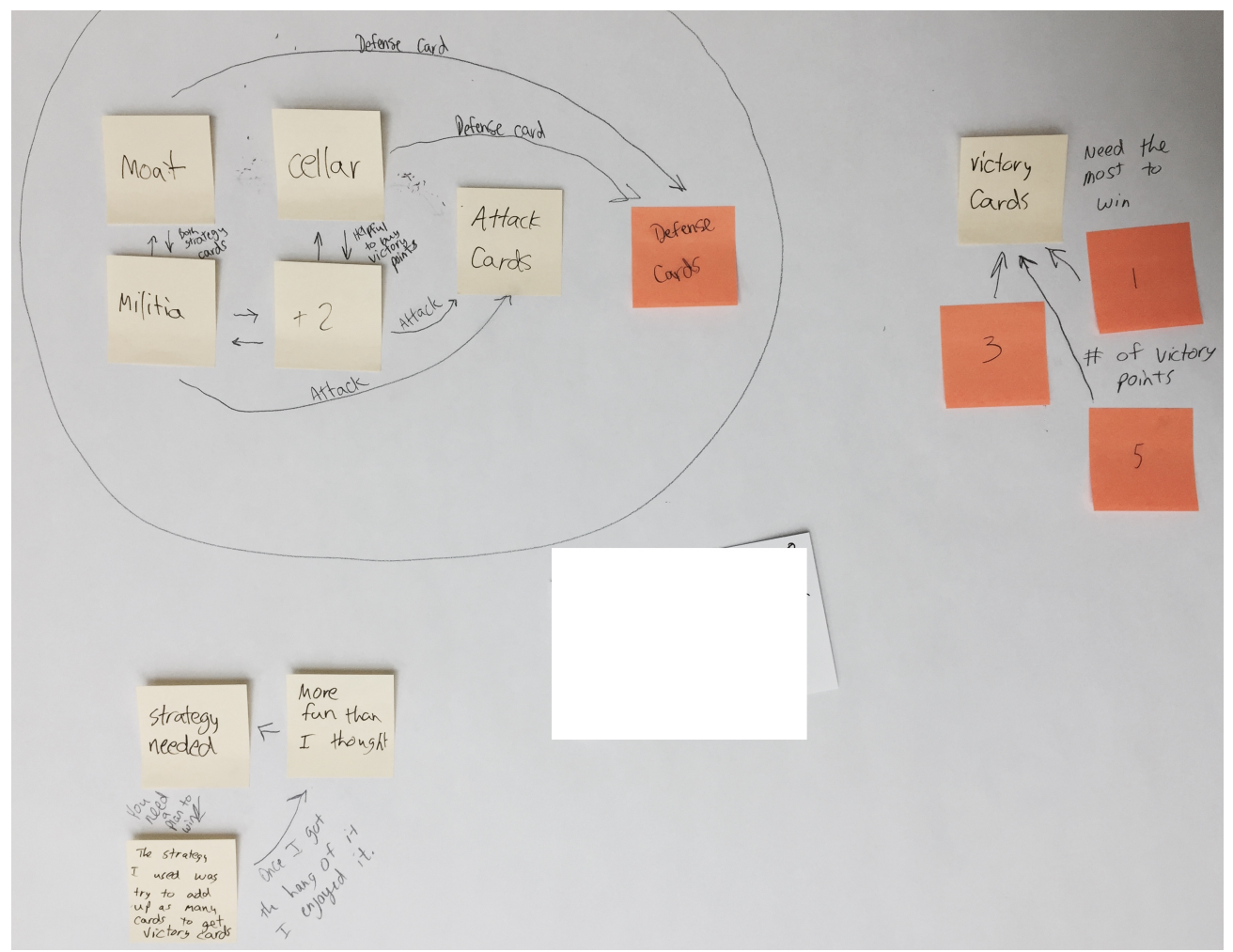

Cognitive map 8

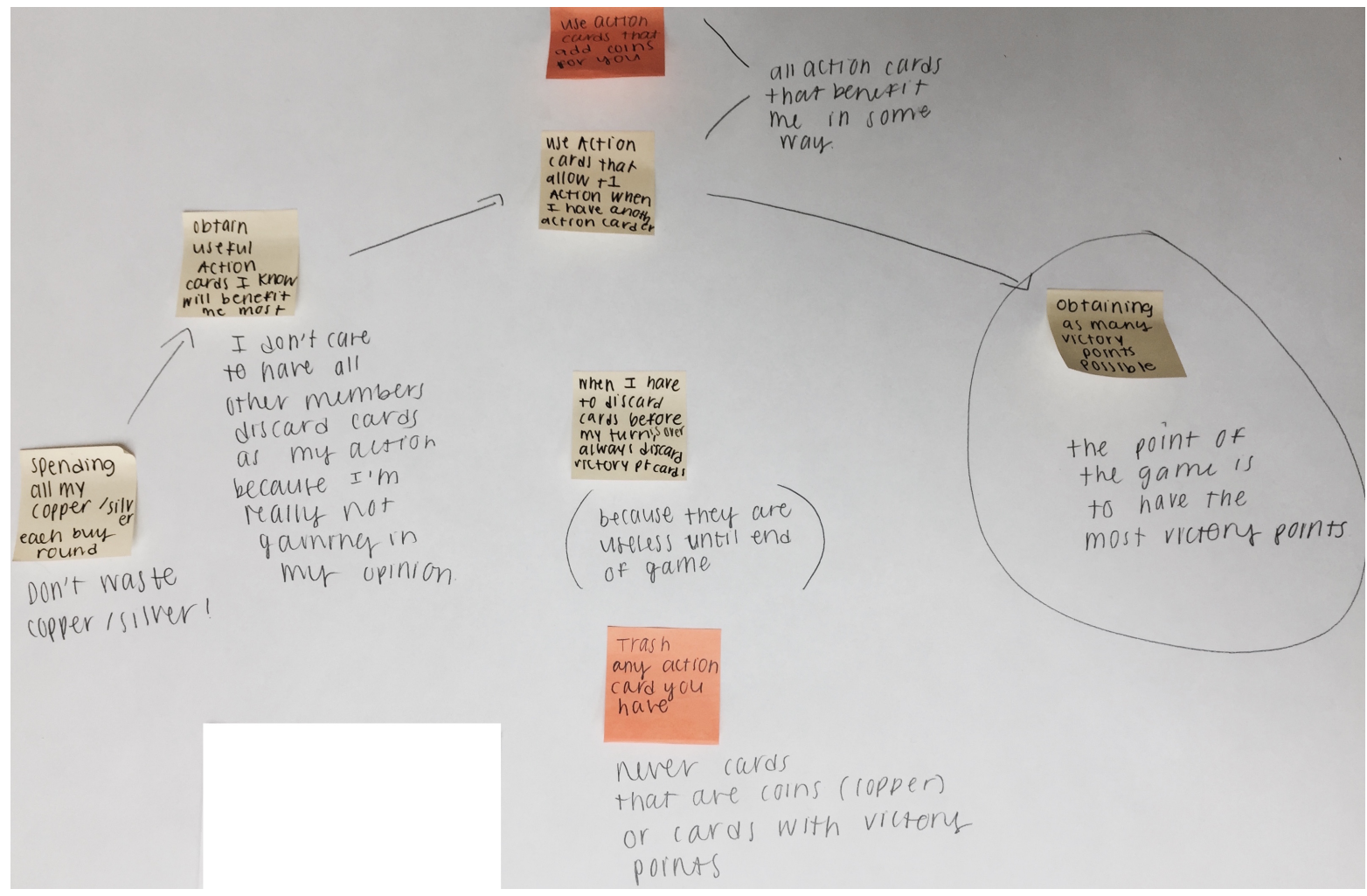

\section{Cognitive map 9}




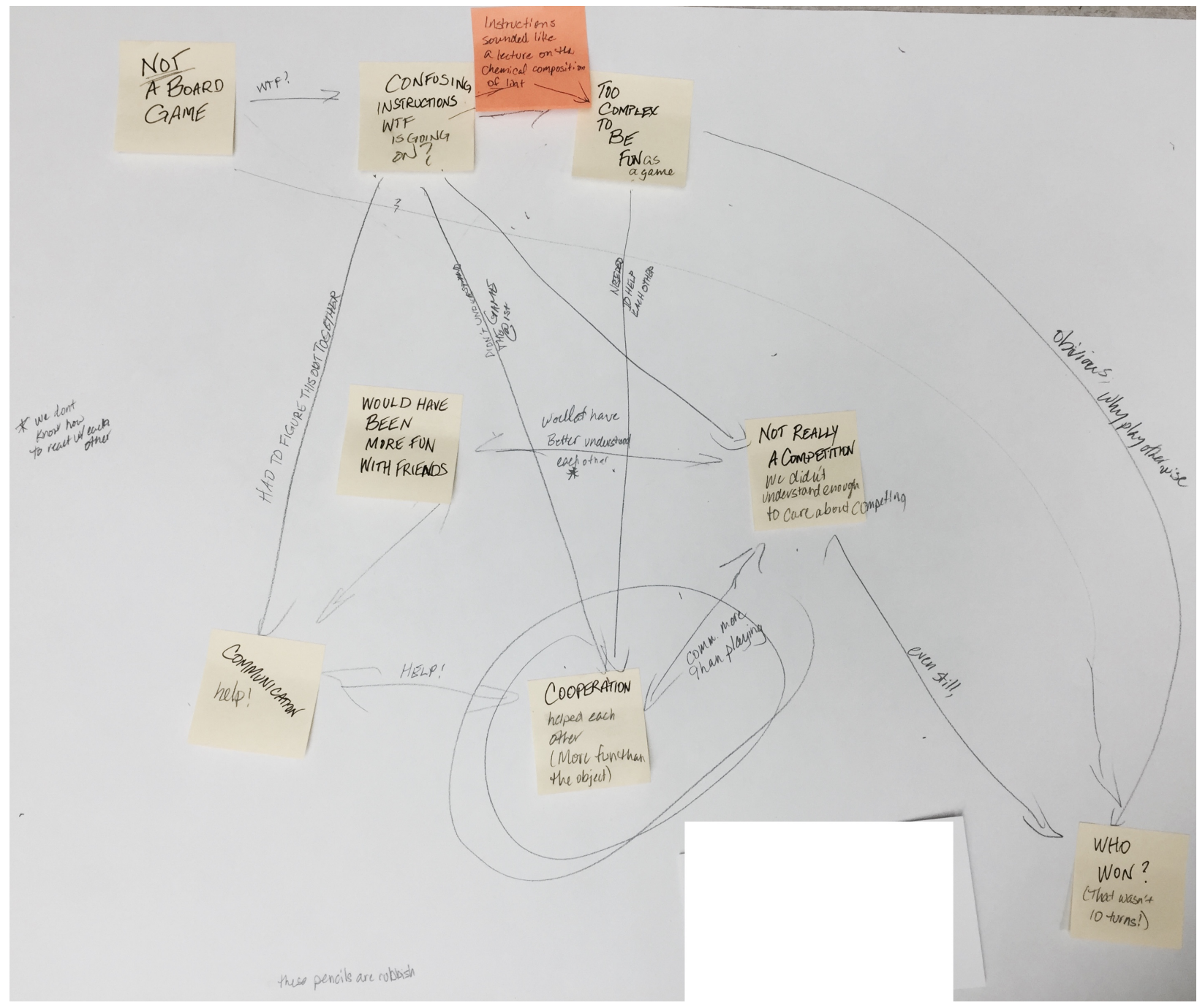

\section{Cognitive map 10}

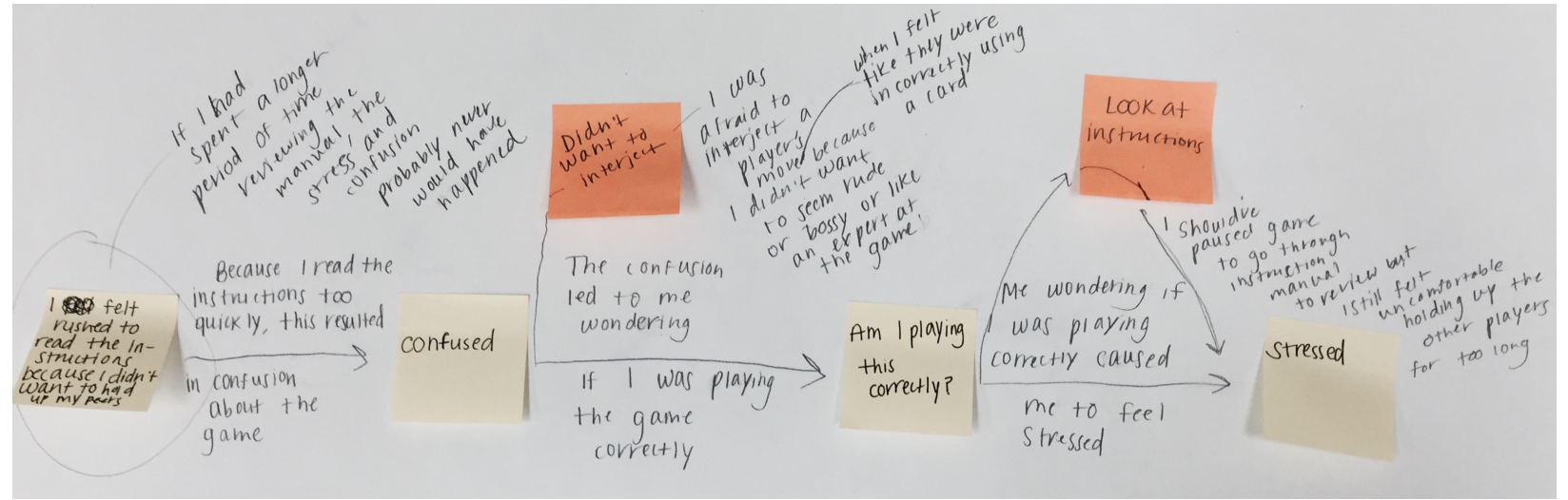

\section{Cognitive map 11}




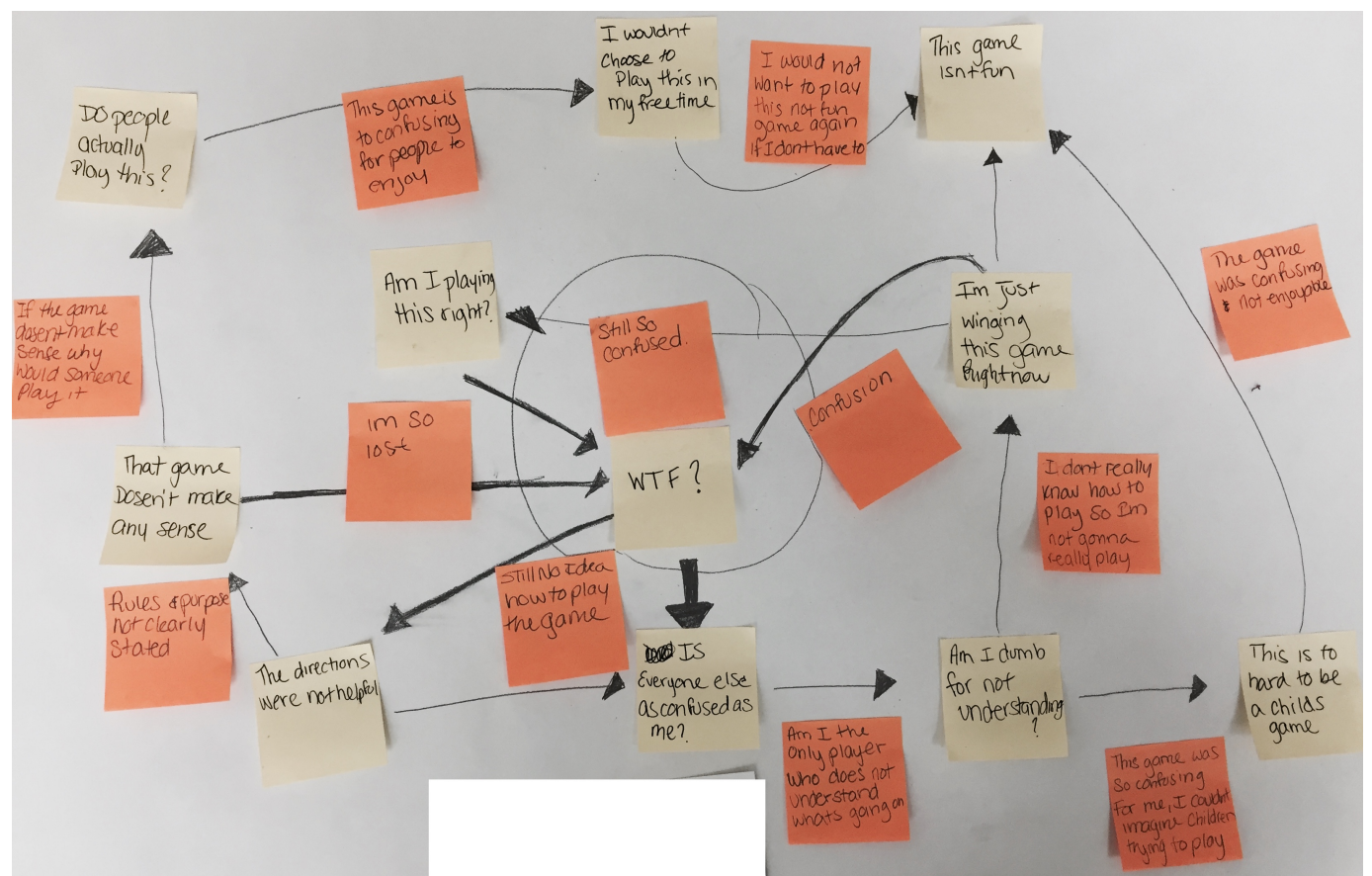

Cognitive map 12

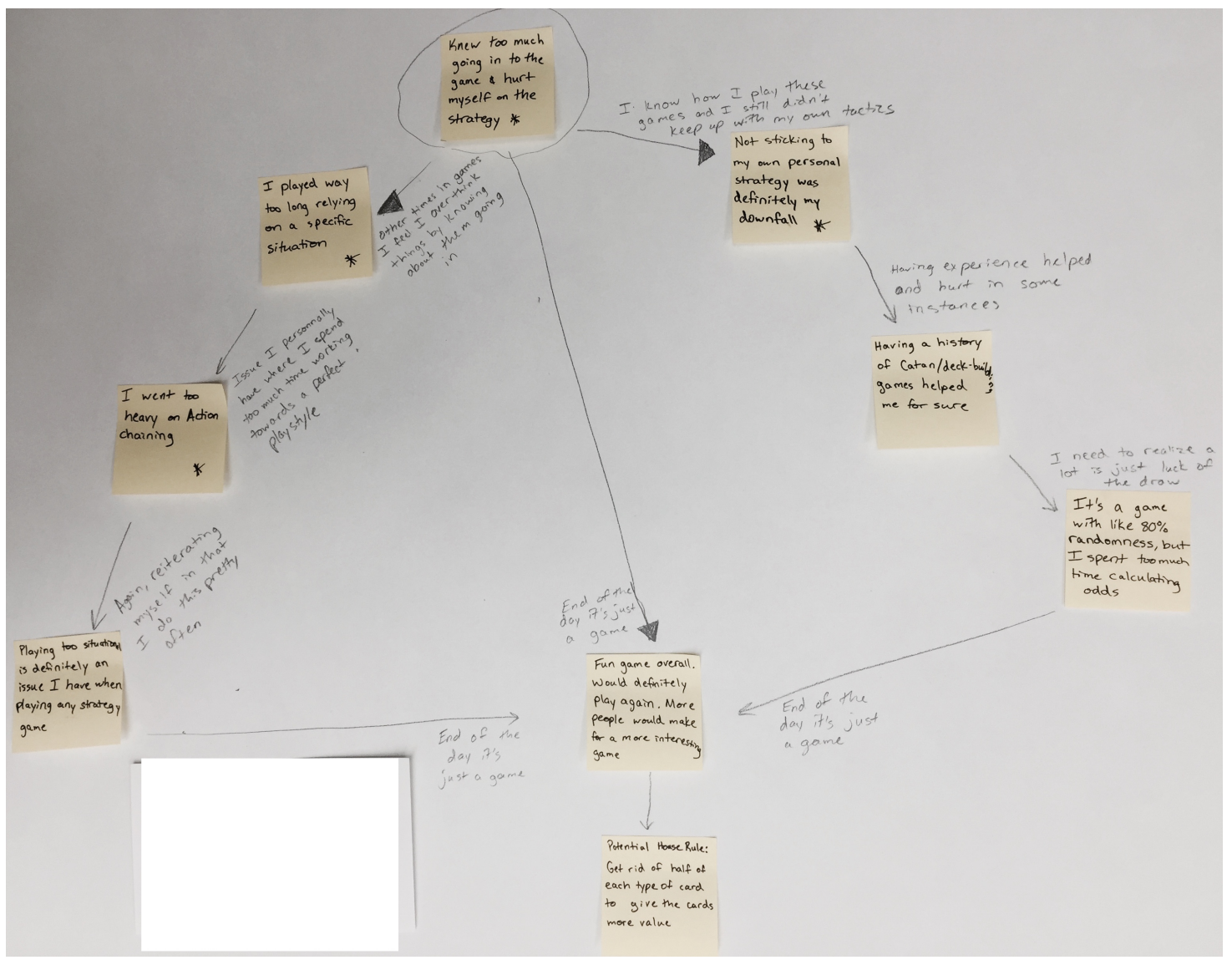

Cognitive map 13 


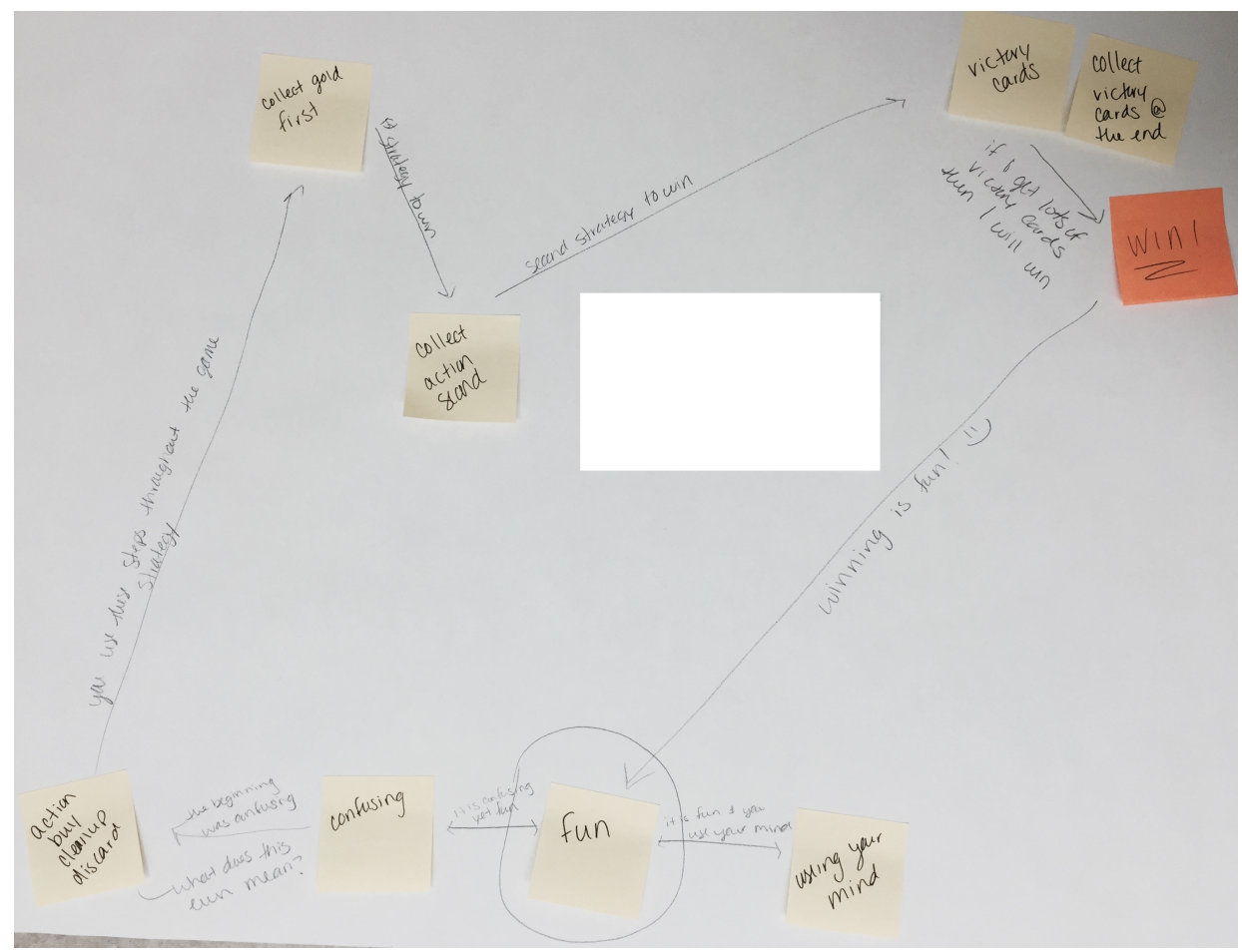

\section{Cognitive map 14}

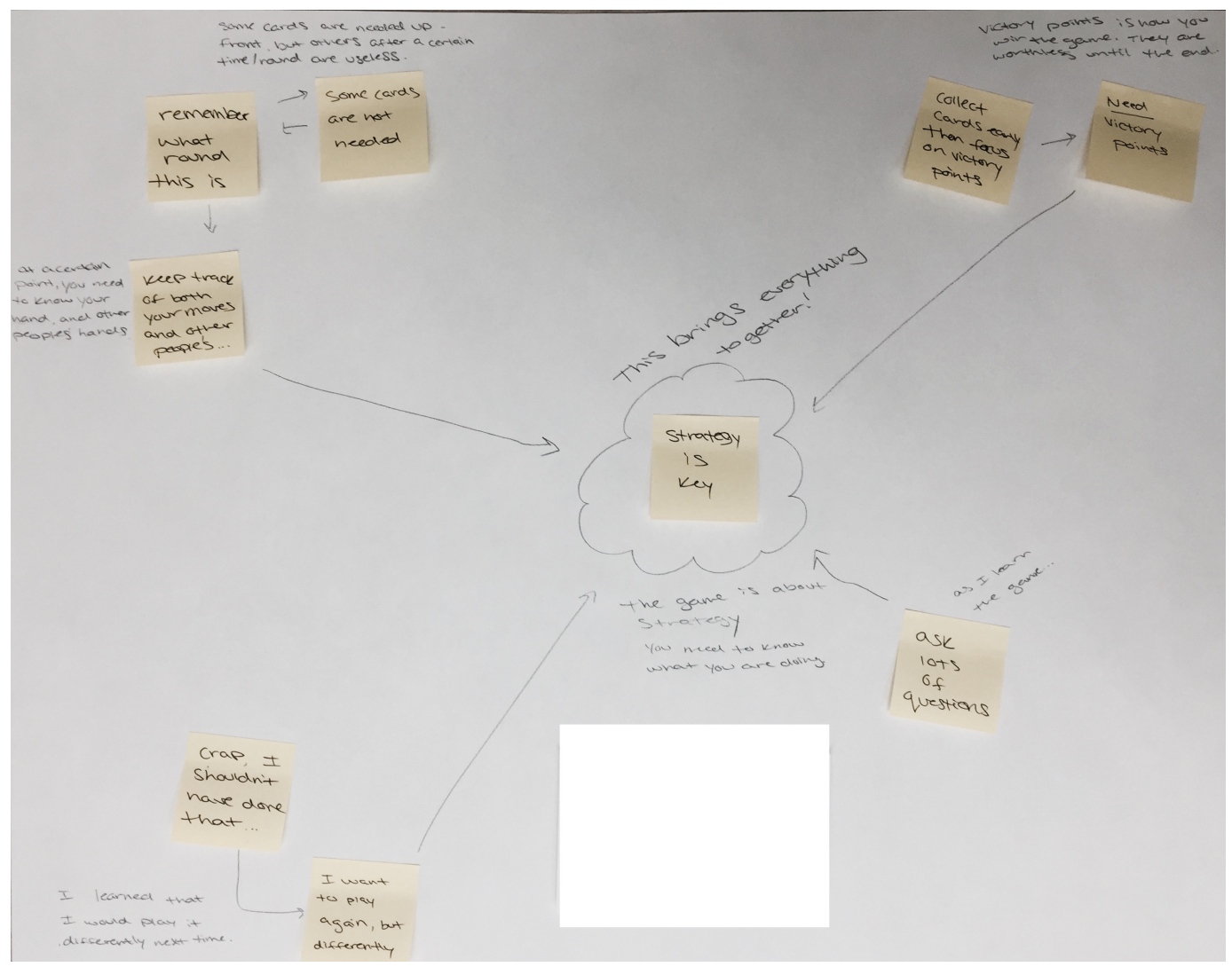

Cognitive map 15 


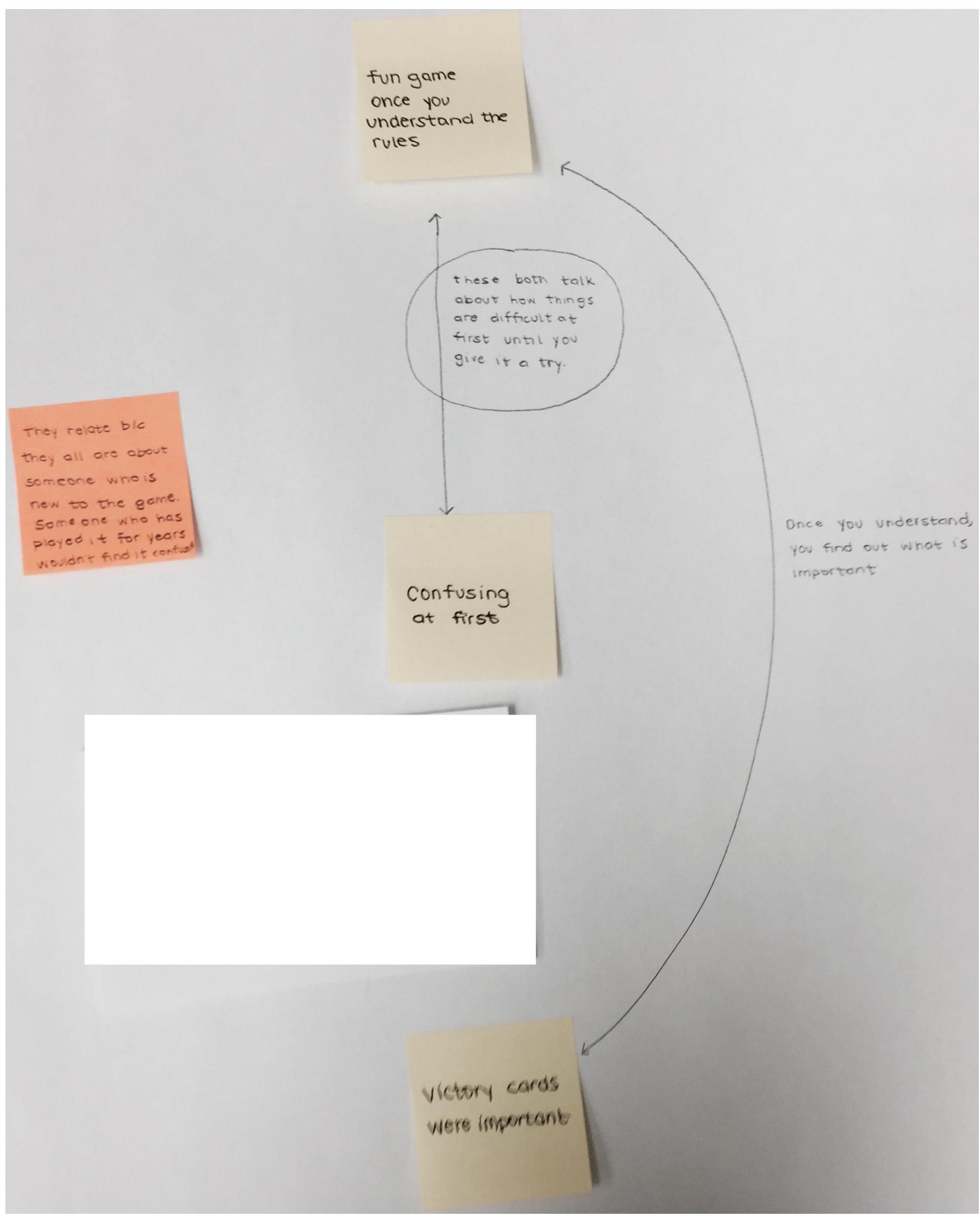

Cognitive map 16 


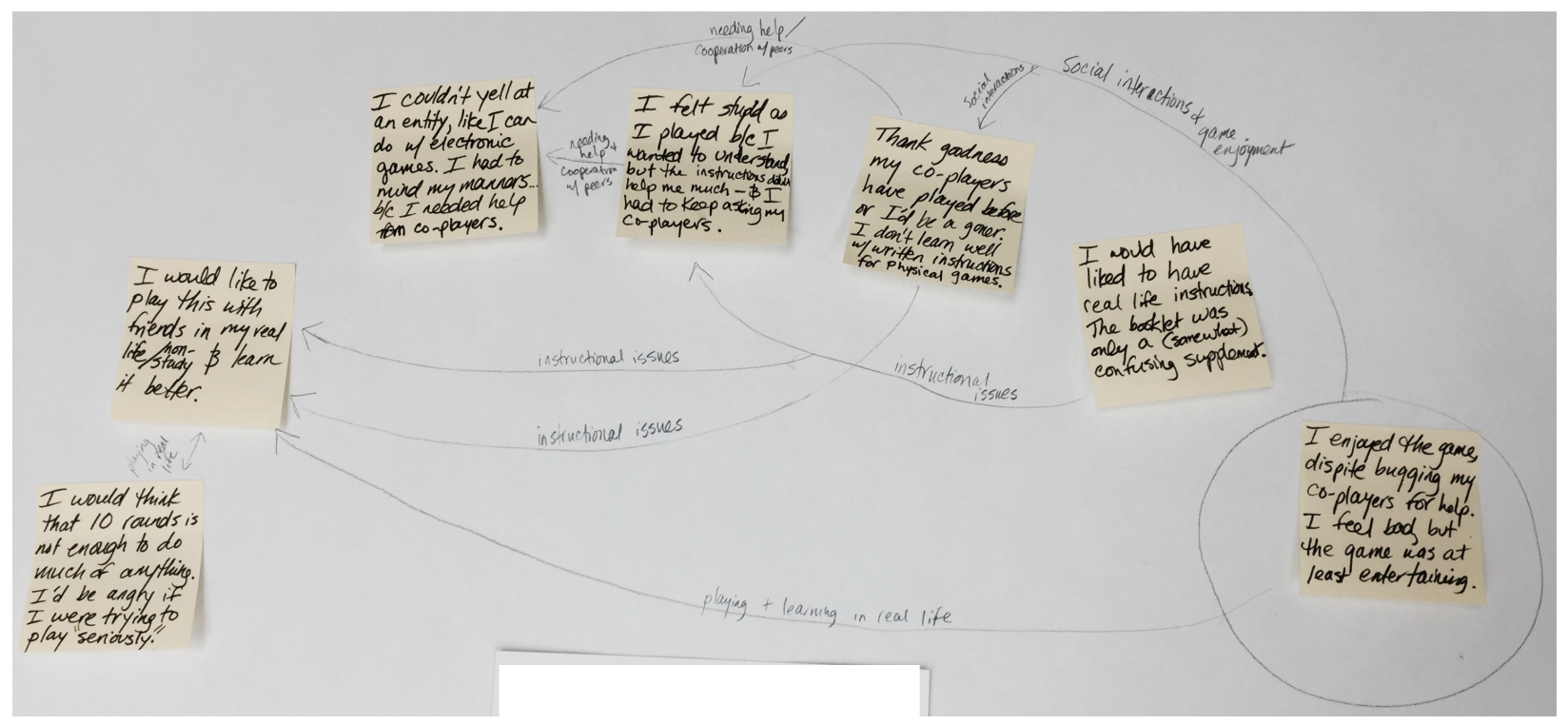

\section{Cognitive map 17}

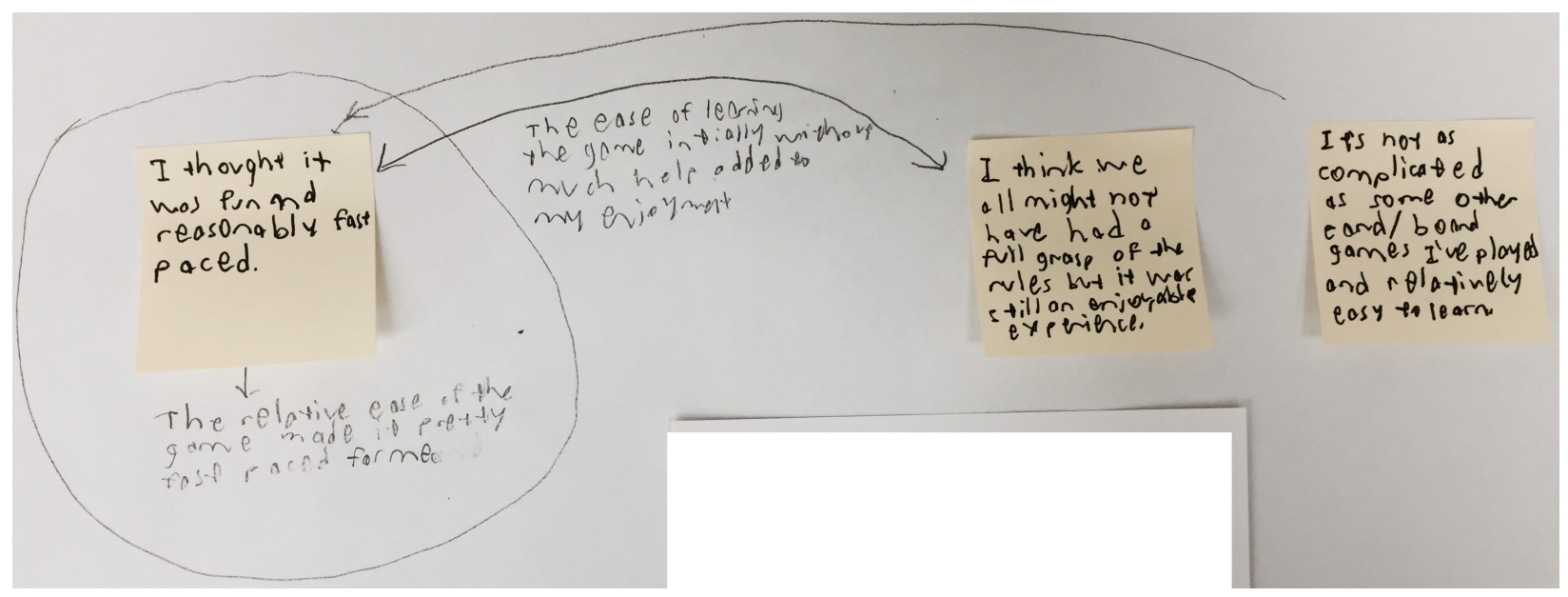

Cognitive map 18 


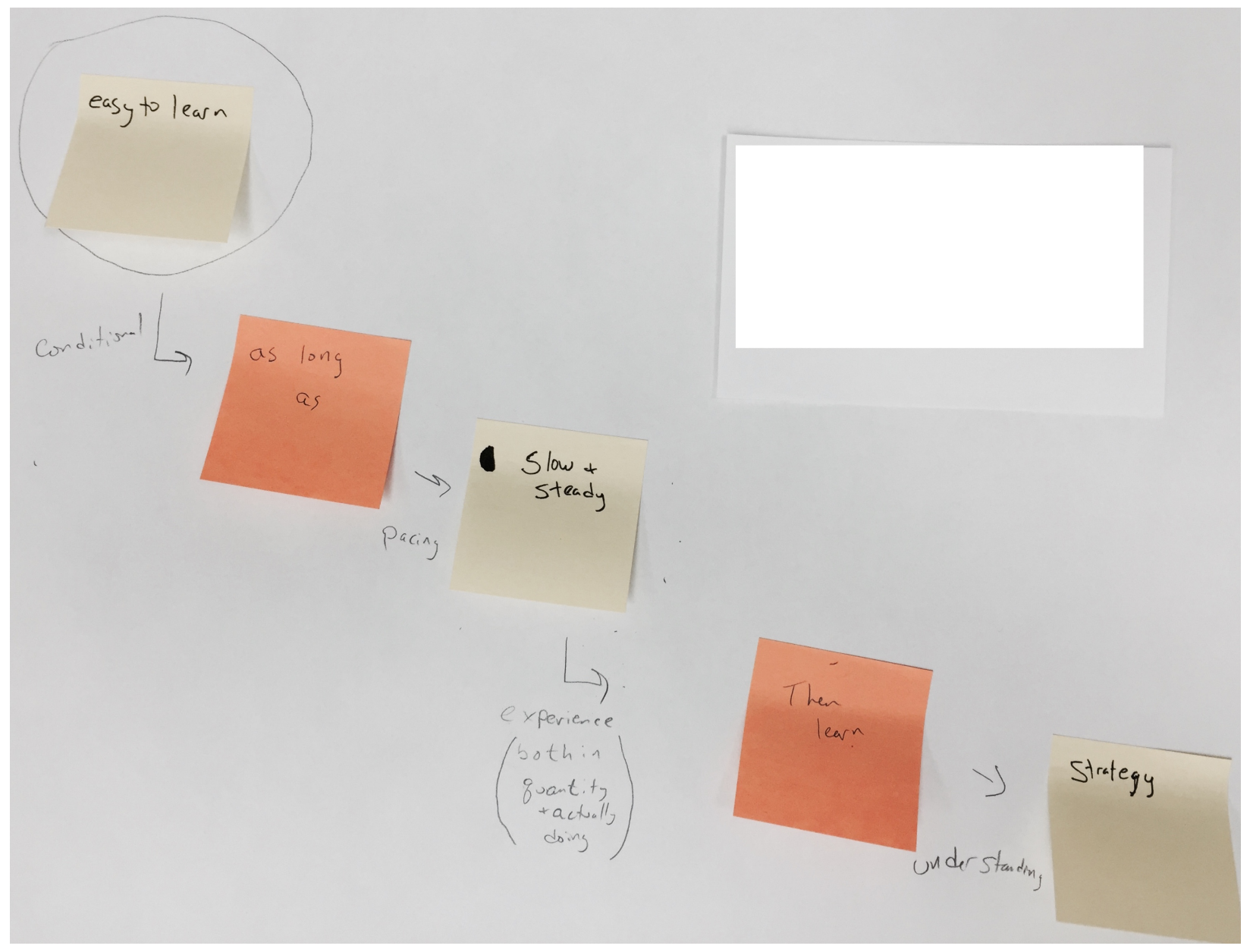

Cognitive map 19

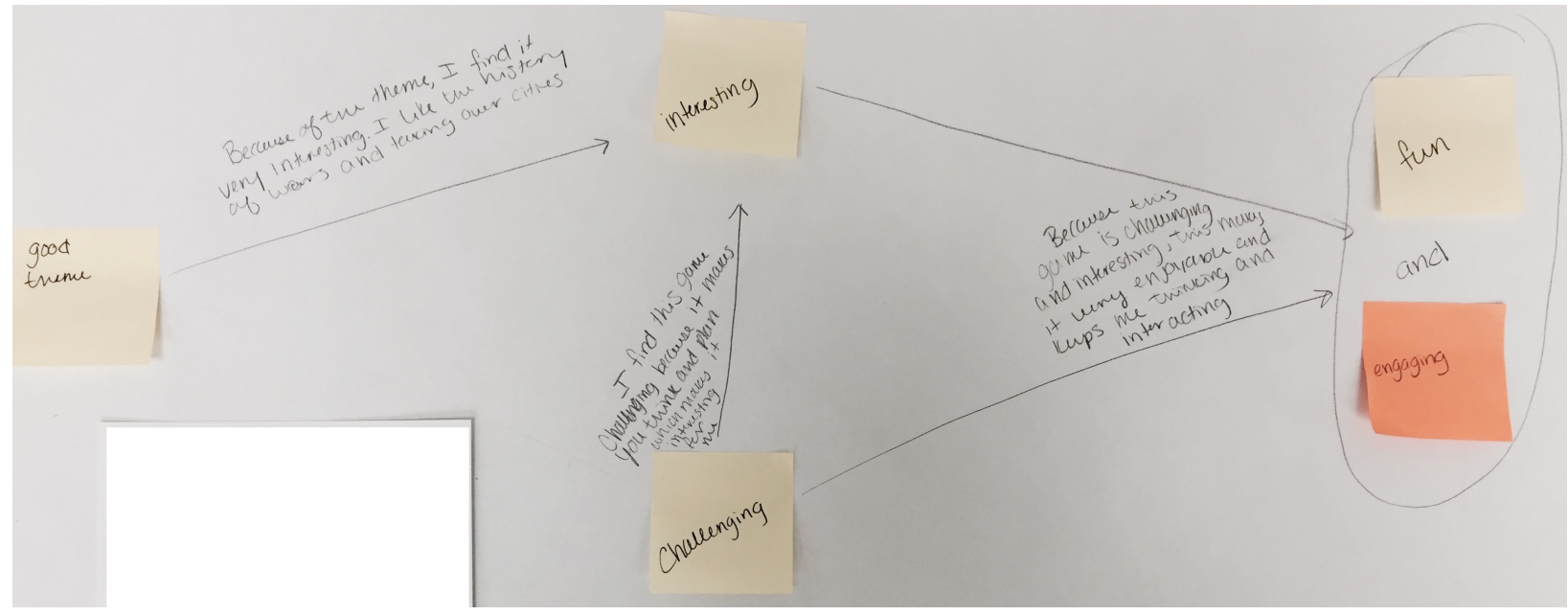

Cognitive map 20 
I do feel an thouph

only 10 turns is

a bit shirt to

get a good feel

for the game

and the others

playstyles.
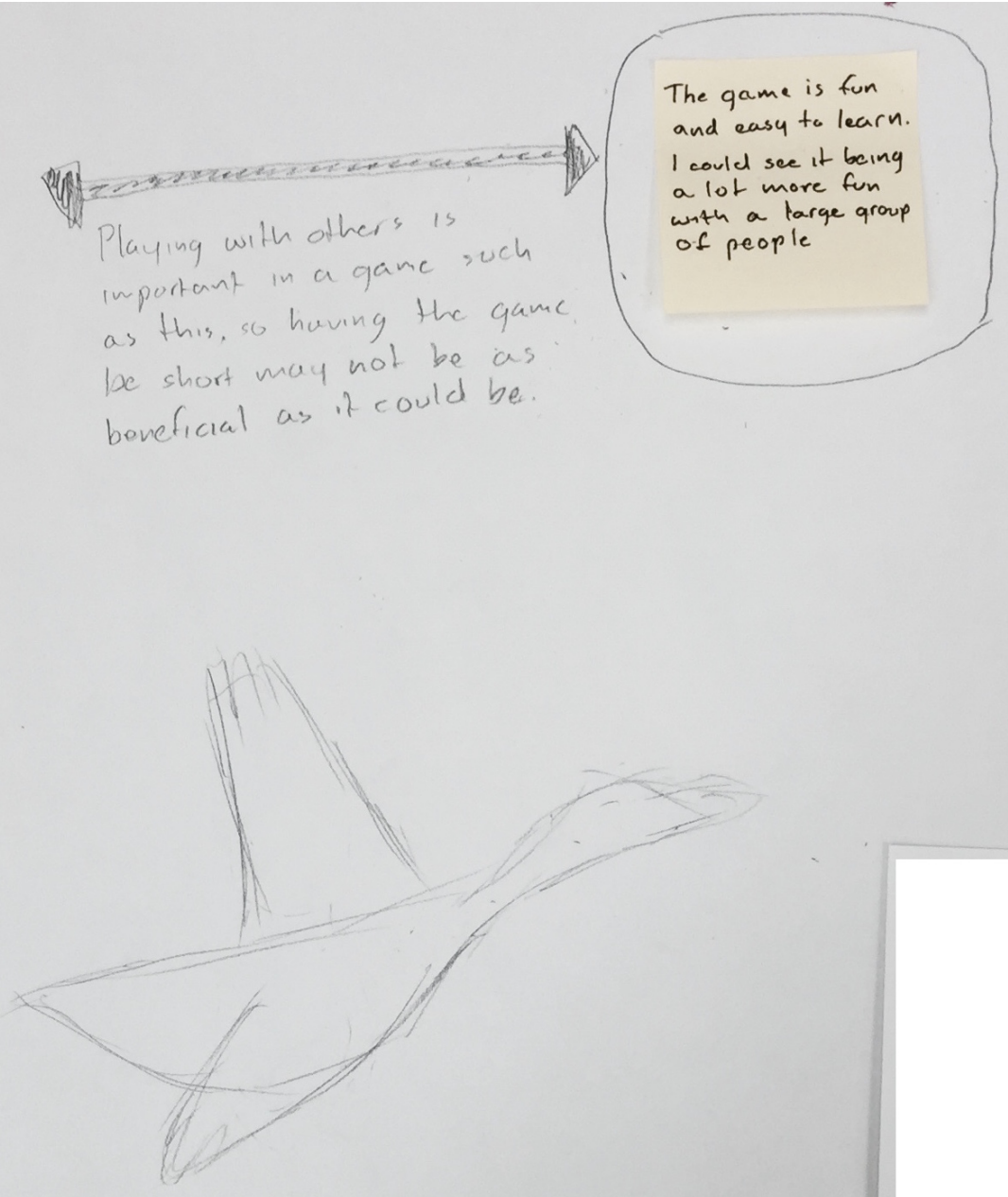

\section{Ensuring that each card for the action phase is played in the right order is important in maximazing your own progress}

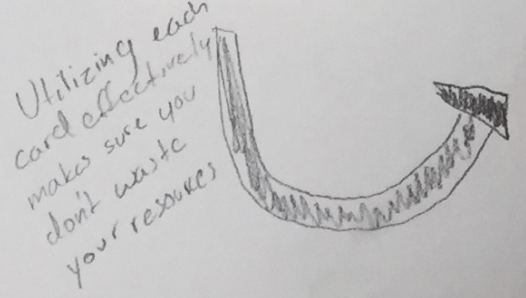

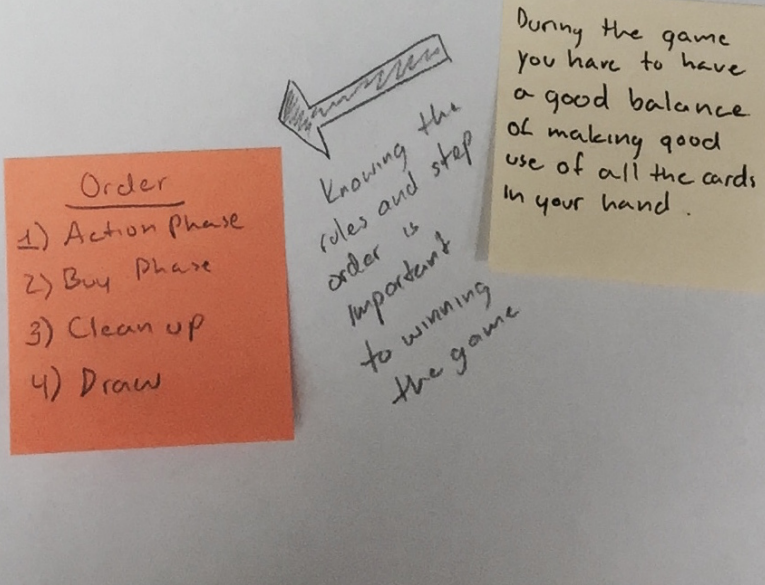

Cognitive map 21 


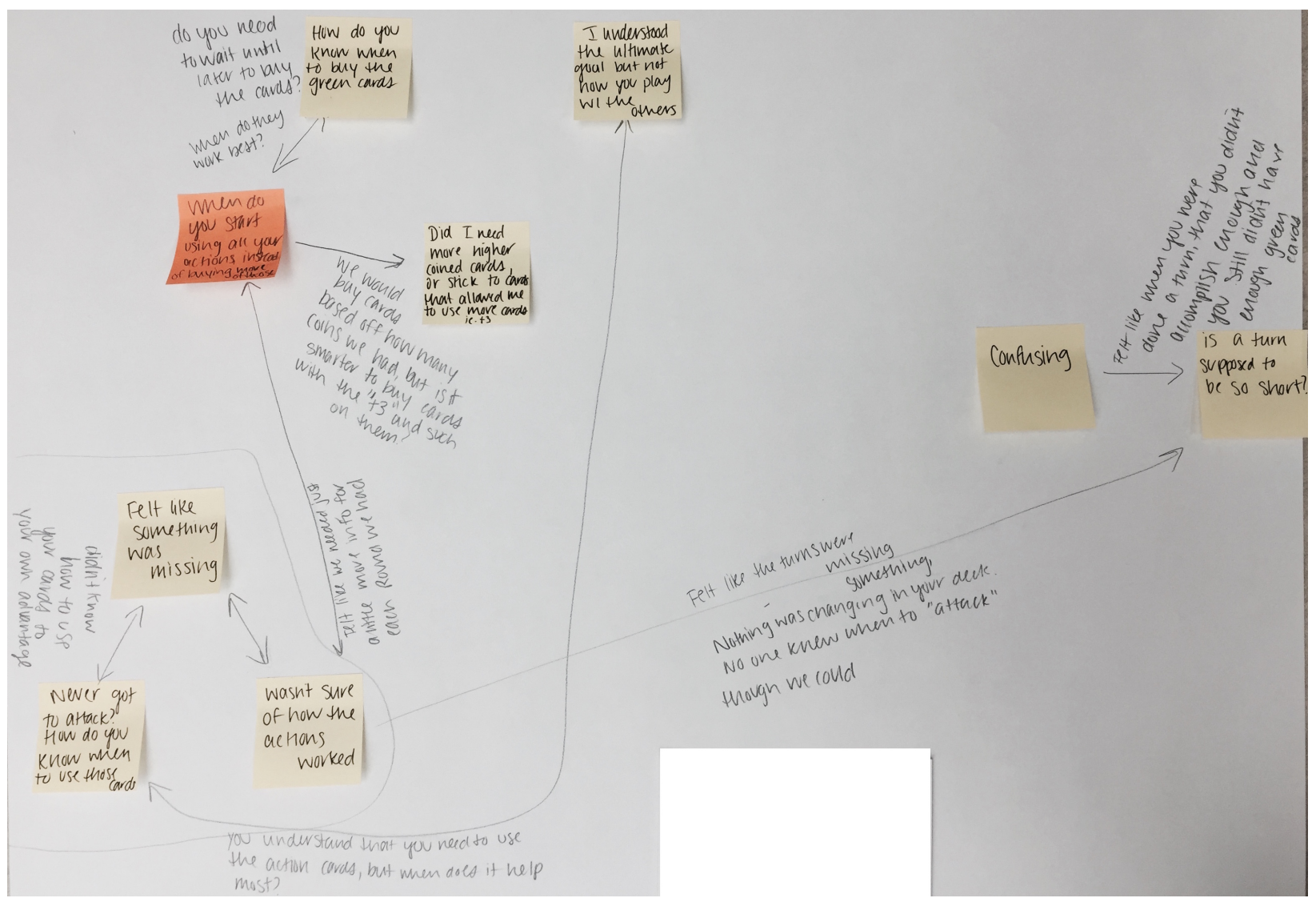

\section{Cognitive map 22}

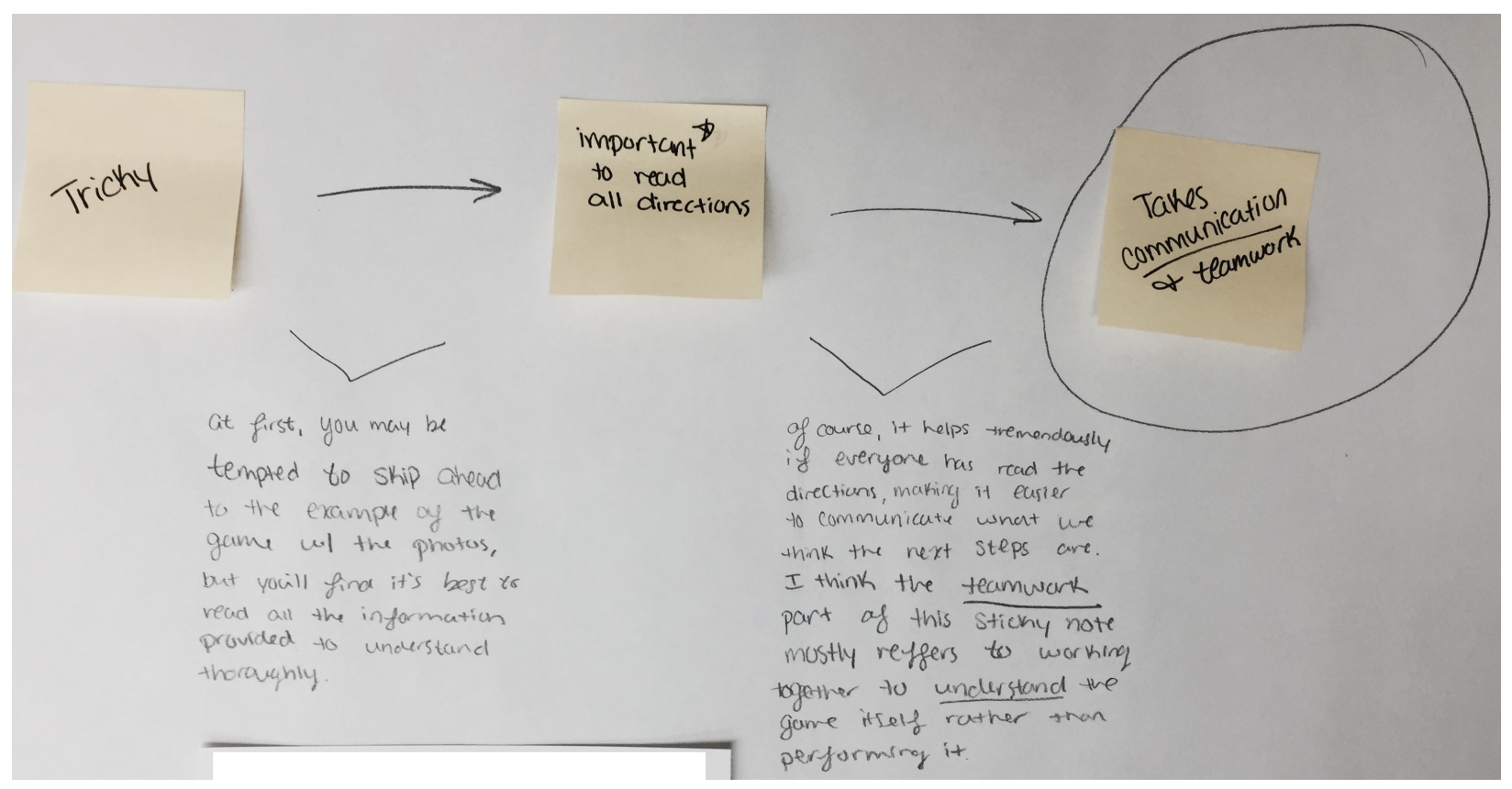

Cognitive map 23 


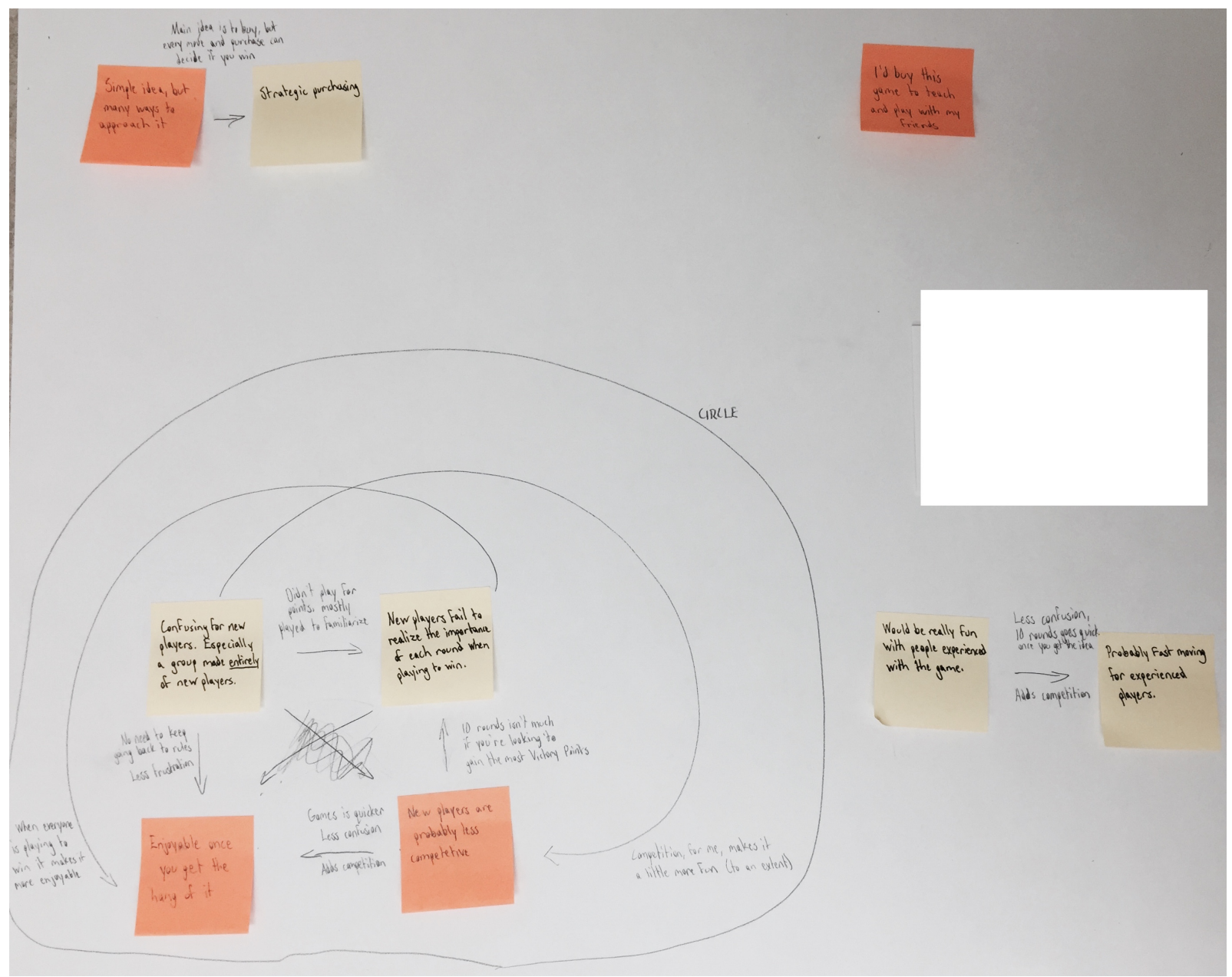

Cognitive map 24

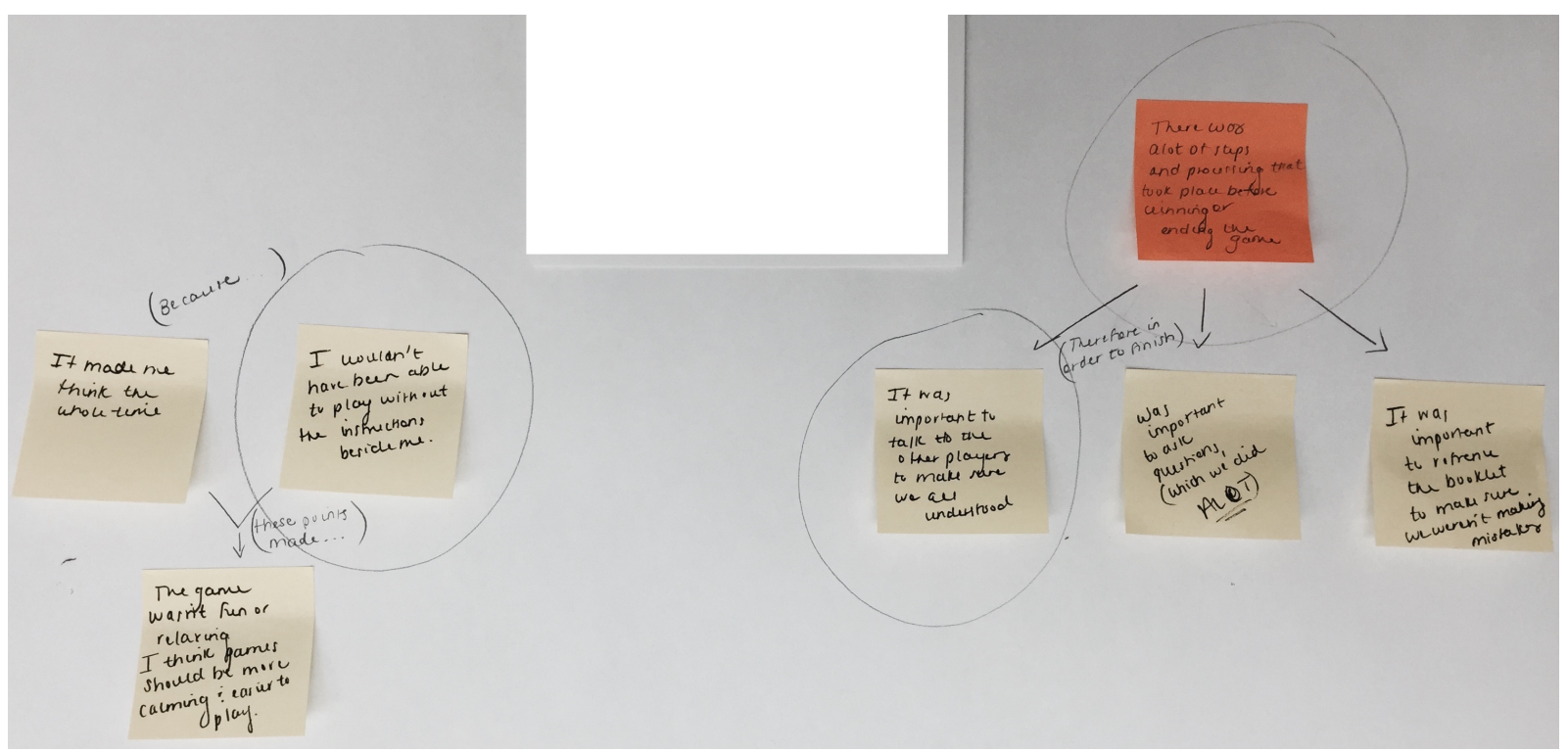

Cognitive map 25 


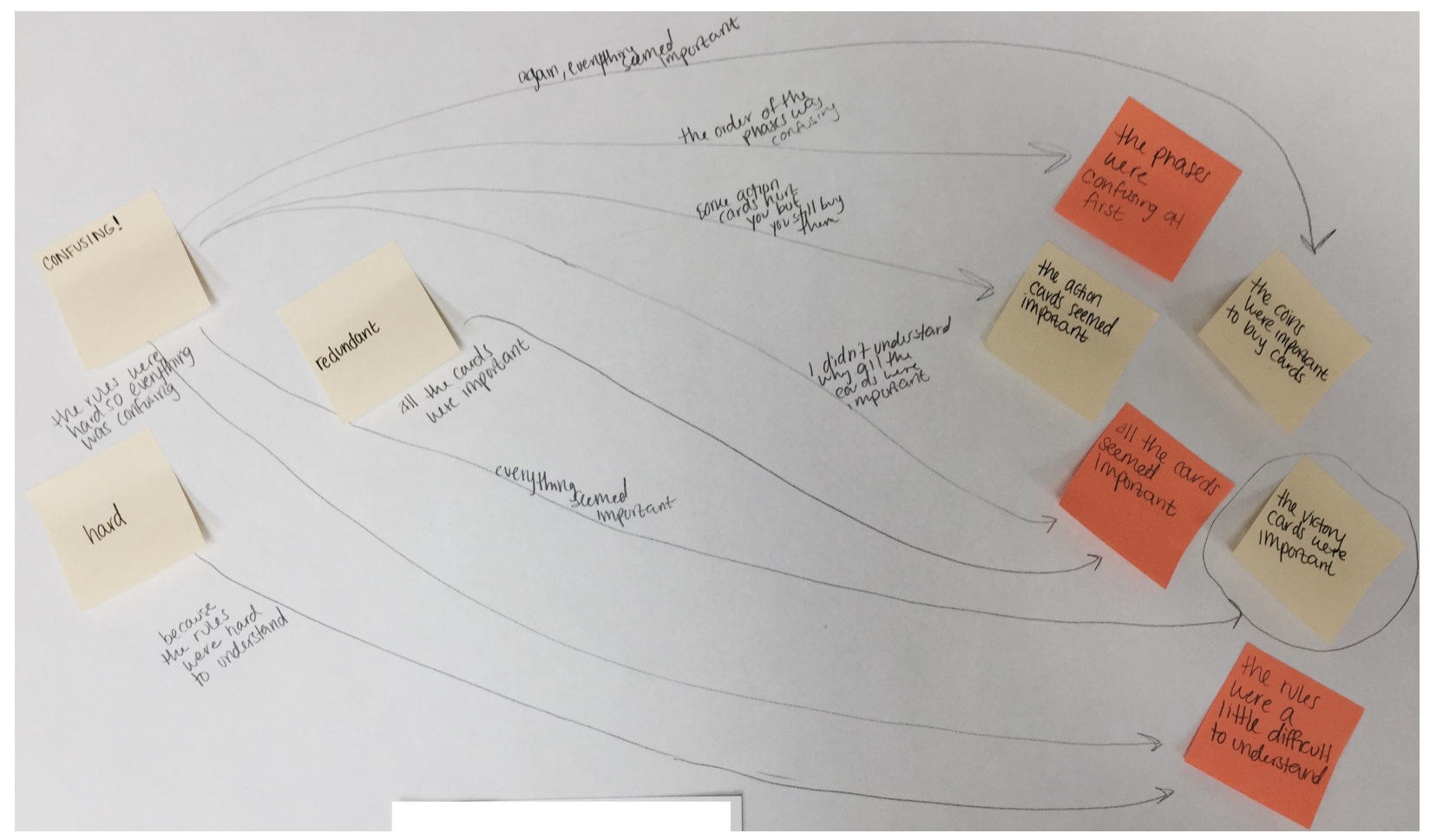

Cognitive map 26

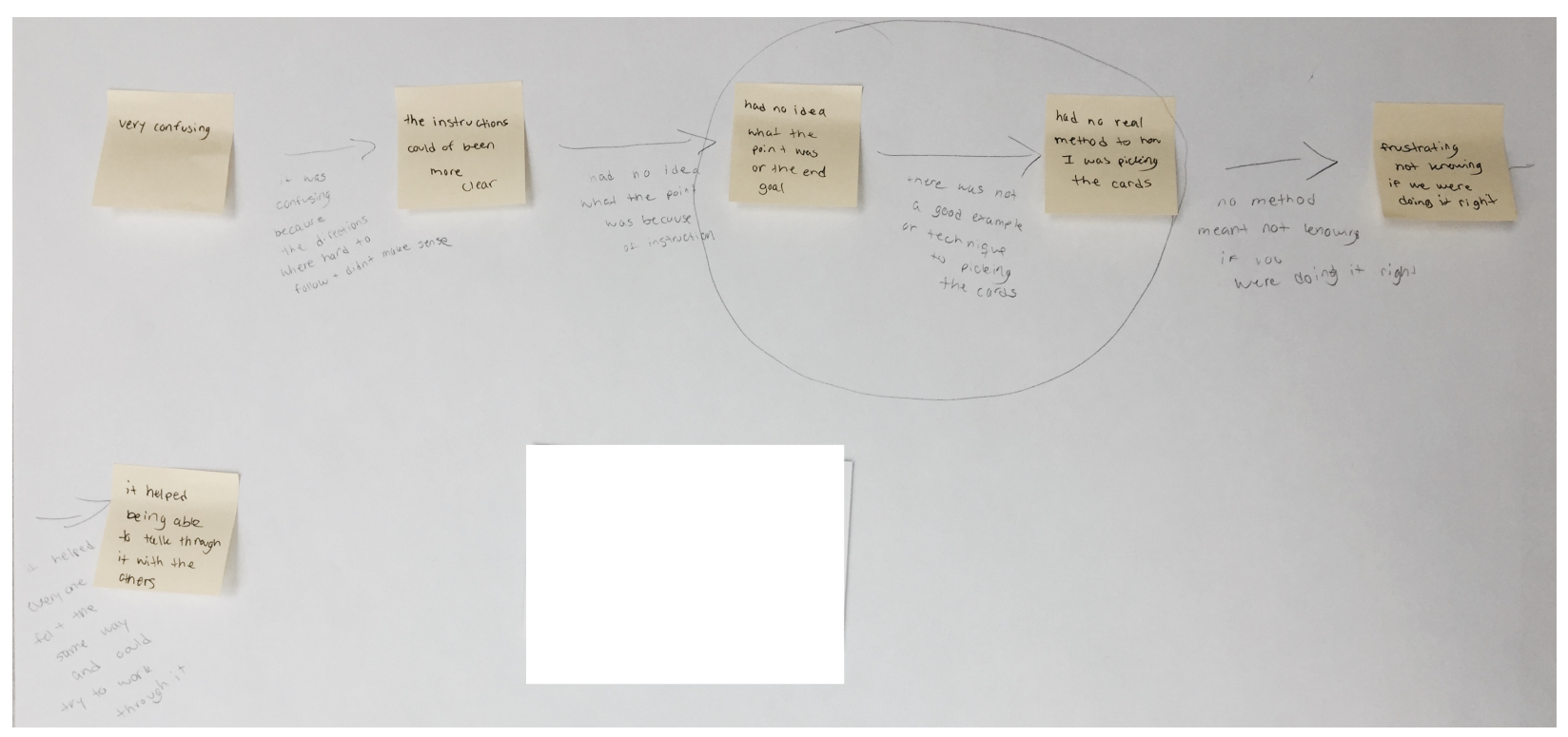

Cognitive map 27 


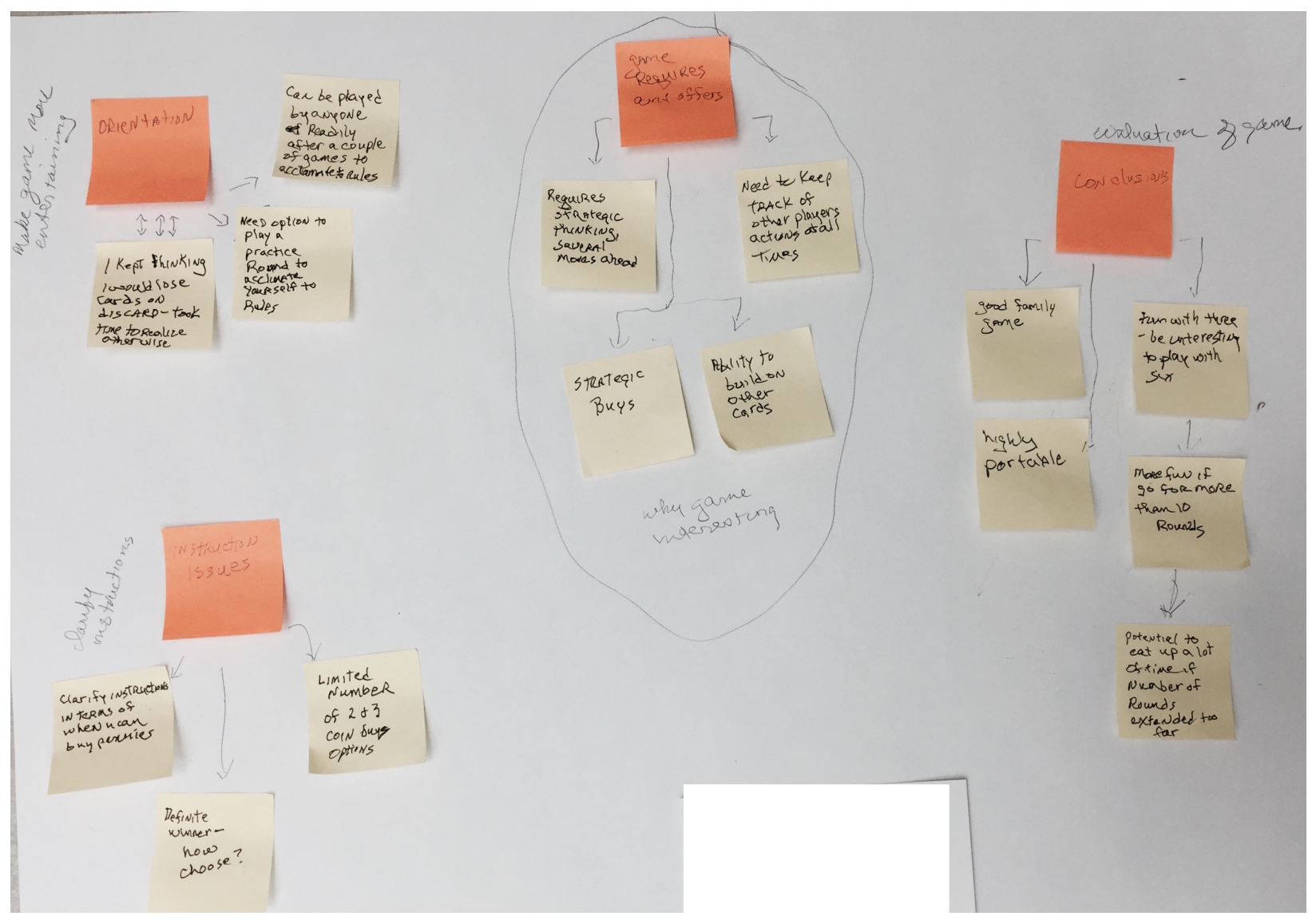

Cognitive map 28 


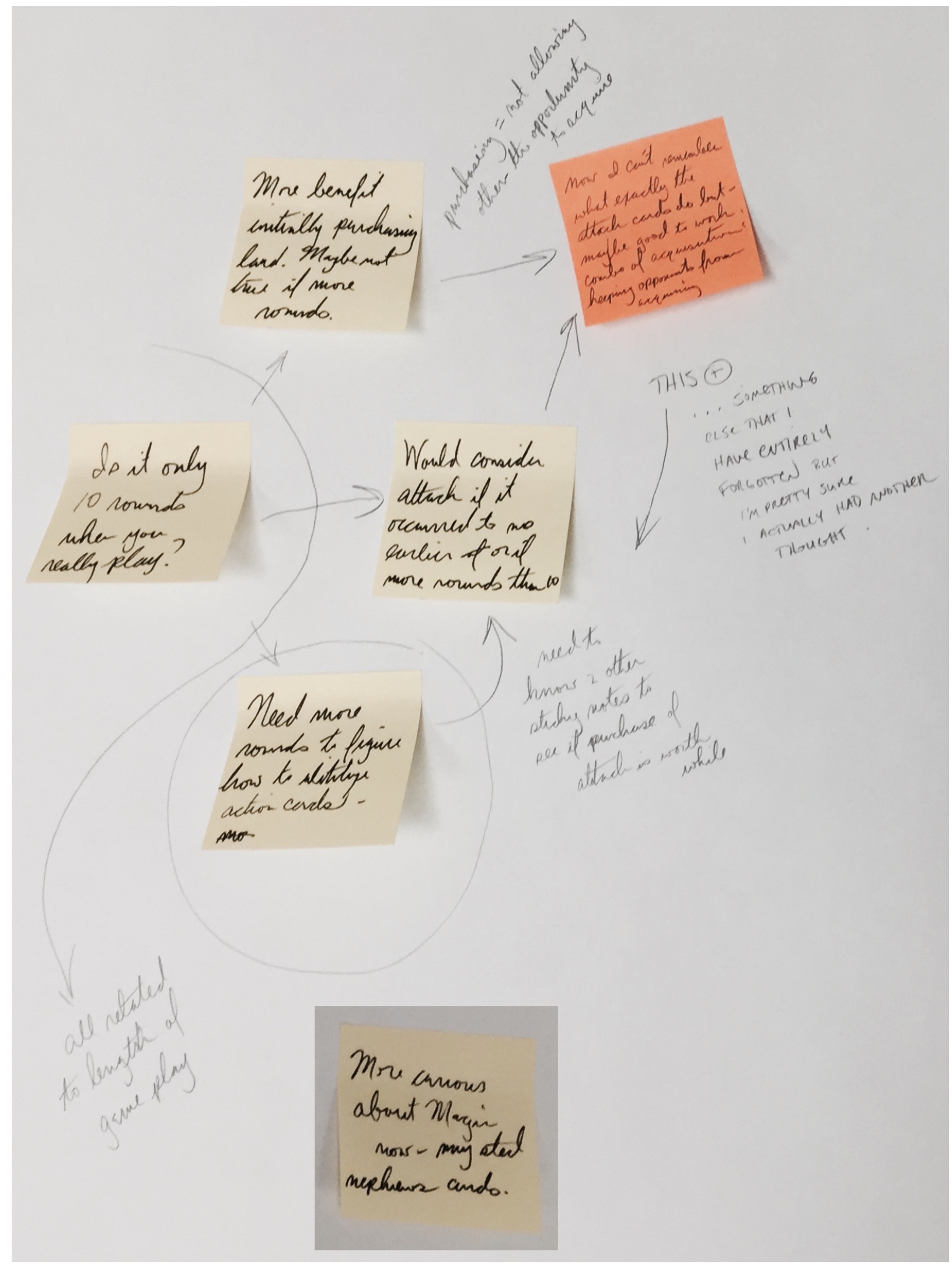

Cognitive map 29 


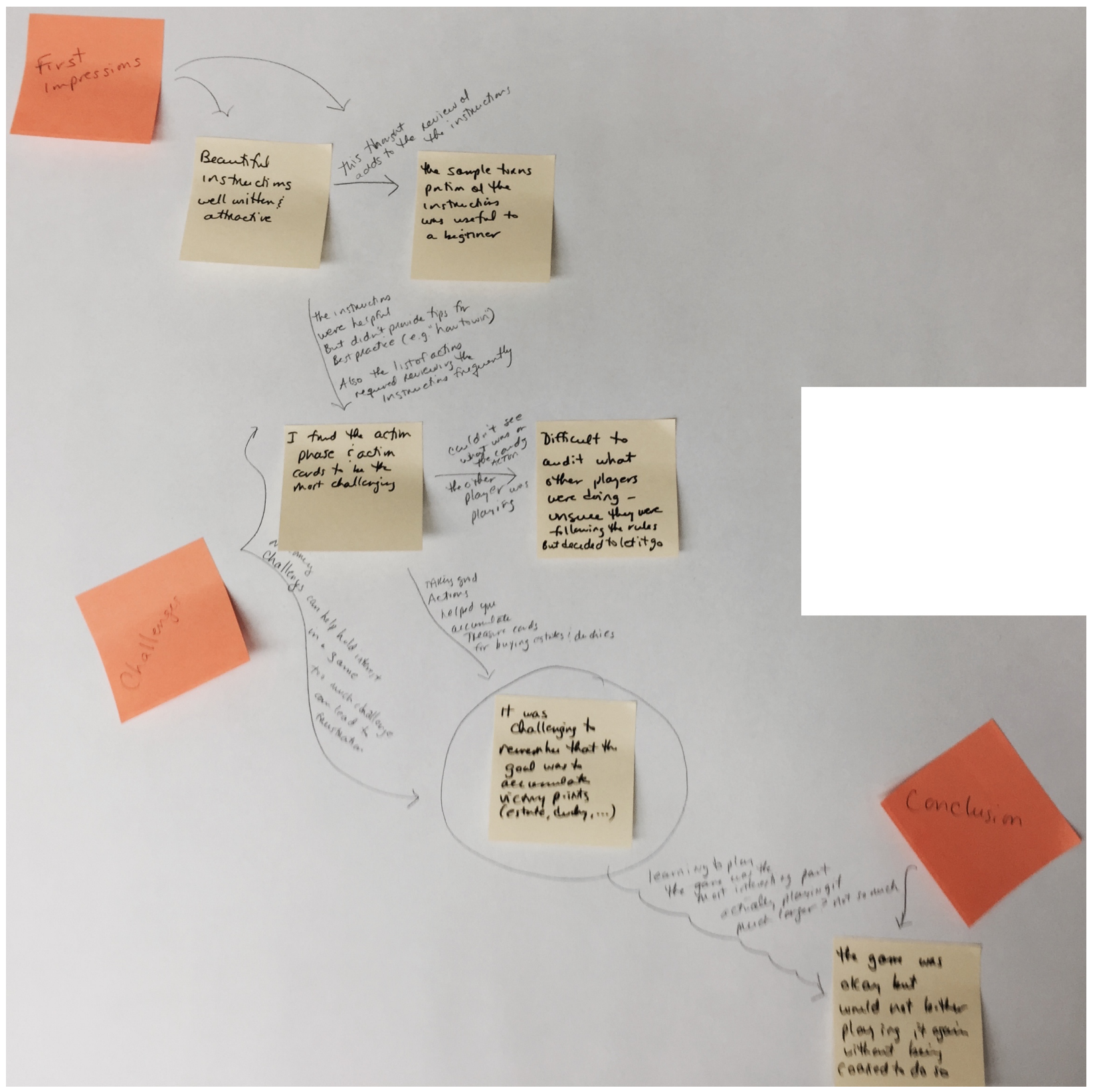

Cognitive map 30 


\section{Appendix G: Codebook: Complex Relationship Variables}

This codebook describes the coding rules for content analyzing cognitive maps of systems for relationships between entities that are typical of complex systems. Specifically, in this study this codebook is to be applied to cognitive maps of the analog game, Dominion. Identifying the presence or absence of these relationships in cognitive maps of an analog game will help to understand which kinds of relationships individuals find salient and include in their mental models of systems without special training.

Coding involves identifying whether data match conceptualizations of these types of relationships. As described in Design, Procedure, and Data Collection, pp. 26 - 31, data in this dataset has several parts: a) descriptions of entities, b) arrows drawn between entities to indicate relationships, and c) descriptions associated with these arrows to describe these relationships in more detail.

First code the relationships between two descriptions of entities. These are tie-level variables. To code this data, first read and fully understand the two descriptions of entities that are being connected. Then, consider the direction of the arrow connecting these entities. Read and fully understand the description of the relationship between the entities, taking into account this arrow. The written description should take primacy over the direction of the arrow. Next, consider how the two descriptions of entities are related in light of the arrow and relationship description. Finally, considering the three tie-level variables, code 1 or 0 for presence or absence of these three variables. Because each relationship may describe multiple of these relationships, multiple tie-level variables may be coded 1 .

After coding all tie-level variables, next code relationships that potentially include more than two descriptions of entities. These are structure-level variables. Structure-level variables 
identify ties, described above, that are part of larger cognitive map structures. Examine the photo of each cognitive map in turn. Use transcriptions as the final source for interpreting the writing in these maps. Examine each tie within the cognitive map in turn to decide whether it may be a part of one of the larger structures identified below under Structure-level Variables. Assess the first structure-level variable (Indirect) before the second (Feedback). If it might be part of one of these structures, examine the descriptions of entities, arrows, and descriptions of relationshipsas described above-for every tie that may be a part of these structures. Considering all of these, code 1 or 0 for presence or absence of these two variables. Because each relationship may be a part of multiple structures, multiple structure-level variables may be coded 1 .

An important concept in the coding rules below involves semantic connection. Semantic connection is based on what is written in descriptions of the relationships between entities, and is the explicit reference to these entity descriptions within the relationship description.

\section{Tie-level Variables}

Tie-level variables are identified between two descriptions of entities connected by one arrow. This data has been transcribed.

\section{Variable 1: Unlabeled}

Some relationships between descriptions of entities were indicated with an arrow, but were not described. In this case, code a 1 . If a relationship is coded as a 1 for this variable, do not code it a 1 for any other variable.

When to use: Any undescribed relationship.

When not to use: If there is any description of the relationship, code 0 .

$$
\begin{aligned}
& 1=\text { Unlabeled } \\
& 0=\text { Labeled }
\end{aligned}
$$




\section{Variable 2: Stochastic}

Stochastic relationships are relationships between entities that involve randomness (Resnick \& Wilensky, 1998). Because of randomness, stochastic relationships are nondeterministic. A given event, action, or input may yield a range of possible consequences, outcomes, or outputs. Which outcome, the magnitude of the consequence, or the number of outputs may potentially have a knowable_ - or potentially even fixed_-probability distribution. Stochastic relationships may be linear or nonlinear (see variable 4). Whereas linear/nonlinear relationships have to do with changing input-output ratios, stochastic relationships have to do with randomness.

When to use: Any mention of randomness, variable or multiple outcomes or consequences, probability, or chance in a tie description should be coded 1 . If randomness, variable or multiple outcomes or consequences, probability, or chance are mentioned in an entity description, code 1 if and only if some part of this description is semantically connected in the link description. Otherwise, code 0. Example:

\begin{tabular}{|c|c|c|}
\hline $\begin{array}{c}\text { Having a history of } \\
\text { Catan/deck-building } \\
\text { games helped me } \\
\text { for sure }\end{array}$ & $\begin{array}{c}\text { I need to realize a lot is } \\
\text { just luck of the draw }\end{array}$ & $\begin{array}{c}\text { It's a game with like } \\
80 \% \text { randomness, but } \\
\text { I spent too much time } \\
\text { calculating the odds }\end{array}$ \\
\hline
\end{tabular}

When not to use: Any relationship description that does not mention the above.

Descriptions of ordered events or outcomes, such as "first" or "second," should be coded 0. Conditional statements, such as "if a then b, but if $x$ then $y$," should be coded 0 . When in doubt, code 0. Example: 


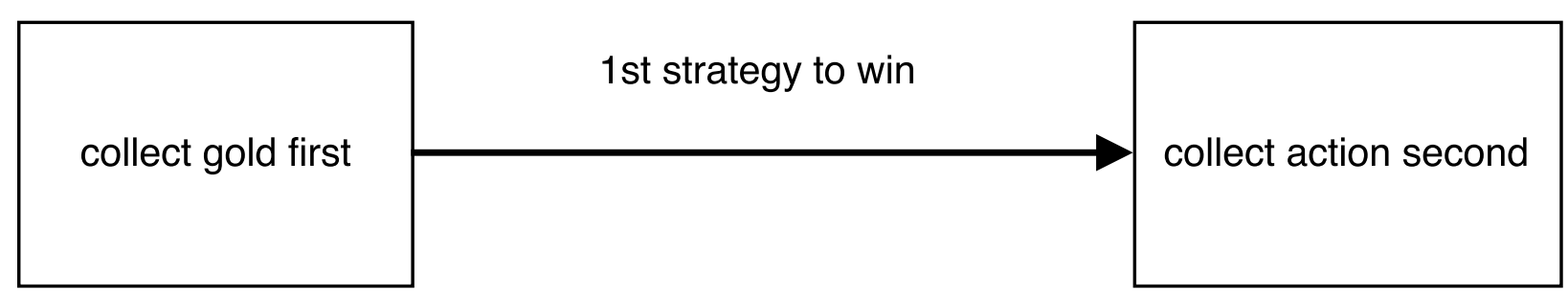

$1=$ Stochastic relationship

$0=$ Non-stochastic relationship

\section{Variable 3: Delayed}

Delayed relationships are relationships that are separated temporally (Groesser \& Schaffernicht, 2012; Landriscina, 2013; Sweeney \& Sterman, 2007). In a delayed relationship, the consequence, outcome, or output of an event, action, or input occurs not instantly, but at some later point in time. This time lapse is the central characteristic of delayed relationships.

When to use: Any relationship description that mentions the intervening time after an event or input and before some outcome or output, including words that reference the passage of time like "later." If delay is described in a node, code 1 if and only if the node is semantically connected in a tie description. Example:

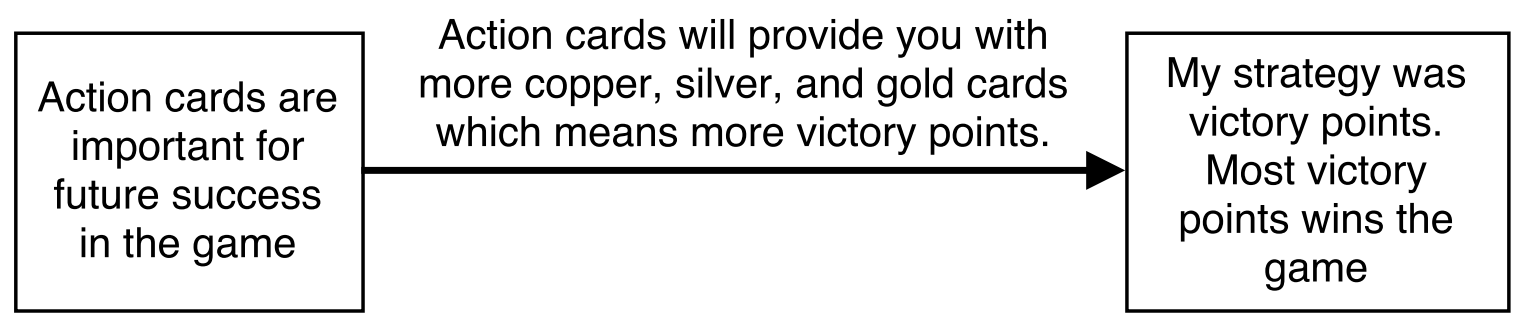

When not to use: Any relationship that does not mention the above. Simply mentioning a temporal order (e.g., "first," "second," "after") is not enough to qualify as a delayed relationship. When in doubt, code 0. Example: 


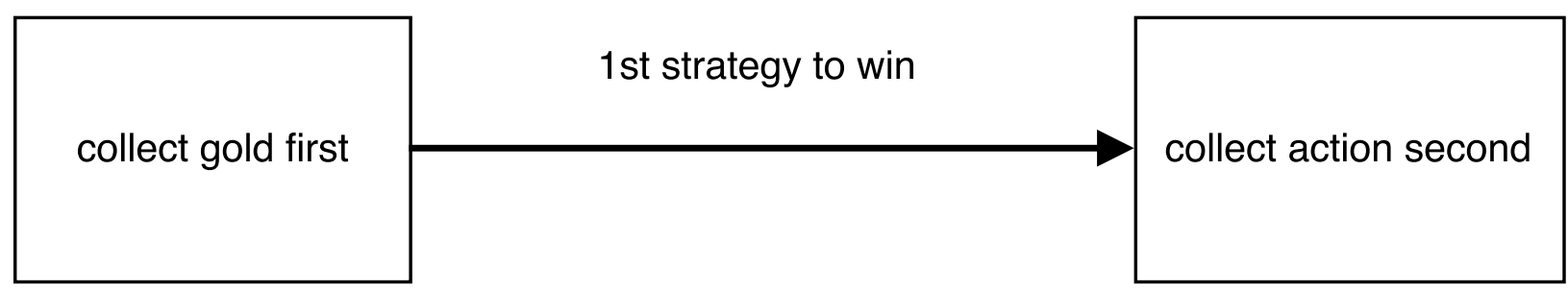

$1=$ Delayed relationship

$0=$ Non-delayed relationship

\section{Variable 4: Nonlinear}

Nonlinear relationships are those in which outcomes are disproportional to the input (Groesser \& Schaffernicht, 2012; Hmelo-Silver \& Pfeffer, 2004). In other words, the magnitude of an outcome or the number of outputs changes at a different rate depending on the magnitude of the event or input. Example of nonlinear relationships include exponential and logarithmic relationships. Nonlinear relationships may be stochastic or deterministic (see variable 2). Whereas stochastic relationships have to do with randomness, linear/nonlinear relationships have to do with changing input-output ratios.

When to use: Any description of dis-proportional relationships in relationship descriptions, including mentions of small inputs and large outputs or vice versa, should be coded 1. May be described in terms of proportions, comparisons of quantities/magnitudes, or words like "more and less." Some difference between magnitude of inputs and outputs (e.g., small input, large output, or vice versa) must be stated or strongly implied. If this disproportionality is mentioned in an entity description, the relationship should be coded 1 if and only if that relationship description semantically connects to the entity description. Example: 


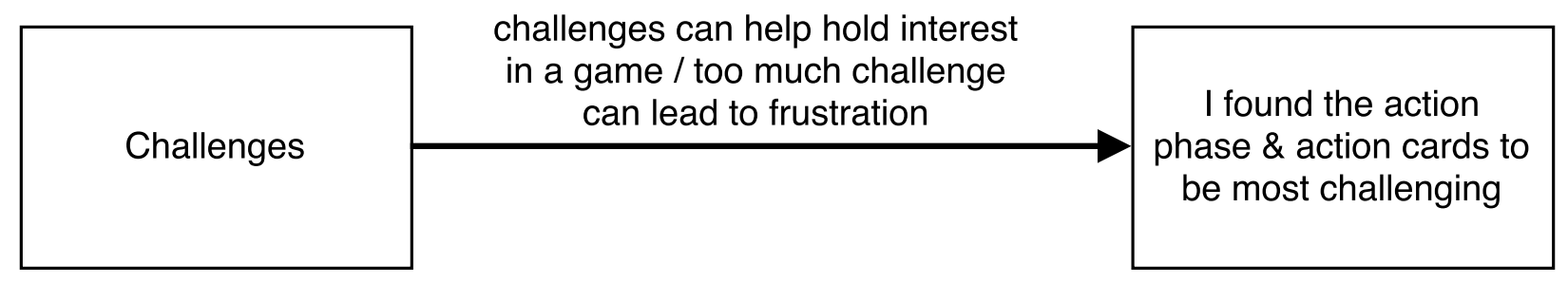

When not to use: Any relationship that does not mention the above. Simply mentioning a magnitude or quantity—or even multiple magnitudes or quantities—does not qualify. When in doubt, code 0. Example:

The more control over the game you had went hand-in-hand with how much power you could or ended up having

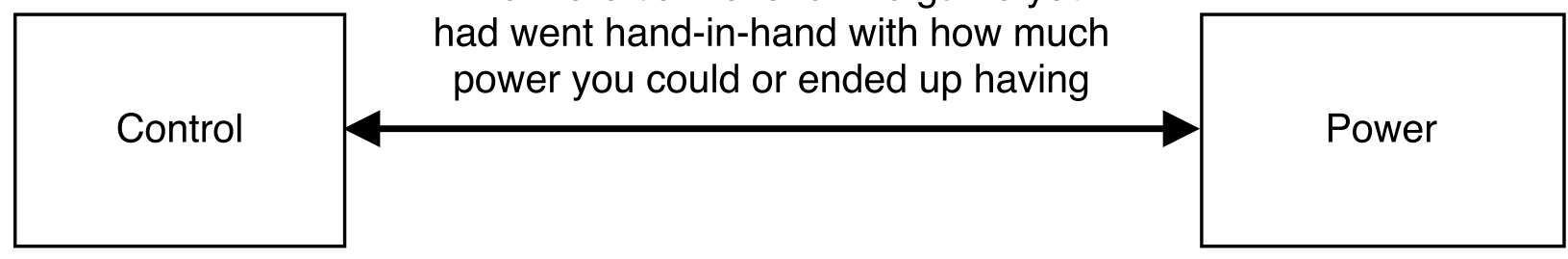

$$
\begin{aligned}
& 1=\text { Nonlinear relationship } \\
& 0=\text { Non-nonlinear relationship }
\end{aligned}
$$

\section{Structure-level Variables}

Tie-level variables are those that cannot be identified by examining solely the relationship between two descriptions of entities connected by one arrow. Instead, it requires analyzing participants' overall cognitive maps more holistically. Structure-level variables incorporate more than one relationship between entities. Although this data has been transcribed, photographs of these cognitive maps must be examined to identify these larger structures and triangulate between the overall structure and the individual entities and relationships that comprise it. 


\section{Variable 5: Indirect}

Indirect relationships are those in which an entity influences another entity via at least one other. Instead of A directly influencing B, A influences X, and X influences B.

When to use: In order for 3+ entities to be indirectly related, the relationships between A -> X must be semantically connected, and the relationship between X -> B must be semantically connected. Moreover, these relationships must be directional and in the same direction, such that A influences $\mathrm{X}$ and $\mathrm{X}$ influences $\mathrm{B}$. The direction of relationships described by text takes primacy over the direction of relationships implied by arrow directions. The same rules apply to indirect relationships that involve more than 3 entities, because they are all composed of 3-entity indirect relationships. Indirect relationships that begin and end with the same entity should be coded 1; for example, A -> X -> A. Example:

The confusion led to me

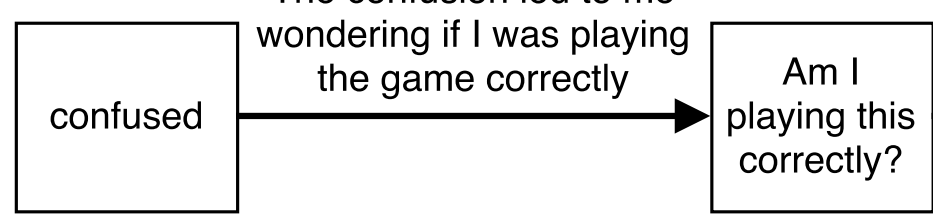

Me wondering if I was playing correctly caused me to feel stressed

When not to use: Multiple entity descriptions merely connected by a series of arrows does not qualify — entities must be semantically connected in the relationship description. Additionally, two entities influencing the same entity does not count $(\mathrm{A}->\mathrm{X}<-\mathrm{B})$. When in doubt, code 0. Example: 


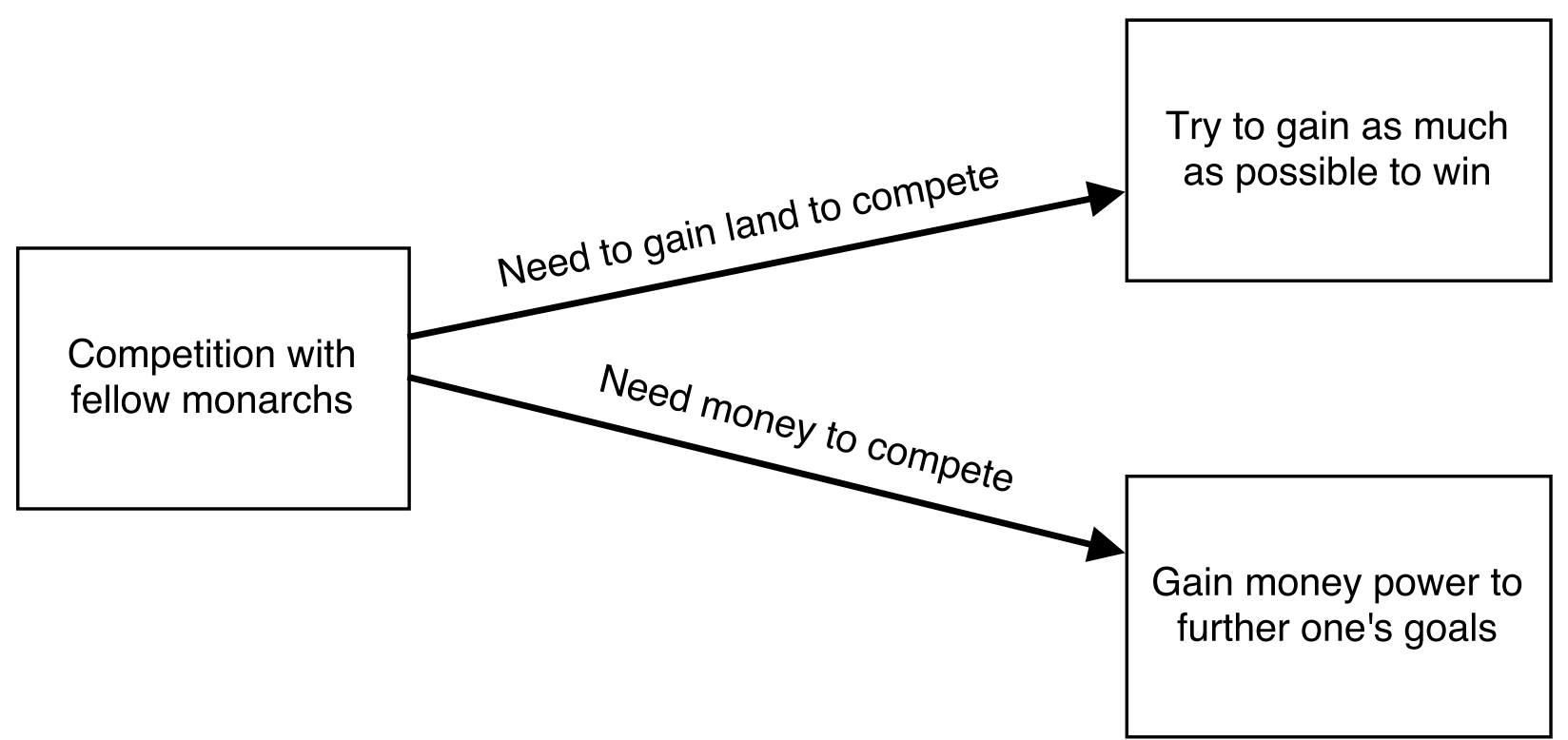

\section{Variable 6: Feedback}

Feedback loops involve an entity influencing itself (Eden et al., 1992; Groesser \& Schaffernicht, 2012; Jacobson \& Wilensky, 2006; Landriscina, 2013). An entity may directly influence itself. An entity may also influence itself indirectly (see variable 5). The direction of relationships described by text takes primacy over the direction of relationships implied by arrow directions.

When to use: To count as a feedback loop, the all entities must be semantically connected via relationship descriptions, and the direction of these relationships must be able to be traced away from an entity description and then back to the same entity description. The direction of relationships described by text takes primacy over the direction of relationships implied by arrow directions. Feedback loops may include only one entity that influences itself, two entities that influence each other, or 3+ entities that indirectly influence each other. Relationships may be coded 1 for both Indirect and Feedback. For potential feedback loops that include $3+$ entities, the full rules in Indirect must also be followed. Example: 


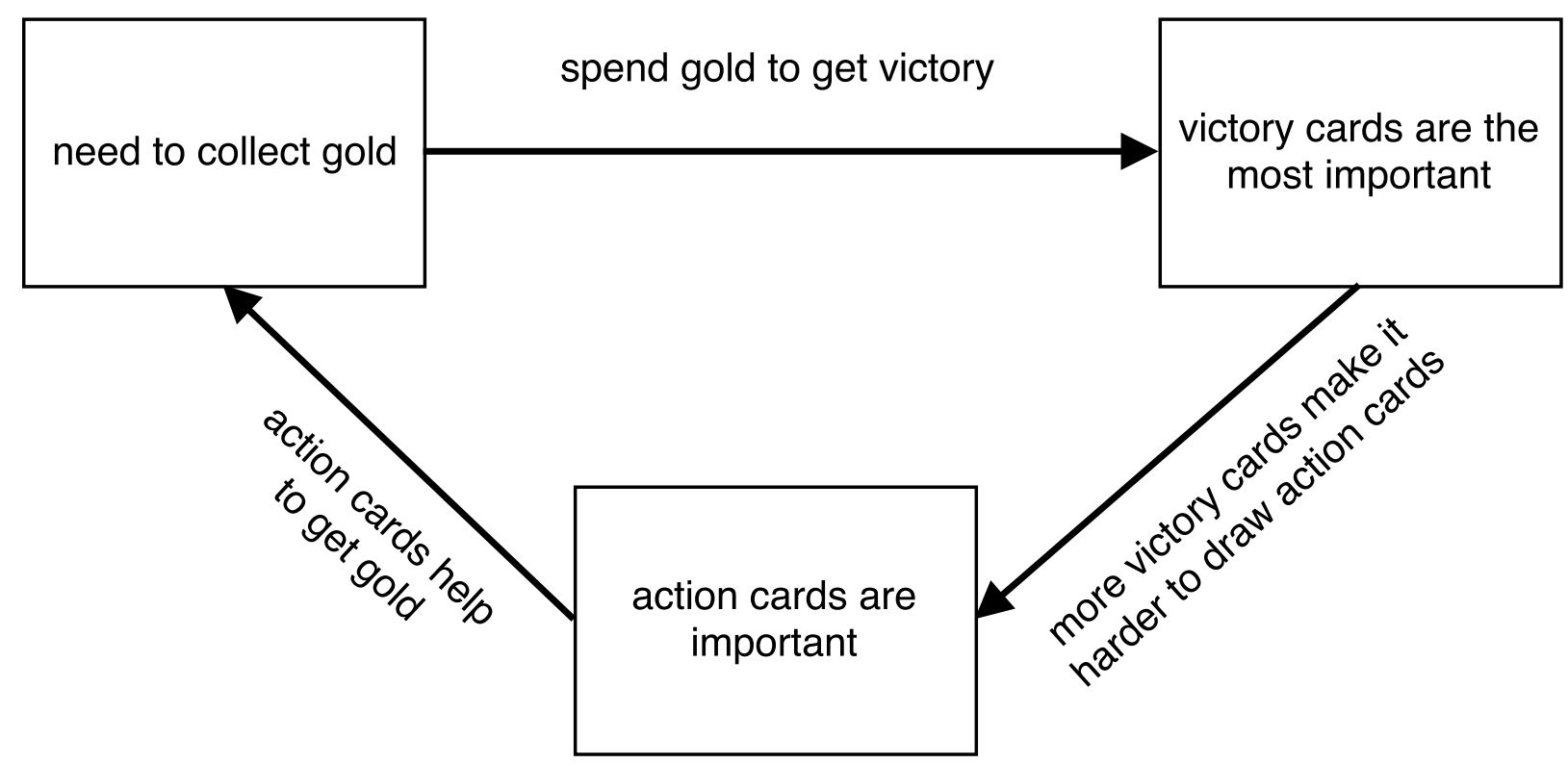

When not to use: A loop of entities merely connected by a series of arrows does not qualify — semantic or logical relationships linking them must be present. Relationships that are not in the same direction should be coded as 0 ; for example, $\mathrm{A}->\mathrm{X}<-\mathrm{B}->$ A should be coded 0. When in doubt, code 0. Example:

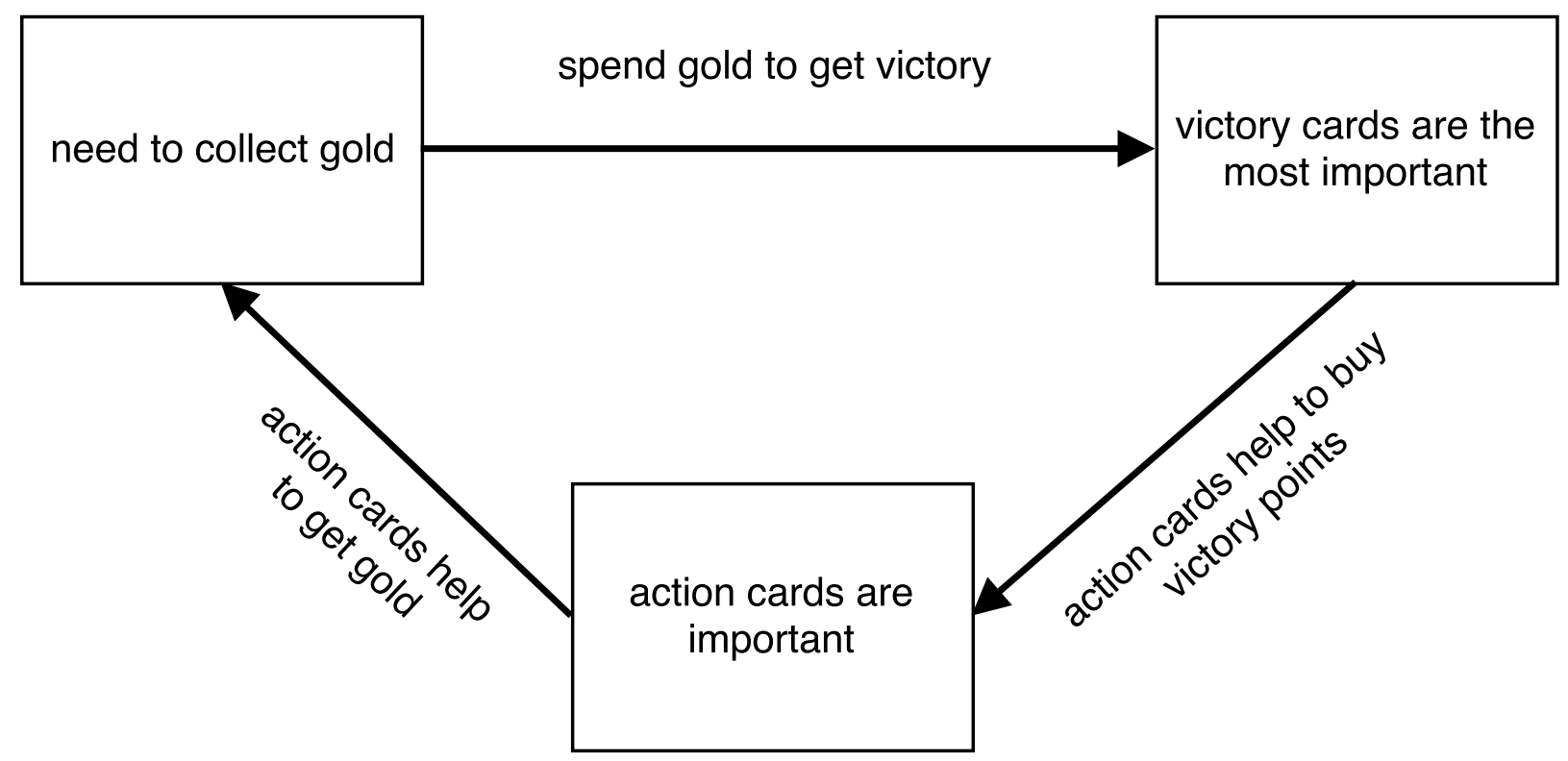




\section{Other Variables}

Do not code for these variables during the regular coding process. These variables will be assigned after regular coding.

\section{Variable 7: Simple}

Relationships between entities can be simpler than any of the complex relationships described above. Often, individuals perceive or conceive of relationships as simple — direct, linear, immediate, and deterministic — even when they are not (Jacobson \& Wilensky, 2006; Penner, 2000; Resnick, 1996; Resnick \& Wilensky, 1998; Sweeney \& Sterman, 2007). These simple relationships are the complete absence of the complex relationships described above. When to use: If variables $1-6$ are 0 , code 1 . When not to use: If one or more of variables $1-6$ are 1 , code 0 .

\section{Appendix G References}

Eden, C., Ackermann, F., \& Cropper, S. (1992). The analysis of cause maps. Journal of Management Studies, 29, 309-324. doi:10.1111/j.1467-6486.1992.tb00667.x

Groesser, S. N., \& Schaffernicht, M. F. G. (2012). Mental models of dynamic systems: Taking stock and looking ahead. System Dynamics Review, 28, 46-68. doi:10.1002/sdr.476

Hmelo-Silver, C. E., \& Pfeffer, M. G. (2004). Comparing expert and novice understanding of a complex system from the perspective of structures, behaviors, and functions. Cognitive Science, 28, 127-138. doi:10.1207/s15516709cog2801_7 
Jacobson, M. J., \& Wilensky, U. (2006). Complex systems in education: Scientific and educational importance and implications for the learning sciences. The Journal of the Learning Sciences, 15, 11-34. doi:10.1207/s15327809j1s1501_4

Landriscina, F. (2013). Simulation and learning: A model-centered approach. New York: Springer.

Penner, D. E. (2000). Explaining systems: Investigating middle school students' understanding of emergent phenomena. Journal of Research in Science Teaching, 37, 784-806. doi:10.1002/1098-2736(200010)37:8<784::AID-TEA3>3.0.CO;2-E

Resnick, M. (1996). Beyond the centralized mindset. The Journal of the Learning Sciences, 5, 122. doi:10.1207/s15327809j1s0501_1

Resnick, M., \& Wilensky, U. (1998). Diving into complexity: Developing probabilistic decentralized thinking through role-playing activities. The Journal of the Learning Sciences, 7, 153-172. doi:10.1207/s15327809j1s0702_1

Sweeney, L. B., \& Sterman, J. D. (2007). Thinking about systems: Student and teacher conceptions of natural and social systems. System Dynamics Review, 23, 285-311. doi:10.1002/sdr.366 